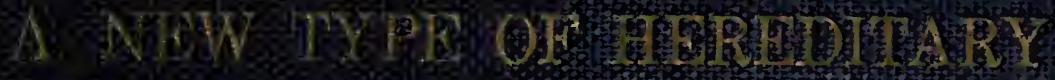

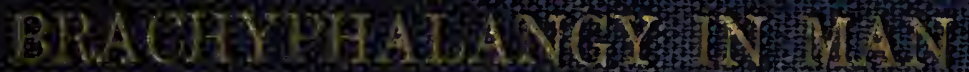




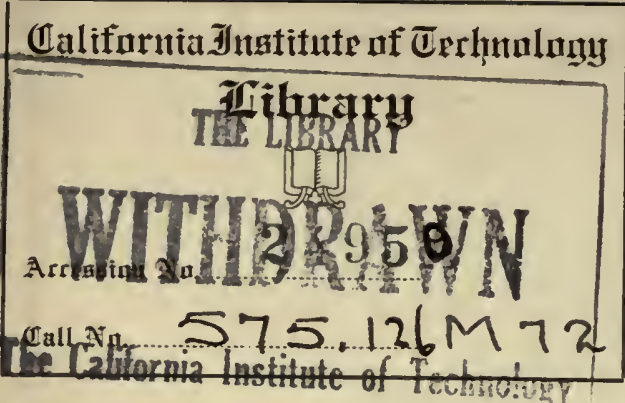

\section{BIOLOGY LIBRARY}

Calinnrnia lisitute of Technology 
14 - DAYS

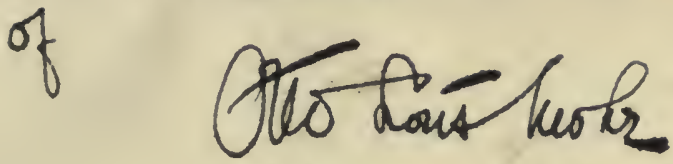
thankful ness chr. Tried 
Digitized by the Internet Archive in 2007 with funding from Microsoft Corporation 




\section{A NEW TYPE OF HEREHTTARY}

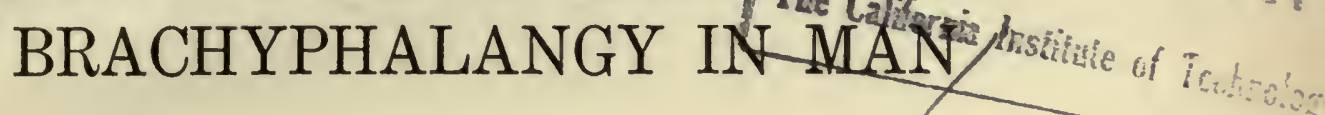

BY

OTTO L. MOHR AND CHR. WRIEDT

(I)

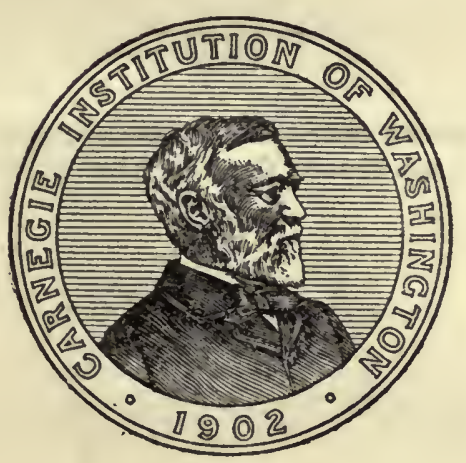

24950

Published by the Carnegie Institution of Washingtos Washington, 1919 


\title{
CARNEGIE INSTITUTION OF WASHINGTON
}

\author{
Publication No. 295
}

Paper No. 31 of the Station for Experimental Evolution at Cold Spring Harbor, New York

PRESS OF GIBSON BROTHERS, INC.

WASHINGTON, D. C. 


\section{QH 431. 1155}

\section{CONTENTS.}

I. Introduction.....................

II. Review of literature ................................ 8-13

111. Method of examination.................................. 14-15

IV. General description of the brachyphalangy studied.............. 16-19

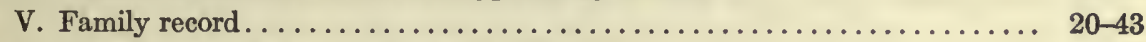

V1. Hereditary type of the character studied.................. 44-61

1. General discussion............................ 44-49

2. The ratio between affected and normal individuals........... 49-50

3. The B-type and the B!-type....................... 51-61

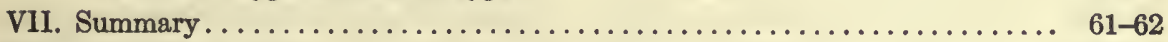

VIII. List of literature..................................... $63-64$ 

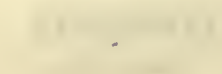


\section{A NEW TYPE 0F HEREDITARY BRACHYPHALAGNY IN MAN.}

\section{INTRODUCTION.}

No other field in biology has within recent years yielded such farreaching and important results as the field of genetic work. Thanks to the introduction of analytical experimentation, one after another of the central problems in natural science has been solved or brought near to a solution-problems which after so many vain attempts seemed almost beyond the reach of ordinary scientific analysis. The progress has been so considerable that one of the most prominent workers in this field, T. H. Morgan, in 1916 felt justified in stating: "I venture the opinion that the problem of heredity has been solved."

It scarcely needs to be pointed out that the broad general significance of the hereditary phenomena makes it urgently necessary to determine whether the results obtained through experimental work with animals and plants may be applied to the inheritance of human characters. There was a priori no reason to doubt that this would prove to be the case, and several human characters, physiological as well as pathological, have been shown to be inherited in a way fully accordant with the laws established through experimental genetic work.

Human material, however, presents several serious obstacles for genetic analysis. Not only the principal handicap involved in the lack of experiments, but also other special features make man a very poor subject for work in heredity. The number of individuals within each family is very small; intermarriage is comparatively rare; the interval of time between the generations is very long; and the characters studied are rarely amenable to accurate measurements.

Only the application of the most general hereditary laws, those of Mendelian inheritance and of sex-linked inheritance, has accordingly so far been possible with human material. Still, the experimental work has shown that even though these laws form the basis of all our knowledge of heredity, their manifestation is far more complicated than it would seem from many earlier investigations, where the case seemed closed when it was possible to demonstrate the occurrence of Mendelian segregation.

In spite of the difficulties and the incompleteness of the data which are due to the nature of this material, it is nevertheless desirable, whenever human characters are observed which are accessible for genetic analysis, to carry out this analysis and determine, if possible, whether or not the principles established through experimental work may be extended so as to include human material.

The hereditary character which forms the subject of the following investigation is a symmetrical shortness of a single (the second) 
phalanx of the second fingers and toes. This character is inherited within a Norwegian family, some members of which have emigrated to North America. Our attention was called to the material by Dr. Frimann Koren, of Christiania, who observed the malformation in some members of the family 15 years ago.

Dr. Frimann Koren, who intended to study the inheritance of the character, showed foresight in securing not only ordinary photographs but also radiographs and casts of the hands of four affected members, viz, a father and three of his sons. Being prevented from carrying out the investigation himself, he later very generously permitted us to do it, and at the same time he kindly transferred to us the material he had already collected. We wish to express to him our most sincere thanks for this courtesy.

Through the interested and intelligent cooperation of two members of the family we have since been able to gather detailed information about the pedigree for six generations, an investigation that has been greatly facilitated by the fact that the family owns an old "family book" with elaborate data concerning each member of the earliest three generations dealt with in this paper. The photographs of the malformation cover five generations, the radiographs four.

The material here studied may be regarded as especially favorable because the brachyphalangy is always restricted to a single and the same phalanx, and a numerical expression for the character can be obtained by measuring from the radiographs the long axis of the affected phalanx. These data have made possible the analysis of two distinctly different somatic types under which the brachyphalangy manifests itself. A suggestion is given for an explanation of these types on a genetic basis. Much attention is paid in the investigation to this special point.

The family studied includes a case of intermarriage, giving rise to an individual that is interpreted as homozygous for brachyphalangy. This case reveals features of special interest from a medical point of view.

As to the name used in this paper to characterize the abnormality, the following might be mentioned: Farabee, when he described the anomaly often spoken of later as "Farabee's disease," used the name hypophalangia, or diminution in the number of phalanges (1905). Drinkwater, in his papers dealing with the same subject, uses the term of the old anatomists brachydactyly, which is still generally adopted in pathological anatomy and clinics. According to Drinkwater, the fingers are in "brachydactyly reduced to about half the normal length" (1915). As a special type he separates "minor brachydactyly." The fingers are here "intermediate in length between these very short ones and the fingers of average normal individuals" (1915). 
Drinkwater's terms are found in most of the text books, but it will be seen from the citations given that their definition is rather vague. Moreover, the radiographs show that not the fingers and toes as a whole, but quite definite phalanges, are shortened. It is therefore preferable to abandon these inadequate terms and use the precise name "brachyphalangy" earlier proposed by Pfitzner. In our case it is quite necessary to use the latter term because the malformation can not be characterized by one or the other name as outlined by Drinkwater's definition, both degrees of shortening occurring within the family studied. The term brachyphalangy has furthermore the advantage of covering all the numerous types of analogous malformations to which neither of the two terms of Drinkwater can justly be applied.

During the course of the investigation the authors have become indebted to several persons who have rendered valuable assistance in providing radiographs and photographs, and our most sincere thanks are tendered to Dr. Heyerdahl, of Rigshospitalets Röntgenavdeling, Christiania; Dr. P. F. Holst, of Rigshospitalet, Christiania; Dr. Olav Hanssen, Bergens kommunale sygehus; Dr. Paus, Lindboe's Klinik, Christiania; Dr. Wood, of the Cancer Laboratory, Columbia University, New York; Mr. A. F. Huettner, New York; and Dr. Hektoen, of the John McCormick Institute, Chicago. We are similarly indebted to the medical students Kreyberg, Waaler, and Lie.

One of the authors, Mohr, who carried out the composition of this paper while working in the laboratory of Dr. T. H. Morgan, at Columbia University, wishes to express his most sincere thanks to Dr. Morgan for his help and encouragement in many ways as well as for the hospitality and facilities enjoyed during the work. He also takes the opportunity of acknowledging his large indebtedness to Dr. Bridges and Dr. Sturtevant for their assistance. Dr. Sturtevant, in addition, took the burden of correcting the English text, a kindness for which the authors feel specially and sincerely thankful.

The collection of radiographs and photographs of members of the family, often living in distant communities, was made possible through a grant awarded by Nansenfondet, Christiania. An opportunity of including some of the American members of the family in the present investigation was obtained when one of the authors obtained a fellowship of the American-Scandinavian Foundation. 


\section{REVIEW OF LITERATURE.}

After the rediscovery of Mendel's work it was not long until evidence was presented to the effect that several human characters are inherited in a way consistent with the Mendelian laws. Among the clearest cases are, as is well known, several malformations affecting the hands and feet, such as adactyly, monodactyly, hypodactyly, syndactyly, and polydactyly; hypophalangy, brachyphalangy, hyperphalangy, and ankylosis of phalanges, separately or in different combinations. They all behave as dominant characters; and as the standard case, Farabee's fundamental investigation of a brachyphalangous (by him described as hypophalangous) family will retain its merited place in the text-books dealing with this subject.

In the following pages consideration will be given only to brachyphalangy and combinations in which brachyphalangy is the main feature. Brachyphalangy is defined as a shortening of definite phalanges along their long axis, while other phalanges are normal. Scattered around in the literature, a great many cases are reported which belong to this group of malformations. When we take into consideration the mechanism of the growth in length of the phalanges (the undisturbed growth during the growth years of the epiphysial cartilages which continuously yields material for the ossification process) it is at once clear that many different influences which interfere with this mechanism will result in a shortening of the phalanx in question. A trauma (or different pathological processes, such as inflammations, etc., which destroy the epiphysial cartilages) will result in a cessation in the growth in length of the bone, and disturbances in the normal embryological development may lead to the same result.

Several cases belonging to these types of brachyphalangy are easily excluded from the material because they have no bearing upon our subject, but some may present a pathological-anatomical picture which is likely to be confused with the ones we are here considering. This is especially true of some of the cases of brachyphalangy called forth by embryological disturbances. One group deserves special mention, as presenting features of interest for our purpose.

This type is rather commonly met with in the literature. It is characterized by a total absence or marked shortening of all the phalanges of the second row on one hand, combined with a defect of the musculus pectoralis major and minor and eventually of some other breast muscles on the same side. Fürst (1900) gives 12 cases from the literature, all very like each other in appearance. The interesting point is that this brachyphalangy, which is not inherited and is recognized as belonging to the embryological malformations, invariably affects the second row of phalanges.

When the cases previously mentioned are excluded, those cases of brachyphalangy remain in which we have more or less information, 
proving that they are inherited, together with cases where no such information is given, but where the type described renders it almost certain that they belong to the same class.

With regard to the first class, cases where heredity is demonstrated, it is of interest to notice that some of the clearest investigations demonstrating the Mendelian inheritance of this malformation are "pre-Mendelian" in point of time.

As far back as in 1857, MacKinder published an account of a family in which a case of brachyphalangy combined with hypophalangy was inherited for six generations in a way quite typical for a regular dominant Mendelian character. MacKinder examined individuals representing three of these generations.

The most characteristic feature in MacKinder's case is a brachyphalangous condition or more often a total absence of the second row of phalanges of the second to fourth fingers on both hands, combined with brachyphalangy or absence of the third row on all or on the two ulnar fingers with a corresponding lack or abortive condition of the nails. In most of the individuals the feet are affected similarly to a greater or less degree.

The most important point, besides the Mendelian inheritance of the malformation, is the fact that it manifests itself under several distinctly different somatic types.

A somewhat similar case is reported by Clarke (1915). The thumbs are normal; the second and third fingers have only two phalanges, the second row being absent; the fourth and fifth fingers have only one phalanx, namely, the basal one. Judging from the two radiographs given, it seems probable that there really is present a very much shortened rudimentary second phalanx in the fourth and fifth fingers, ankylosed to the basal ones. Nails are absent. No information is given concerning the feet. The malformation is found in 10 individuals, covering four generations. From the short description it can not be seen whether or not different somatic types are found in the affected individuals.

A third case of hypophalangy combined with brachyphalangy is published by Cragg and Drinkwater (1916). The abnormality consists in a symmetrical and entire absence of the distal phalanges and the most extreme brachyphalangy of the second row of phalanges in each digit except thumb and big toe. Nails absent. The abnormality is found in 27 individuals, inherited as a typical Mendelian dominant for five generations. However, 6 of the affected members of the family represent another somatic type.

In these individuals there is in addition a very characteristic bifurcation of the thumb. They belong to three different families, two in each, and the thumb of their hypophalangous parent was in all cases normal. The authors state that "there is little doubt that there is 
some hereditary influence at work, but how it acts it is impossible to say." The supposition of a dominant modifying factor, introduced through the normal parents of these individuals, would account for the occurrence of this special type, a point that is discussed to some extent later in the present paper.

Before leaving this group a case reported by Walker (1901) deserves mention. He followed a case of complete bony ankylosis of various joints between the phalanges, combined with brachyphalangy and hypophalangy, transferred by the affected individuals through five generations. The shortening was in nearly every instance most strikingly observed in the middle phalanx. The hypophalangy, absence of one or more bones of the little and ring finger, occurred in some members of the fifth generation. This case accordingly represents another example of a dominant malformation of this class manifesting itself under different somatic types.

A second group of brachyphalangy, less extreme than the one just spoken of, is the one to which Farabee's case belongs. Here, too, we have a very clear "pre-Mendelian" case, described by Kümmel in 1895 (Fall xx), "Alle Finger haben nur zwei Phalangen." The second row is described as being entirely absent. "Nichts auffallendes" was noticed with regard to the feet, a statement to which not very much importance can be attributed since radiographs are lacking. The malformation of the hands is "auf das genaueste symmetrisch."

Kümmel investigated three generations and his pedigree -including more than 50 individuals, of which about 30 are affected (some uncertain) - clearly shows the features typical for the inheritance of a simple Mendelian dominant. Kümmel was fully aware of the fact that family members who do not show the malformation have only normal children.

The standard case of this type is that of Farabee (1905), who followed the malformation through five generations including 33 normal and 37 abnormal individuals, of which 3 were photographed and radiographed. Farabee interpreted his case as one of "hypophalangia," "reduction in the number of phalanges." "One is hardly justified in saying that one or the other segment is missing." But Drinkwater (1908 and 1914-15) recognized, by means of his more numerous radiographs, that the nature of the malformation is in reality a very pronounced brachyphalangy of the second row of phalanges combined with a bony ankylosis of this rudimentary phalanx with the terminal one. Farabee states that "in all cases hands and feet were affected in exactly the same way."

That the malformation can hardly have been as invariable as Farabee's description seems to indicate may be concluded from Drinkwater's paper (1914-15). This author succeeded in proving that his "second brachydactylous family" was an English line of the American family studied by Farabee, one member having emigrated to England, there giving rise to the family studied by Drinkwater. 
It is true, from Drinkwater's investigation, that the main feature is the abortive condition of the ankylosed second row of phalanges in the second to fourth fingers and a brachyphalangy of the first phalanx of the thumb. But Drinkwater's description and radiographs demonstrate that there is a marked variability in the somatic appearance of the character. Not only is the typical ankylosis lacking in several hands on one or more fingers and the degree of brachyphalangy conspicuously different in different individuals, but in addition to the malformation of the finger bones a typical brachyphalangy of one or more metacarpal and metatarsal bones occurs in some cases. The distribution of these special types within the family can not be traced from Drinkwater's paper. The author states that the malformation was always exactly symmetrical, even in those cases that show special peculiarities.

Another case analogous to those of Kümmel, Farabee, and Drinkwater is recorded by Gubler (1850) and Gruber (1865) who, however, give no information concerning the heredity.

More numerous than the extreme cases so far considered are those in which the shortening is less pronounced, so that the brachyphalangous bone, in general, more or less clearly retains the shape of a normal bone shortened along the long axis. This type of malformation may affect phalanges alone, metatarsal or metacarpal bones alone, or at the same time bones of both these categories. Machol, in his elaborate review of the literature (1907), finds that the phalanges are affected in only 21 per cent of his cases, metacarpalia and metatarsalia in 58 per cent, and combinations of both in 21 per cent. But it must be added that his material is very heterogeneous. The shortening may affect many different hand bones, but here, too, a certain predilection seems to rule with regard to the second row of phalanges in the second to fourth fingers.

As a typical case may be cited Joachimsthal's Fall 3 (1900), where a mother and one of her daughters showed brachyphalangy of these phalanges. But most representative are Drinkwater's observations (1912-13, 1913-14). In his two families the brachyphalangy affected the second phalanx of the second to fourth fingers and toes. In the toes there was also an ankylosis between the shortened phalanx and the terminal one. Drinkwater's pedigree covers in both cases five generations, and there is a remarkable constancy of the somatic appearance of the character.

A peculiar type of brachyphalangy, restricted to the phalanges only, is the one recorded by Leboucq (1896) and Joachimsthal (1900), where the shortening of different phalanges (especially of the second row) is combined with hyperphalangy, the index or the middle finger consisting of four phalanges, some of which are brachyphalangous. Joachimsthal describes this type in three members of the same family and in the following generation two individuals were affectedin thesame 
way. That there must be here a marked variation in the somatic appearance of the character seems indicated by the fact that one of these affected members of the last generation is said to have had normal parents.

A very interesting case where brachyphalangy in some individuals is combined with hyperphalangy, as in the cases just mentioned, is reported by Vidal (1910), and extensively referred to and discussed by Rabaud (1912). The record covers five generations, including 84 individuals. Two members of the third generation show the combination of brachyphalangy with hyperphalangy and ankylosis. In two individuals from the next generation only brachyphalangy is present. One of these is interesting because the somatic type is very much like the one here studied, the second phalanx of the index fingers only being affected. In the other the second phalanx of the third and fifth fingers are also brachyphalangous.

Vidal does not try to bring his results in relation to the Mendelian laws, and Rabaud uses his radiographs and records to prove that the Mendelian heredity does not hold true for human material, since the ratio between brachyphalangous and not-brachyphalangous individuals in the offspring of affected family members is not in accord with the theoretical expectation, and since the brachyphalangy which in some cases behaves as a Mendelian dominant in others skips a generation. Many family members are, however, described by Vidal as having what he calls "doigt crochu" on one or on both hands, and these are considered as "not brachyphalangous." A glance at the pedigree shows that this is only another somatic manifestation of the character, and in fact the most common one. The "doigt crochu" is shown by 19 individuals, while 11 are brachyphalangous. When both types are counted together and considered as "affected," the ratio between normal and affected individuals in the offspring of heterozygous individuals is very close to $1: 1$, the theoretical expectation.

The case represents accordingly a very striking example of a dominant malformation which manifests itself under very different somatic types, a relation which can be explained through the assumption of the presence of modifying factors.

Cases in which the shortening affects metacarpal and metatarsal bones are more frequently met with in the literature than the cases in which principally the phalanges show the brachyphalangy. This type is reported by Goldmann (1891), Kümmel (1895), Roughton (1897), Fontana and Vacchelli (1902), Sternberg (1902), Wagner (1903-04), Hochheim (1903-04), Kenyeres (1905-06), Riedl (1907), and others. The malformation generally affects one to three of the metacarpæ and metatarsæ. The ulnar side seems most often to be affected. The symmetry and vertical correspondence is not so marked as in the cases discussed above, and since information concerning the 
heredity of the malformation is very unsatisfactory or entirely lacking these cases will not be the object of further examination.

Brachyphalangy of the second row of phalanges combined with a shortening of the metacarpal bone of the thumb is instanced in Colson's case (1883), referred to by Leboucq (1896). The malformation was here inherited through four generations. The examination is not elaborate enough to permit conclusions to be drawn with regard to the possible occurrence of different somatic types.

A consideration of the cases of brachyphalangy reported in the literature brings out the following facts:

Several distinctly different types of brachyphalangy are known. In all cases where sufficiently elaborate information is secured concerning their inheritance, they are seen to be inherited as dominant Mendelian characters. Some of the cases which clearly show a Mendelian inheritance were published previous to the rediscovery of Mendel's work.

The malformations are known only in heterozygous individuals. Intermarriage between affected individuals is not so far recorded.

In the inheritance of many cases of brachyphalangy, it is a characteristic feature that the inherited malformation shows a very marked variation in its somatic appearance. Within a family where a gene for brachyphalangy is inherited, the character very often presents itself under quite different somatic types. This tendency suggests the assumption that the normal individuals married into the family are heterozygous for different modifying genes which may change the effect of the gene for brachyphalagy in question. (See pp. 58-61.)

In hereditary cases of brachyphalangy, as well as in brachyphalangy due to embryological disturbances, the second row of phalanges seems to be most often and most severely affected. In the embryo it is this row in which the ossification is last to begin (Fürst, 1900; Mall, 1906); and in young individuals the cartilage epiphysis of this row of phalanges is the last to complete ossification (Holmgren, 1910).

NotE.-The paper by H. M. Smith (1904) was overlooked until after the above discussion had gone to press. 


\section{METHOD OF EXAMINATION.}

Special features in the character under consideration soon convinced us of the absolute unreliability and insufficiency of second-hand information. It was found necessary to pay fully as much attention to those said to be normal as to those reported to be brachyphalangous. A satisfactory examination had to comprise photographs and radiographs in both cases. In some cases it was almost impossible to persuade members of the family to permit photographs and radiographs to be taken. This was especially true with regard to those who considered themselves to be normal; but we are indebted to other family members who took special interest in the work and tried to help in every way possible.

We have thus been able to trace the abnormality without any break through six generations. The photographs of the malformation cover five generations, the radiographs four. In the line of the family which forms the principal subject of the present publication we have secured photographs of the hands of all the members of four generations with only two exceptions, two children who died young. In the large majority of cases we have also succeeded in obtaining radiographs of the hands. This complete collection of radiographs has furnished us with measurements of the hand phalanges of both the normal and abnormal members of the family - exact numerical material invaluable for the analysis of the inheritance of the character.

In order to get this collection of measurements as complete as possible we have usually been forced to abstain from taking radiographs and photographs of the feet. Because of malformation due to wearing shoes, the radiographs of the feet in general are not nearly as favorable as those of the hands for measuring shortened phalanges. We have therefore endeavored to gather only sufficient radiographs of affected feet to demonstrate that the abnormality affects the same phalanx of hands and feet symmetrically; that it shows symmetry and vertical correspondence as well.

The lengths of the phalanges were secured from the radiographs by measuring in millimeters the distance between the center of the proximal and the center of the distal articular surface, this distance representing the axis of the bone in question. No difficulties are involved in determining the latter of these two points. The distal articulation surface is convex and the line marking this limit of the phalanx is therefore always perfectly clear in the radiographs.

Not quite so easy is the determination of the other measuring-point. The proximal articular surfaces of the middle row of phalanges present a slight middle elevation and two lateral depressions adapted to articulate with the condyles of the first phalanges. The articular surface as a whole being slightly concave, a lighter shadow of the peripheral parts 
of the phalangeal extremity often overlaps the darker shadow that outlines the main mass of the bone. A very dark, condensed shadow in the radiograph, however, indicates the limit of the two depressions and the central elevation just mentioned, and the point representing the apex of this shadow is always used as the second measuring-point, $i . e$, not including the light, overlapping shadow where this is present. In cases where the brachyphalangy is so pronounced that the form of the phalanx is entirely altered, the longest diameter (in the longitudinal direction) of the remaining roundish bone is used as the value representing the length.

In some of the most elaborate earlier publications in regard to hereditary brachyphalangy (Farabee 1905; Drinkwater 1908, 1912-13, 1913-14, 1914-15) it was stated that the affected individuals were also below the average in stature. Attention was paid to the possibility of a similar occurrence in our case, but it soon became clear that this condition could not be regarded as typical for the affected members of the family here described. We therefore refrained from measuring the height of the individuals in order to make the examination simple.

All unrelated individuals married into the family will be regarded as normal-that is, free from the type of brachyphalangy here investigated. In view of the unique character of the described type and the rare occurrence of inherited brachyphalangy in general, this point needs no further explanation. 


\section{GENERAL DESCRIPTION OF THE BRACHYPHALANGY STUDIED.}

The hands of the brachyphalangous individuals which first came to our knowledge are of a very characteristic aspect (figs. $4,7,10$ ). While the middle part of the hand and all the other fingers are normal, the index finger appears strikingly shortened. In the most pronounced cases this finger as a whole is only a little longer than the basal segment of the third finger. Inspection from the dorsal side of the hand shows at once that the shortening is limited to the middle segment of the index. The basal segment is normal and so is the distal one, and in all cases the nail is quite normal.

Seen from the volar surface, it is noticed that the index fingers in the most pronounced cases have only two instead of the normal three grooves. This is, for instance, true of the hands represented in fig. 4 and fig. 7. In other cases there are three grooves, but the distance between the two distal ones appears very markedly shortened when compared with the same distance in normal hands. In one case there are three grooves on one index and only two on the other (fig. 12).

It will easily be understood from the photographs that a superficial examination would lead to the conclusion that the middle segment of the finger is entirely missing, an opinion which is general within the family. But palpation quickly makes it clear that the middle phalanx is present, even if only as a rudimentary sesamoid bone. This malformed phalanx is often subluxated to the ulnar side of the joint, where it can be felt, a relation which explains a characteristic feature in the aspect of many of the affected index fingers; for, as will be seen from several of the photographs, the brachyphalangous index is not straight, but slightly bent, the basal phalanx forming a slight angle with the terminal one, the latter pointing in a radial direction.

It is typical that this bent condition is most often met with on the right hand, while the left brachyphalangous index is generally straight. This relation is explained by the information frequently obtained that the mothers of the affected children always tell them to pull and straighten the index fingers. The children, being right-handed, are more energetic in their treatment of the left index, and the result just described is obtained. The bent condition of the brachyphalangous finger is in several cases very marked, and the brachyphalangy is often referred to by the members of the family as "crooked fingers."

The brachyphalangy seems not to affect the use of the hand in any particular way. Family members of the most different occupations all state that they can easily do any kind of work with their hands. The flexion of the indices is, however, limited when compared with normal hands, and in some cases it is easy to produce a subluxation of the terminal phalanx. 
An inspection of the photographs represented will demonstrate that the brachyphalangy is in general strikingly symmetrical if we disregard the bent condition just mentioned. The difference in length between the brachyphalangous indices of the same individual is never very pronounced.

With regard to the type of the brachyphalangous hand in general, it has been found that some of the individuals have a rather clumsy hand with fairly short fingers (figs. 4, 7), but this condition can not be regarded as characteristic for the affected individuals only. Their normal brothers and sisters may represent a similar type (fig. 1), and on the other side we have cases where the brachyphalangy is present in hands of a very slender type with long, thin fingers (fig. 18).

These general statements concerning the type of the brachyphalangy described are confirmed and made clearer by the study of the radiographs. It will be seen from these that-the brachyphalangy is restricted to the second phalanx of the index, its form and size having undergone a complete change. In many cases the shortening of this bone is so pronounced as to leave merely a scarcely visible rudimentary roundish bone, generally situated at the ulnar side of the articulation established through the coming together of the distal articular surface of the basal phalanx with the proximal of the terminal one (figs. 4,7 , 10). Every trace of the normal form of the second index phalanx has disappeared; but we have no case in our material where the second phalanx is entirely absent.

In some cases the rudimentary second phalanx has one or two (figs. $39,40)$ small articular surfaces for articulation with the other phalanges. In the last case the radial part of the articulation is established through the articular surfaces of the first and third phalanx, while at the ulnar part they have adapted their form for articulation with the two oblique articular surfaces of the rudimentary second phalanx. The articulation shows in these cases a $Y$ form in the radiographs (fig. 40). Not always, however, is the change in form so thoroughgoing. Figs. 42, 45, and 51 show how the brachyphalangous bone may retain its character of a phalanx with two typical articular surfaces. The bone is thick and lacks the narrower middle part, characteristic for a normal phalanx.

A radiograph from a 12-year-old child (fig. 15) shows a total absence of epiphysial cartilage and reveals the fact that the brachyphalangous condition is brought about by a premature ossification of the cartilage, resulting in a stopping of the growth in length.

An examination of the feet of the brachyphalangous individuals confirms their statements that the feet are affected in exactly the same way as the hands. We have made sufficiently numerous personal examinations to conclude that the brachyphalangy shows a striking vertical correspondence. Only the second phalanx of the second toe is brachyphalangous. The other bones of the feet are normal. Fig. 
50 is from a radiograph of the foot of a brachyphalangous member of the family. It demonstrates the typical condition and needs no further description.

The investigation of the so-called normal individuals within the affected family soon demonstrated that the malformation also manifests itself under another and markedly different somatic type. Several examples of this type are given in figs. 13, 19-25, and 31-36. Examined from the dorsal surface, the hands in some cases would easily be regarded as normal (figs. 13, 23, 31, and 35); in other cases a slight shortening of the indices is clearly recognizable. An inspection from the volar surface shows that here also the shortening is restricted to the second phalanx of the indices. This is indicated by a shortening of the distance between the middle and the distal grooves of the skin.

Sometimes this shortening is very marked and can not be overlooked (figs. 20,21, and 34); but in other cases it is so slight that even a careful comparison with normal hands leaves it doubtful whether the abnormality is present or not (figs. 13, 24). Index fingers of this type often seem to be a little narrower around the second segment, which makes the third segment look a little club-shaped and thickened (figs. 9, 34). They are always straight, a bent condition (as described above) never being observed.

It will be easily understood that the shortening of the distance between the second and third grooves as a measure is very inexact. It is therefore in many cases very unsatisfactory as a diagnostic feature, and a control by radiographs is absolutely essential.

The radiographs in most cases clearly show that the second index phalanx is shortened and sometimes a little narrower, but we have cases where it is very hard to tell whether a shortening is actually present or not. The length of the finger bones is very variable in normal hands, and only a very careful analysis of the measures obtained from the radiographs permits certain conclusions to be drawn. This point is discussed on pages 51-55. It may here be stated only that this analysis in the great majority of the more doubtful cases clearly shows that a brachyphalangy of the second index phalanx is present, but we have a few cases where the measurements fall within the limits of extreme variation in normal hands. Here a conclusive decision can be reached only through the genetical test obtained from the examination of the offspring.

With regard to the form of the shortened phalanx, it will be noticed in the radiographs that the typical phalanx form is retained. The radiographs from children's hands show that the epiphysial cartilages are present in the affected phalanges.

We have in our material no cases representing an intermediate condition between the two types just described. We are evidently dealing 
with two distinct somatical types of brachyphalangy. They will in the following be characterized respectively as the simply brachyphalangous or "B-type" and the very brachyphalangous or "B!-type." It needs no special explanation to show that this presence of the B-type, which in some cases seems to overlap the extreme variations in normal, not brachyphalangous hands, makes it necessary to examine and especially to procure radiographs from all the members of the family-not only the evidently brachyphalangous members, but also those who from a superficial examination seem to be normal. If this had not been done the whole pedigree would have been full of mistakes and contradictions. 


\section{FAMILY RECORD.}

In this family record the following method of numeration will be used:

Each individual is given a number corresponding to his order of birth in his fraternity. His offspring have the same number plus their own ordinal number. Since in some families there are more than 10 children, a period is always placed just before the fraternity number of each invididual. Thus the first brachyphalangous member of the present family is 1 . Her offspring are 1.1, 1.2, 1.3, etc., to 1.17 . The offspring of 1.1 are $11.1,11.2$, etc.; of $1.5: 15.1,15.2$, etc. The number of digits in each case represents the number of generations from individual 1. Relationship is also obvious at a glance-1153.2 and 1154.1, for example, are evidently cousins.

One of the main advantages of this system is that it enables new individuals to be inserted in the pedigree without renumbering any of those already pedigreed. As a rule, only initials and dates of birth and death will be used to mark the individuals. Men and women will be designated in the ordinary manner by $\sigma^{T}$ and $\%$. In the description and measurements the Roman numerals $I-V$ will characterize the fingers, I meaning the thumb, $\mathrm{V}$ the little finger. The Arabic figs. 1-3 will be used in referring to the phalanges, 1 being the basal, 3 the terminal phalanx.

\section{Generation.}

1. Marthe Kristine Haarbye (Dec. 19, 1764-Feb. 1, 1826) is the first brachyphalangous individual concerning whom the family book contains detailed information. She was born in Fredrikshald, Norway, as the oldest daughter of merchant Andreas Haarbye, from Aarhus in Jylland, Denmark. Her mother, Kristine Skouw (1729-1814), was born in Fredrikshald, Norway.

Marthe Kristine Haarbye married, in 1782 , district judge L. $\emptyset$, born in Flekkefjord, Norway, between 1750 and 1760, died May 18, 1812. About her the family book gives the following very interesting information, here quoted literally:

"She left 10 living children and 22 grandchildren, 18 living, about whom the following pages are written, and be it noticed that every second child has, as she had herself, crooked or shortened index fingers with only one joint. Besides the 10 children she had also 7 other children, who were stillborn."

This portion of the family book was written by her son, bailiff L. Ø., $1.7 \sigma^{7}$. He was a very intelligent and precise man who took special interest in genealogy and wrote the family book for three generations with admirable care. He had the shortened index fingers himself in a very pronounced degree, as will appear later. The information he gives about his 9 brothers and sisters is in every respect 


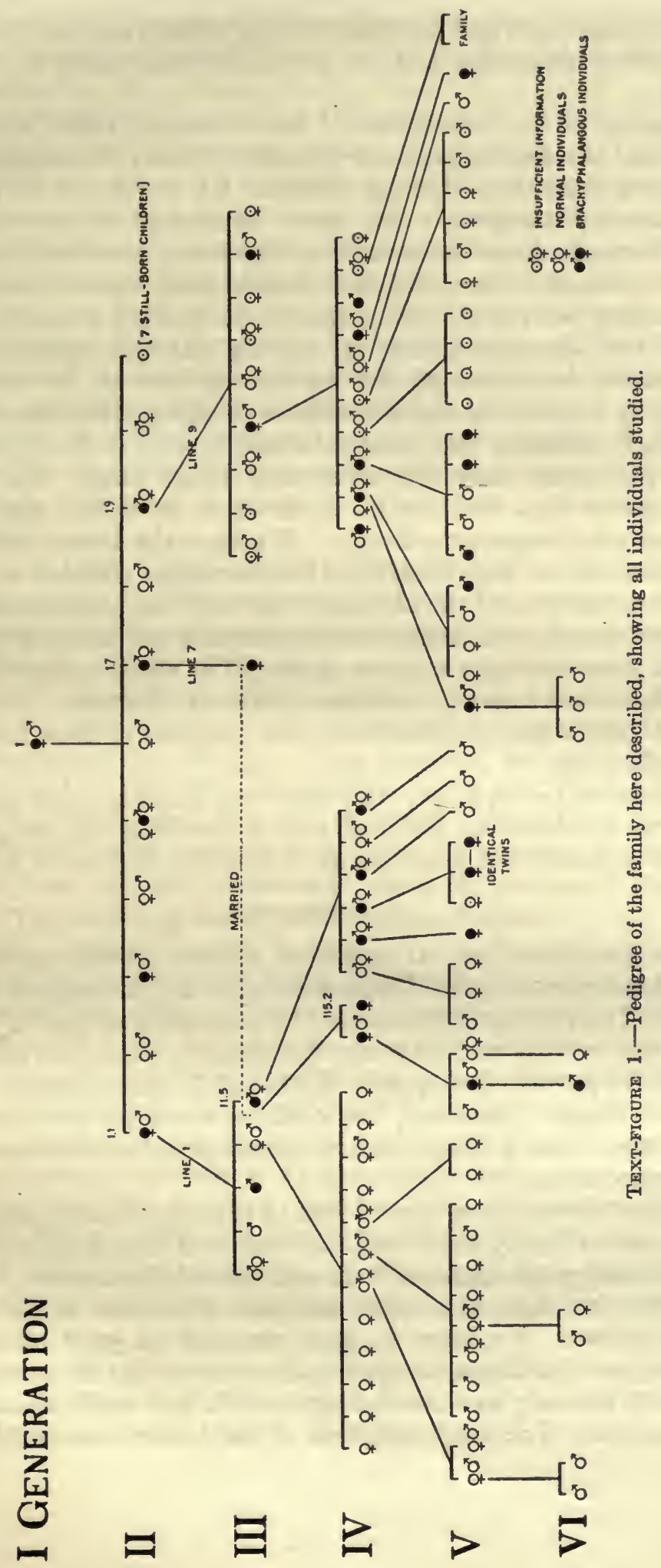


unusually elaborate and accurate and the quoted statement concerning the hands of his mother and her 10 children can safely be regarded as reliable.

A control of the correctness of his statement that "every second child" had the malformation is furnished by our investigation, which has shown that the following children: $1.1 \%, 1.3$ \% $1.7 \sigma^{7}$, and $1.9 \sigma^{7}$ were brachyphalangous. We have succeeded in determining this either through direct information concerning the individuals themselves or through the occurrence of affected individuals in their offspring.

Regarding No. $1.5 \sigma^{\top}$, who married twice and left 5 children, we have not yet had the opportunity of carrying out the examination of his descendants; but since all the results we have so far obtained are strongly in support of the correctness of the quoted statement, it is exceedingly probable that it holds for this brother of the author as well.

The statement that the malformed index fingers had "only one joint" shows that No. 1 \% M. K. H. must have had the B!-type of the brachyphalangous condition. Whether the brachyphalangy was transferred to this individual from her parents or whether we here have the first occurrence of the character has not been determined No remarks are found in the family book concerning the hands of her parents. She had three brothers and one sister, all of whom married, and their descendants are living in different parts of Norway. But we have not had time to find out whether or not members of these families show brachyphalangy.

The husband of $1, L . \varnothing$., who was from quite another part of Norway, was unrelated to her and may be regarded as normal. Their children represent the members of Generation II, now to be described.

\section{Generation.}

From this generation we have been able to provide our first photograph demonstrating the characteristic brachyphalangy of the indices (fig. 3). The photograph is owned by a member of the IV generation and he knows with certainty that it represents one of his grand-uncles, a son of the parents just spoken of, though he can no longer remember which of them. Moreover, the clothing worn by the photographed man proves beyond doubt that he belonged to this and not to the following generation.

The photograph gives a good idea of the abnormality (fig. 3). Both indices are strikingly shortened and look as if they had only one joint. The terminal phalanges and their nails seem to be normal, but on both hands they are bent in a radial direction in relation to the axis of the basal phalanx. We have in later generations good examples of a similar type. Radiographs show in these cases that the second phalanx is present, but only as a bone of the size of a pea, while phalanges 1 and 3 are normal. The bent condition of the finger is caused by the dis- 
location in ulnar direction of this rudimentary bone (cf. figs. 39, 40, and 41). This individual belongs clearly to the B!-type of our brachyphalangy.

The II generation comprises, as already stated, 10 individuals born alive (1.1-1.10) and 7 who were still-born (1.11-1.17).

1.1 G. H. Ø. (May 17, 1784-Nov. 21, 1849) brought the malformation into the line of the family which forms the main subject of this publication. No photographs of her hands have been obtainable, but information from different sources agrees in the statement that she had very short index fingers. This is also in accord with the quoted statement from the family book, which in addition indicates that she showed the B!-type of the brachyphalangy. Genetically she must have been heterozygous for the factor in question.

She married in 1811 district judge and "kancelliraad" P. F. M. H. (May 3, 1780-Aug. 19, 1838) from Kongsberg, Norway. His hands were normal. They had 5 children (11.1-11.5) who will be spoken of in detail later.

1.2 T. K. S. Ø. (May 25, 1788-Mar. 19, 1867). She married in 1806 J. H. (Aug. 20, 1780-Aug 19, 1838) and had numerous descendants. No information of brachyphalangy has been found concerning either herself or her descendants.

1.3 ㅇ M. K. Ø. (Aug. 3, 1791-May 15, 1867). According to the statement of the family book, her index fingers must have been brachyphalangous of the B!-type. She married, in 1812, proprietor Aa. Aa. (1790-Oct. 23, 1854), from the Trondhjem district in Norway. They had 9 children, most of whom married. One of her sons married twice, both times with unrelated women. By his second marriage he had a son, born in 1859, concerning whom the author of the family book adds the following note: "with crooked fingers."

The term "crooked fingers" is very often used by the family members to mark the brachyphalangous condition of the indices. Clearly the author, who was brachyphalangous himself to a very pronounced degree, intends by the note to state that the individual had brachyphalangous index fingers. This information of the occurrence of a brachyphalangous individual among the descendants of 1.3 \% M. K. $\varnothing$. strongly supports the statement formerly quoted and causes us to regard it as certain that she was brachyphalangous.

1.4 A. K. Ø. (Dec. 24, 1794-Sept. 28, 1853). She married, in 1818, merchant J. H. (1791-Oct. 23, 1860) from Christiania, Norway, and had 3 children. They all married and had several children. No data about brachyphalangy have been obtained concerning either herself or her descendants.

$1.50^{7}$ H. T. Ø. (born Dec. 13, 1795). To judge from the above statement in the family book, his indices must have been brachyphalangous and of the B !-type. Like the other affected individuals of 
this generation, he must have been heterozygous for the factor in question. He married twice: (1) C. E. who died May 15, 1823, after having had 3 children. (2) in 1828 M. C., born in 1802, by whom he had 2 children. One of his married daughters had 2 children. We have, as stated above, not yet been able to carry out the examination of this line of the family and do not know if brachyphalangy has occurred among the rather few descendants.

1.6 \% A. C. Ø. (June 18, 1800-Jan. 4, 1882). She married in 1822 bank treasurer P. Ø., from Østerdalen, Norway, who died Oct. 21, 1841. They had no children. There are no data indicating that her indices were brachyphalangous.

$1.7 \sigma^{7}$ L. Ø. (Aug. 6, 1801-Mar. 6, 1870), bailiff, Nesodden, near Christiania, Norway. This man is the author of the family book so far as the three earlier generations are concerned. He was the most prominent member of the family and had an extensive acquaintance. Three different persons still living, who knew him personally, agree in the statement that his index fingers were "very short," "with one joint," that is of the B !-type. Genetically he must have been heterozygous for the factor for brachyphalangy. Though we have seen several photographs of him, none of them shows his indices. Where he is taken full length, he always conceals his hands in a very obvious manner. He married in 1828 E. K. $\varnothing$ (Nov. 28, 1807-Mar. 19, 1858), from Bærum near Christiania, Norway. She and her husband were unrelated. Her hands were normal. They had only one child, a daughter F. G. H. Ø., 17.1 \% (p. 28).

1.8 \& S. C. Ø. (Nov. 5, 1802-Mar. 17, 1857). She married, in 1825, proprietor J. S. F. (May 31, 1788-Apr. 18, 1863), Voss pr. Bergen, Norway. They had 5 children with many descendants. No information yet obtained indicates whether she or any of her descendants had brachyphalangous hands.

$1.90^{7}$ F. J. Ø. (May 10, 1804-Sept. 28, 1872) was a tanner. According to the statement in the family book he must have been brachyphalangous and of the B !-type, being heterozygous for the factor. One of his granddaughters (194.1 C. F. A.) told of her own accord that his index fingers had "only one joint." He married, in 1834, C. R., from Asker, Norway, and had 9 children, most of them married and with numerous descendants. Among his children, as well as among the members of the two following generations, we have been able to find brachyphalangous individuals. From members of the fourth, fifth, and sixth generation we have taken photographs and radiographs to be described below.

$1.100^{7}$ S. A. L. Ø. (born Oct. 14, 1807), bank treasurer. He married P. M. I. (Nov. 6, 1794-July 17, 1873) and had one daughter who married and had two children. No information has been obtained indicating that he or his descendants had brachyphalangy. 
1.11-1.17. Seven still-born children of unknown sex. No information concerning their hands has been obtainable.

This finishes the description of the II generation. Our investigation shows that 5 of the 10 members of the family born at full term had brachyphalangy of the B !-type. It is impossible to tell whether any of the members whom the author of the family book regarded as normal may not have been brachyphalangous of the B-type. The instances in which this condition has escaped the observation of very intelligent observers are numerous within our experience. It is true that we have not been able to point out the occurrence of brachyphalangy among the descendants of those members of the family who were supposed to be normal, but not very much importance can be attributed to this fact, because we have so far concentrated our attention on the lines descending from 1.1, 1.7, and 1.9.

The inquiries and examinations we have been able to make within the other lines are not elaborate enough to permit certain conclusions drawn from a negative result. Where the result has been positivethat is, where we have been able to show the occurrence of brachyphalangy among the descendants of members of generation II, the conditions are different. The inheritance of the malformation as worked out in this paper allows us, in such cases, to conclude with certainty that the member of generation II, from whom the line in question descends, was brachyphalangous, at least when no intermarriages within the lines have taken place.

In the following only the descendants of No. 1.1 ㅇ, $1.7 \sigma^{7}$, and $1.9 \sigma^{7}$ will be described. They will be spoken of as belonging respectively to "Lines" 1, 7, and 9.

\section{Line 1, III Generation.}

The members of the III generation belonging to line 1 comprise the 5 children of the brachyphalangous $1.1 \%$ G. H. $\varnothing$. and her husband P. F. M. H.

$11.10^{7}$ C. E. H. (Mar. 11, 1814-1884), a farmer, married in 1859 M. C., but had no children. None of the members of the family or other persons now living, who knew him, noticed any abnormality of his indices.

$11.2 \sigma^{7}$ F. G. H. (May 13, 1819-Aug. 29, 1856), unmarried. A member of the family who knew him "never noticed or heard of shortness of his fingers."

$11.30^{7}$ F. L. C. G. H. (Mar. 31, 1821-Mar. 20, 1895), unmarried. A letter from one of his nieces states that "uncle $\mathrm{L}$. had short index fingers." This statement is confirmed by one of his nephews, who adds that "both his index fingers had a crook" - that is, were bent. The bent condition indicates that his brachyphalangy was of the B !-type. Genetically he must have been heterozygous for the factor in question. 
11.4 ㅇ L. A. H. H. (Sept. 15, 1822-Feb. 11, 1907). All information concerning her, including that from her daughter, is in accord concerning the fact that her fingers were normal. The correctness of this statement is confirmed by a photograph. She married, in 1846, district physician A.H.H. (Aug. 17, 1815-May 29, 1880), who was quite unrelated to her. They had 12 children (114.1-114.12).

$11.5 \sigma^{7}$ C. A. B. H. (Jan. 11, 1825-July 21, 1910), bailiff. He is the first member of the family whose hands were photographed and radiographed. Dr. Frimann Koren, who took these photographs, at the same time obtained casts of his hands. His hands show the B !-type of brachyphalangy in a very characteristic form. Genetically he was heterozygous for the factor for brachyphalangy. The photographs (fig. 4) give a good idea of the shape of his hands and make it easy to understand how the affected members who show the B !-type generally believe that the second phalanx of their index is missing. It will be seen that the entire brachyphalangous index is only a little longer than the basal phalanx of the third finger. The left index is straight, but on the right the basal phalanx forms a slight angle with the terminal one, the latter being somewhat bent in a radial direction. Except for the indices the hands are normal, as shown in the photograph.

The radiographs (fig. 39) give a clear conception of the nature of the B !-type brachyphalangy. They show that the shortening is completely restricted to the second phalanx of the indices. This bone is not absent, but remains as a rudimentary sesamoid bone. This small bone is in both hands dislocated in the ulnar direction, thus leaving the basal and the terminal phalanx to constitute the main articulation surfaces. At the ulnar side of the joint the rudimentary second phalanx sticks between the other two and the articular surface of the terminal phalanx is oblique, articulating with the basal only on the radial side. The striking symmetry of the malformation needs only to be mentioned.

It will be noticed that some of the other phalanges of the hands show indications of pathological alteration. The individual was, however, nearly 80 years old when the radiographs were taken and our large collection of radiographs from brachyphalangous hands permits us to conclude that these alterations are of another nature and bear no relation to the brachyphalangy. The lengths of II 2 and IV 2 measured from the radiographs are respectively 6 and $27 \mathrm{~mm}$. on both hands.

This individual married twice and his first marriage is of especial interest, being the only intermarriage between members of affected lines. He married, namely, first his cousin 17.1 \& F. G. Ø. (Mar. 15, 1829-Mar. 22, 1872), the only child of his uncle $1.70^{7} \mathrm{~L} . \emptyset$., who had the B!-type of the brachyphalangy (p. 24). We have made numerous efforts to determine whether she was brachyphalangous, but it has not 
been possible to reach a certain conclusion. A photograph of her hands (fig. 5) shows at least that she did not have the B !-type of brachyphalangy, but from our discussion of the B-type later it will be seen that she may very well have had this type of the malformation. It would have been necessary to have a photograph of the inside of her hands to settle the question. One of her husband's children by his second marriage has heard that her index fingers were slightly shortened, but our experience with such information prevents us from regarding it as of much value.

The question is a very important one for our investigation, as will be seen later when we describe the two children, $115.1 \%$ and 115.2 \%, who were born from her marriage with her brachyphalangous cousin. If she was heterozygous for brachyphalangy, the only possibility in our material for children homozygous for brachyphalangy is present. The investigation of her children furnishes us, as we shall see, with very interesting points for a further discussion of this question.

$11.5 \sigma^{7}$ C. A. B. H. married the second time, in 1874, S. M. C. W., who was unrelated to him and had normal hands. They had 6 children $115.3-115.8$ (p. 29-32).

This finishes the study of this family, representing the III generation of line 1. The result indicates that 2 out of the 5 members of the family had the B !-type of the anomaly. The 3 others are supposed to have been normal, but the possibility that some of them may have had the B-type can not with certainty be excluded. In treating this line we have also finished the record of line 7 , the only individual belonging to this line, namely 17.1 \% F. G. Ø., the daughter of 1.7 \% L. Ø., having married into line 1 and being therefore referred to here.

\section{Line 1, IV Generation.}

The fourth generation of line 1 includes three families, the children of 11.4 \% L. A. H. H., who had normal hands, and those of the brachyphalangous 11.5 o त $^{7}$. A. B. H. by his two marriages.

First Family of IV Generation.

11.4 \& L. A. H. H. had, by her marriage with A. H. H., 12 children, 114.1-114.12.

114.1 ㅇ A. C. H. (b. Aug. 1, 1847). Unmarried.

114.2 \% A. H. (b. Apr. 21, 1849). Unmarried.

114.3 ㅇ S. H. (b. Feb. 1, 1851). Unmarried.

114.4 \& H. H. (b. Apr. 1, 1852). Unmarried.

114.5 \% L. H. H. (b. Apr. 13, 1853). Unmarried.

$114.6 \sigma^{7}$ H. H. (Aug. 14, 1855-May 6, 1910) married M. E. B. (Dec. 28, 1855-Apr. 21, 1912) and had 2 children, 1146.1 and 1146.2 (p.32).

114.7 \% T. H. (b. Apr. 2, 1857). Married in 1880 J. M. G. B. (b. June 28, 1854), minister. They had 8 children, 1147.1-1147.8 (p. 32). 
$114.80^{7}$ A. H. (Nov. 1, 1858-Apr. 21, 1903). Married in 1900 A. A. L (b. Mar. 28, 1876) and had 2 children, 1148.1 and 1148.2 (p. 32).

114.9 ㅇ E. H. (May 27, 1860-Oct. 10, 1860).

114.10 \& Aa. H. (b. Dec. 2, 1861). Married in 1883 merchant R. L. (b. Feb. 7, 1856). No children.

114.11 V. H. (Jan. 30, 1863-Dec. 18, 1875).

114.12 \& G. H. (Jan. 7, 1865-Dec. 12, 1866).

All information we have obtained concerning the members of this family indicates that their hands were normal, thus confirming the conclusion that their mother was free from the factor for brachyphalangy.

\section{Second Family of IV Generation.}

The B !-type brachyphalangous $11.5 \sigma^{\top}$ C. A. B. H. had by his first marriage with his cousin 17.1 \& F. G. $\varnothing$ (p. 24), daughter of the B !-type brachyphalangous $1.7 \sigma^{7}$ L. Ø., 2 children, 115.1 and 115.2.

115.1 ㅇ E. A. H. (May 16, 1853-Nov. 3, 1913). She married proprietor $\emptyset$. G., d. 1905, and had 3 children, 1151.1-1151.3 (p. 33). One of her half-brothers, when asked, gave us the information that her fingers were "not absolutely normal"; but her own son answered in a letter that her hands were normal, a statement which also was confirmed by her daughter. A clear case of brachyphalangy is known to us among her descendants. At last we succeeded in getting a photograph showing her right hand. Though not very good, this photograph settles the question (fig. 6). It shows clearly that she was brachyphalangous to a characteristic degree. The ends of the other fingers are in the photograph hidden, but enough of them is seen to show that she had the B-type of the malformation. The study of her descendants proves that she was heterozygous for the factor in question.

115.2 \& C. F. H. (May 9, 1855-Apr. 4, 1856). This second daughter, who died one year old, demands special attention. All information is to the effect that she was a cripple, unable to develop; but it has so far been impossible to investigate the exact nature of her malformation. This is explained through the fact that the family has intentionally not talked about her, regarding the birth of a cripple within the family as a point not to be mentioned. This practice has been followed so carefully that even the daughter of her own sister, when asked, did not know of her existence. The small amount of information resulting from our very elaborate inquiries is limited to the following rather vague statements:

Her half-brother, a very intelligent man, to whom we are highly indebted for much valuable information, states that "her whole osseous system was in disorder." Her half-sister knows with certainty that "her hands and feet, or at any rate her fingers and toes, were entirely absent." 
This occurrence of a cripple, the only one in the whole family for six generations, as a result of an intermarriage between one brachyphalangous individual and his cousin whose father had brachyphalangy, is very remarkable. It suggests the possibility that this cousin was brachyphalangous, genetically heterozygous for the factor, and that this child may have been homozygous for it, receiving one gene from her father and one from her mother. This explanation, if correct, involves the assumption that the character we have studied, the brachyphalangous index, represents only the heterozygous condition, and that the factor, when homozygous, affects the individual in a much more serious way. This conclusion is by no means certain, but is at least strongly suggested by the facts of the case. This point will be more especially discussed later.

Summing up: Brachyphalangous $11.5 \sigma^{\top}$ C. A. B. H., who showed the B!-type of the malformation, by his first marriage with his cousin 17.1 \& F. G. $\varnothing$., had 2 children, one brachyphalangous and one cripple unable to develop.

Third Family of IV Generation.

The brachyphalangous $11.50^{7}$ C. A. B. H. married in 1874 for a second time. This wife (S. M. C. W., Aug. 1, 1843-May 3, 1899) was normal and quite unrelated to him. They had 6 children, 115.3-115.8.

115.3 o $^{7}$ P. F. G. H. (b. Nov. 16, 1875), mail carrier. A photograph of his hands is given in fig. 1. The indices are quite normal. We mention especially that photographs taken from the inside show that the distance between the two distal grooves in the skin marking the joints is very little shorter in the indices than in the fourth fingers. In brachyphalangous hands of the B-type this distance is generally markedly shorter in the indices. The radiographs prove that the relative lengths of the finger bones are normal, the lengths of II 2 and IV 2 being respectively 25 and $29 \mathrm{~mm}$. on both hands.

$115.30^{7}$ P. F. G. H. married J. G. (b. Oct. 10, 1880) who was not related to him and who has normal hands. They have 3 children, 1153.1-1153.3 (p. 34).

$115.4 \sigma^{7}$ M. H. (b. Apr. 4, 1870), merchant. A photograph of his hands (fig. 7) shows a very characteristic B !-type brachyphalangy. As in the case of his father's hands, the right brachyphalangous index is bent, while the left is straighter.

Radiographs are given in fig. 40. In the right hand the short second phalanx of the index remains as a bone the size of a pea and is dislocated in the ulnar direction, as described when speaking of the father's hands. In the left index the second phalanx is seen to be reduced so much in size that its existence might almost be overlooked. Its position is (as on the right hand) in the ulnar part of the joint.

The other finger bones are normal except the second phalanx of the fifth finger of the right hand, which is thicker and $4 \mathrm{~mm}$. shorter than 
the same bone on the left hand. This part of the radiograph is not very good and it is hard to tell how much importance should be attributed to this irregularity. It is the only case in our material where a bone in addition to the second phalanx of the index or the second toe is shortened. The fact that the corresponding bone of the left hand shows the normal length, in connection with the slight degree of the shortening, makes it doubtful whether this shortening ought to be regarded as a part of the brachyphalangy or merely as a variation due to other causes.

The symmetry of the brachyphalangy of the indices is very pronounced. The lengths of II 2 and IV 2 are respectively 5 and $29 \mathrm{~mm}$. on the right hand, 5 and $28 \mathrm{~mm}$. on the left.

$115.4 \sigma^{7} \mathrm{M}$. H., who is genetically heterozygous for the factor for brachyphalangy, married the normal H. G. (b. May 16,1887), a sister of J.G., the wife of his brother 115.3. They had onedaughter 1154.1 (p.34).

$115.5 \sigma^{7}$ H. M. H. (b. Feb. 11, 1879), bailiff. All of the second-hand information concerning this man agrees in indicating that he had normal hands. His brothers had not observed any malformation of his indices. We knew, however, that he had two small daughterstwins - who both were brachyphalangous, and when we wrote to him he answered that "the second phalanx of both the index fingers seems to be somewhat shortened." We have not so far had the opportunity of personally examining or procuring radiographs of his hands because he lives in a distant community, but the photographs (figs. 8 and 9) give a good idea of the malformation.

We are dealing with a clear case of the B-type of brachyphalangy. Seen from the back of the hands the shortening is not very conspicuous and might easily be overlooked. The indices are only a little shorter than in a normal hand and the second phalanx is a little narrower than it is in a normal finger. This makes the terminal phalanx look as if it were somewhat club-shaped and thickened. The shortness of the second phalanx is far more strikingly seen in fig. 9, showing the inside of the hands. The distance between the two distal grooves is considerably shorter on the indices than on the fourth fingers. The shortening seems to be strongly symmetrical.

This individual is genetically heterozygous for the factor for brachyphalangy. He married the normal D. K. (b. Nov. 39, 1879) and has 3 children, the two younger being identical twins, 1155.1-1155.3 (pp.34-35).

$115.6 \sigma^{7}$ C. S. H. (b. Nov. 19, 1880), farmer. Photographs of his hands are given in fig. 10. They need no special description, the fingers being very like those of his father, $11.5 \sigma^{7}$, and of the brother, $115.4 \sigma^{\pi}$, already described. On the left index the shortened second phalanx (dislocated as usual to the ulnar part of the joint formed by the first and third) is seen to form a little projection on the left side of the finger. 
The radiograph (fig. 41) of the left hand is not clear enough to show the limits of the shortened bone, but the presence of the luxated rudimentary phalanx in the ulnar part of the joint is clearly demonstrated. On the right index there is no luxation of the shortened second phalanx. It remains as a distinct phalanx with two articulation surfaces. It is longer on the ulnar than on the radial side, thus giving the finger a typical bend. The other finger bones are normal.

The lengths of II 2 and IV 2 are respectively 6 and $27 \mathrm{~mm}$. on the right hand. On the left hand the longest diameter of the luxated II 2 is 8 (?) mm., but it looks as if this diameter represents the breadth and not the length of the affected phalanx. The length of IV 2 is 26 $\mathrm{mm}$. on the left hand.

$115.60^{\top}$ C. S. H., who is genetically heterozygous and shows the B !-type brachyphalangy, married N. G. (b. Nov. 28, 1884) and has a son 1156.1 (p. 35).

115.7 o L. H. (b. Apr. 19, 1882). She emigrated to the United States, where she married J. H. (b. Feb. 15, 1873), who is unrelated to her. One of us has had the opportunity of examining her hands and procuring the photographs and radiographs, figs. 2 and 37. As seen from these, her hands are in every respect perfectly normal. The lengths of II 2 and IV 2 are respectively 24 and $29 \mathrm{~mm}$. on both hands. By her marriage she has 1 son; $1157.1 \sigma^{7}$ (p. 36).

$115.8 \mathrm{o}^{7} \mathrm{I}$. H. (b. June 15, 1885). He also emigrated to the United States and lives now in New York City. Photographs of his hands are given in figs. 11 and 12. They show a characteristic example of the B !-type of brachyphalangy. The right brachyphalangous index is bent, the left one is straight. The photographs from the inside of his hands show two grooves on the left index finger and only one on the right. The radiographs (fig. 42) explain why this happens. The malformation is seen to be strongly symmetrical in that it affects only the same bone on both hands, but the shortening is more pronounced in the left index. The shortened bone is somewhat longer on the ulnar than on the radial side. Both shortened phalanges have two articulation surfaces and articulate with the basal and the terminal phalanges. The length of II 2 and IV 2 are respectively 6 and $29 \mathrm{~mm}$. on the right, 10 and $29 \mathrm{~mm}$. on the left hand. In this case we also have been able to obtain a radiograph of the feet. It shows a marked symmetrical shortening of the second phalanges of the second toes; all other bones in the feet are normal.

This man, who is genetically heterozygous for the factor for brachyphalangy, married the normal O.M. G. K. (b. Dec. 17, 1886). They have 1 son, $1158.1 o^{7}$ (p. 36).

Looking back on these children of the B!-type brachyphalangous $11.50^{7}$ by his second marriage with a normal wife, we find that 2 of the 6 children were unaffected, 1 showed the B-type brachyphalangy, and 3 the brachyphalangy of the B !-type like their father. 
In this family we have secured exact information concerning the feet which proves that the brachyphalangy shows regular vertical correspondence, the two feet being symmetrically affected in exactly the same manner as the hands.

\section{Line 1, V Generation.}

The fifth generation of line 1 includes 10 families, 3 of which descend from the normal 11.4 o L. A. H. H. (p. 26), 7 from the brachyphalangous $11.5 \sigma^{7}$ C. A. B. H. (p. 26).

First Family of V Generation.

$114.6 \sigma^{7}$ H. H. had, by his marriage with M. E. B., 2 children, 1146.1 and 1146.2.

1146.1 G. H. (b. Sept. 22, 1883). She married bank treasurer C. C. (b. May 8, 1852) and had 2 children, 11461.1-11461.2 (p. 36).

1146.2 \% A. H. (b. Aug. 29, 1892). She married in 1917 secretary T. M. No children.

Second Family of V Generation.

114.7 \% T. H. had, by her marriage with J. M. G. B., 8 children, 1147.1-1147.8.

$1147.10^{7}$ A. H. H. B. (b. Mar. 20, 1882). Unmarried.

$1147.2 \sigma^{7}$ E. B. (b. Sept. 24, 1883). Unmarried.

1147.3 o $^{7}$ R. B. (b. Jan. 9, 1885). Married in 1916 B. L. R. No children.

1147.4 \& K. L. B. (b. Dec. 30, 1886). She married in 1910 consultant J. J. and has 2 children, 11474.1-11474.2 (p. 36).

1147.5 \& V. B. (b. Oct. 28, 1889). Unmarried.

1147.6 \& D. B. (b. July 19, 1891). Unmarried.

$1147.7 \sigma^{7}$ G. B. (b. Jan. 30, 1894). Photographs and radiographs of his hands are obtained as a test. They show that his hands are normal in every respect. Lengths of II 2 and IV 2 are respectively 23 and 27 $\mathrm{mm}$. on both hands.

1147.8 \& T. B. (b. Dec. 10, 1895).

Third Family of V Generation.

$114.8 \mathrm{o}^{7}$ A. H. had, by his marriage with A. A. L., 2 children, 1148.1 and 1148.2.

1148.1 ㅇ B. H. (b. Mar. 12, 1901).

1148.2 ㅇ A. H. (b. Oct. 10, 1902).

The result of our investigation and of all information concerning these three families of the V generation, line 1 , is to the effect that the members without exception had normal hands. To make a control test and to get material for our comparative measurements we secured the radiographs of one individual, $1147.7 \mathrm{o}$. This accords with the expectation which was based on the fact that 11.4 o L. A. H. H. was genotypically free from the factor for brachyphalangy (cf. p. 26). 
Fourth Family of V Generation.

The B-type brachyphalangous 115.1 \& E. G. H. had, by her marriage with $\mathrm{O}$. G., 3 children, 1151.1-1151.3.

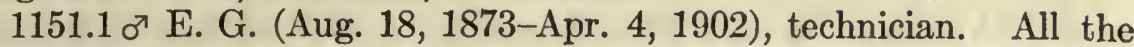
information is to the effect that he had normal hands, a statement that is confirmed by a photograph of his right hand.

1151.2 \% S. G. (b. July 16, 1876). All inquiries about her hands resulted in the statement that they were normal. This will easily be understood when looking at the photograph (fig. 13), showing the hands seen from the back. Aside from the missing of the right fourth finger, lost in an automobile accident, the hands on superficial examination seem to be perfectly normal. From the volar side it is seen, however (fig. 14), that the distance between the two distal grooves on the indices, compared with the corresponding distance on the fourth fingers, is a little shorter than is the case in a normal hand. The radiographs (fig. 43) permit an exact measurement of the phalanges. II 2 on the right hand is $21 \mathrm{~mm}$. On the left the lengths of II 2 and IV 2 are 20 and $26 \mathrm{~mm}$. respectively.

It will be seen later, when we analyze the correlation between the lengths of these two phalanges in normal hands, that Pfitzner (1892, 1893), among 301 normal hands, has in one case found the same measures, 20 and $26 \mathrm{~mm}$. Judged from this character, our individual might therefore be regarded as normal. The aspect of the inside of the indices, however, indicates that we here are dealing with a very extreme case of the B-type brachyphalangy. This-view is supported by the fact that the individual is genetically heterozygous for the factor for brachyphalangy. She has a son, to be mentioned later, who shows the B !-type of the brachyphalangous condition, 11512.1 or (pp. 36-37).

The case illustrates the necessity of making extremely careful examinations in dealing with human material. Even where the inherited factor, when heterozygous, calls forth so striking alterations as in this case of brachyphalangy, we can still find cases where the heterozygous individuals, even after a careful examination, might be regarded as somatically normal.

1151.2 \% S. G married the unrelated factory owner O. S. R. (b. July 16, 1865). She has 1 son, $11512.1 \sigma^{7}$ (pp. 36-37).

$1151.3 o^{7}$ S. G. (b. Apr. 29, 1882), civil engineer. Photographs and radiographs of his hands show that he is free from brachyphalangy. Lengths of II 2 and IV 2 are 25 and $30 \mathrm{~mm}$. on the right, 25 and 29 $\mathrm{mm}$. on the left hand. He married the unrelated J. A. (b. July 29, 1888) and has 1 daughter, 11513.1 o (p. 37).

Investigations as to this family show that the brachyphalangous 115.1 o E. G. H. had two normal and 1 B-type brachyphalangous children. This proves that 115.1 o herself was heterozygous for the factor for brachyphalangy (cf. p. 28). 
Fifth Family of V Generation.

The normal 115.3 o P. F. G. H. had, by his marriage with J. G., 3 children, 1153.1-1153.3.

$1153.10^{7}$ P. F. H. (b. Mar. 21, 1905). Photographs and radiographs of his hands prove that he is free from brachyphalangy. Lengths of II 2 and IV 2 on both hands are 21 and $25 \mathrm{~mm}$., respectively.

1153.2 \& S. E. H. (b. Mar. 12, 1907). Photographs and radiographs of her hands show that she is normal. Lengths of II 2 and IV 2 are on both hands 18 and $20 \mathrm{~mm}$., respectively.

1153.3 \& E. R. H. (b. Jan. 1, 1910). Photographs and radiographs of her hands prove that she is free from brachyphalangy. Lengths of II 2 and IV 2 on both hands 18 and $21 \mathrm{~mm}$, , respectively.

All the children of this family have perfectly normal hands, which was to be expected from the examination of their father.

\section{Sixth Family of V Generation.}

The B !-type brachyphalangous $115.4 \sigma^{7} \mathrm{M}$. H. has, by his marriage with the normal H. G., 1 daughter, 1154.1 o .

1154.1 ㅇ I. S. H. (b. May 9, 1905). A photograph of her hands (fig. 15) shows a typical case of symmetrical brachyphalangy of the indices. The radiographs (fig. 44) demonstrate that all the other finger bones are normal and give a good idea of how the brachyphalangous condition of the indices is brought about. While all the other bones of the hand still have their epiphysial cartilages, those of the second phalanges of the second fingers are already ossified, though the girl was only 12 years old when the plates were taken. This fact indicates that this case is to be regarded as belonging to the $\mathrm{B}$ !-type of brachyphalangy. While all the other phalanges keep on growing, the second ones of the indices remain short. This makes the difference between the lengths of II 2 and IV 2 far less striking than it will be in the adult individual.

The actual lengths of II 2 and IV 2 in this case are 8 and $23 \mathrm{~mm}$. respectively on the right hand, 10 and $23 \mathrm{~mm}$. on the left hand. It will be noticed that the shortened phalanx of the right hand is markedly thicker than that of the left.

Genetically this individual is heterozygous for the factor for brachyphalangy.

Seventh Family of V Generation.

The B-type brachyphalangous $115.5 \sigma^{7} \mathrm{H} . \mathrm{M} . \mathrm{H}$. has, by his marriage with the normal D. K., 3 children, 1155.1-1155.2, $a$ and $b$, the two latter identical twins.

1155.1 ㅇ (b. Mar. 26, 1913) died the day of birth. Parturition was complicated and the child had to be mutilated. Her father states that nothing is known regarding her hands. 
$1155.2 a$ o R. S. H. and $1155.2 b$ ㅇ I. J. H. are identical twins (b. Sept. 19, 1915). Genetically these two individuals are to be regarded as identical, a view that is supported in an interesting way by the fact that they both have brachyphalangous indices of exactly the same type. The photographs (figs. 16 and 17) showing their hands had to be taken under very unfavorable conditions, but still show the brachyphalangy fairly well.

It has not been possible to take radiographs of the children, because they live in a distant community and nothing absolutely certain can therefore be said concerning the type of the malformation; but the fact that the photographs, which were taken when the children were a little more than two years old, already show a very marked shortening of the indices makes it exceedingly probable that the shortening later will prove to be of the B !-type.

Genetically the two children are heterozygous for the factor for brachyphalangy.

Summing up, we find that the B-type brachyphalangous $115.50^{7}$ had one child concerning whom no information is obtainable and two brachyphalangous twins, probably of the B !-type. These two individuals have developed from one egg. When we later work out the numerical ratio between brachyphalangous and normal members of the families here studied, they will have to be counted as one individual.

\section{Eighth Family of V Generation.}

The B -type brachyphalangous 115.6 o C. S. H. has by his marriage with the normal N. G. one son, $1156.10^{7}$.

On external examination and in photographs the hands of $1156.1 \sigma^{7}$ C. R. H. (b. May 23, 1907) look normal. The distance between the second and third grooves at the inside of the indices looks perhaps slightly shortened and the second phalanges of the indices seem to be a little narrower than usual in a normal hand. It can not be denied that the shape of the index fingers as a whole reminds one somewhat of the B-type brachyphalangy.

The radiographs, however, give measures of the phalanges which fall well inside the limits of variation in normal hands. The lengths of II 2 and IV 2 are 17 and $21 \mathrm{~mm}$. on the right hand, 17 and $22 \mathrm{~mm}$. on the left hand.

The second phalanges of the indices are a little irregular, showing slightly oblique terminal articular surfaces; but the irregularities mentioned are so slight that the examination as a whole leads to the result that $1156.1 o^{7}$ is a normal individual, free from brachyphalangy. With the above-mentioned special features in mind it is perhaps safe, however, to make a reservation until this conclusion can be confirmed by examination of the descendants of the individual.

The investigation of 1151.2 \% explains why this reservation seems indicated. 
Ninth Family of V Generation.

The normal 115.7 o L. H. has by her marriage with the normal J. H. one son, $1157.1 \sigma^{7}$.

1157.1 or R. H. G. H. (b. May 14, 1911). Photographs and radiographs of his hands show that he is normal, Lengths of II 2 and IV 2 on both hands are 14 and $17 \mathrm{~mm}$. respectively.

Tenth Family of $\mathrm{V}$ Generation.

The B !-type brachyphalangous $115.8 \sigma^{7} \mathrm{I}$. H. has by his marriage with the normal O. M. G. K. one son, $1158.1 \sigma^{7}$.

$1158.1 \sigma^{7}$ H. L. H. (b. July 19, 1914). Photographs and radiographs of his hands show that he is normal. Lengths of II 2 and IV 2 are 13 and $17 \mathrm{~mm}$., respectively, on both hands.

\section{Line 1, VI Generation.}

The sixth generation of line 1 so far includes 4 families, 2 of them belonging to the descendants of the normal 11.4 o L. A. H. H. (p.26) and 2 to that of the B!-type brachyphalangous 11.5 o C. A. B. H. (p. 26).

\section{First Family of Vi Generation.}

The normal 1146.1 \& G. H., by her marriage with the normal C. C., has 2 children, 11461.1 or $^{7}$ P. C. (b. Aug. 17, 1913) and 11461.2 or $^{7}$ E. C. (b. June 7, 1916).

\section{Second Family of Vi Generation.}

The normal 1147.4 \% K. L. B., by her marriage with the normal J. J., has 2 children, 11474.1 and 11474.2.

$11474.1 \sigma^{7}$ K. L. J. (b. May 29, 1911). Photographs and radiographs of his hands were provided as a test. They prove that he is quite normal.

Lengths of II 2 and IV 2 are 13 and $16 \mathrm{~mm}$., respectively, on the right hand, 14 and $16 \mathrm{~mm}$. on the left hand.

11474.2 \& R. B. J. (b. Sept. 27, 1913).

The examination proves that all these four individuals, descendants of 11.4 o L. A. H. H., are perfectly normal. In one case radiographs and photographs are given as a control.

We have now followed the total descendants of this individual, $11.4 \%$, through three generations. Though she was a daughter of the brachyphalangous 1.1 , her hands were normal (see p. 26). In accordance with the expectation all the 28 individuals descended from her have been found to be normal, free from the factor for brachyphalangy.

Third Family of Vi Generation.

The B-type brachyphalangous 2251.2 \% S. G., by her marriage with the normal O. S. R., has a son, $-11512.1 \sigma^{7}$.

11512.1 o $^{7}$ O. R. (b. Apr. 5, 1898). A photograph of his hands is given in fig. 18. It shows a typical case of the B !-type brachypha- 
langy and needs no special description. The radiographs (fig. 45) show the degree of the shortening. The second phalanges of the indices are reduced to very short bones with two surfaces in articulation with the I and III phalanx.

In this case we were able to secure radiographs from the feet also. They show exactly the same shortening of the second phalanges of the toes, a further control of the fact stated above that the brachyphalangy shows vertical correspondence.

The lengths of II 2 and IV 2 of the right hand are 9 and $28 \mathrm{~mm}$. respectively, and on the left hand 8 and $27 \mathrm{~mm}$.

This individual is genetically heterozygous for brachyphalangy. $\mathrm{He}$ represents the sixth generation of brachyphalangous individuals among the descendants of 1 \% M. K. H. We have been able to trace the inheritance of the malformation without any break from her (1 $q)$, through 1.1 o $, 11.5 \sigma^{7}, 115.1$ o, 1151.2 o to the family member in question (11512.1). All of these were brachyphalangous and genetically heterozygous for the factor. Among them are the most pronounced cases of the B !-type of the malformation (11.5 o ) as well as of the B-type (1151.2 $\%$ ).

\section{Fourth Family of VI Generation.}

The normal 1151.3 or S. G., by his marriage with the normal J. A., has 1 daughter, 11513.1 ㅇ.

11513.1 \% E. G. (b. Oct. 10, 1911). Photographs and radiographs prove that she is normal. Lengths of II 2 and IV 2 are 16 and 19 $\mathrm{mm}$., respectively, on the right hand, 16 and $18 \mathrm{~mm}$. on the left.

We have now given a complete family record concerning all members of line 1 and line 7, including in all 58 individuals.

As already mentioned we have not yet worked out any of the other lines to the same extent. In one of the lines, line 9, where brachyphalangy occurs, we have secured material (photographs and radiographs) of the hands of members of the IV, V, and VI generation that are now living. These are of special interest because they furnish valuable data for a comparative study of the two types of the malformation we are dealing with. This supplementary material will now be presented. The discussion of the facts obtained will be postponed until this is done.

\section{LINE 9.}

The B !-type brachyphalangous 1.9 o F. J. Ø. (II generation, p. 24), by his marriage with the unrelated C. R., from Asker near Christiania, had 9 children, 19.1-19.9 (III generation). One of them, 19.4 ㅇ L. E. Ø. (Nov. 10, 1838-Nov. 25, 1908), married in 1857 the normal L. J. A., a builder. They had by their marriage 10 children, 
representing the third family of the IV generation, line 9 . We have been able to examine several of these individuals and their descendants of the V and VI generation. Only this part of the line 9 will here be treated.

The children of 19.4 ㅇ L. E. $\emptyset$. state that their mother had normal fingers. That she, however, must have been heterozygous for the factor for brachyphalangy is clear in view of the fact that several of the children are brachyphalangous. We may accordingly safely conclude that she had the B-type of the malformation.

Line 9, IV Generation.

Third Familx of IV Generation.

This family comprises the 10 children of $19.4 \circ$ L. E. $\varnothing$. and her unrelated husband, L. J. A., 194.1-194.10. To avoid confusion we may mention that several of these individuals later changed their last name. This is the reason why the last initial differs within the same family.

194.1 ㅇ C. F. A. (b. June 9, 1859) emigrated to Minnesota, where she married farmer F. No children.

Replying to inquiries concerning her fingers, she answers in a letter: "Both my index fingers are a little shortened. The second phalanx is shortened. Mother had not shortened fingers, but an uncle had like mine." It is clear from this description that she has the B-type brachyphalangy, a view that is confirmed by the entirely different way in which she described the index fingers of her niece, $1942.1 \%$ J. G., who has the B !-type brachyphalangy (p. 40).

$194.20^{\pi}$ A. K. A. G. (b. Sept. 22, 1860) manager of a restaurant, Bergen, Norway. The photographs (figs. 19, 20) and radiographs (fig. 46) of his hands represent a typical case of the B-type of brachyphalangy and need no further description. The lengths of II 2 and IV 2 are 17 and $26 \mathrm{~mm}$. respectively on both hands. Aside from the second phalanges of the indices, the other bones of the hand are normal. This man married twice. By his first marriage he has a daughter 1942.1 $\%$. By his second marriage with the normal, unrelated A. E. M. (b. Jan. 30, 1880), he has 4 children 1942.2-1942.5 (pp. 40-41).

194.3 o $^{7}$ E. A. L. (b. Sept. 3, 1862), manager, Bergen, Norway. Photographs of his hands are given in figs. 21, 22. Seen from the dorsal side they could easily be regarded as normal. The photograph of the volar surface, however, in connection with the radiograph (fig. 47), reveals a clear case of B-type brachyphalangy. The lengths of II 2 and IV 2 are 22 and $30 \mathrm{~mm}$. respectively on both hands.

E. A. L. married the normal, unrelated A. M. S. (b. Aug. 9, 1865) and has 5 children, 1943.1-1943.5 (pp. 41-42).

194.4 \% K. O. A. (Sept. 25, 1864-1914). Emigrated to Alaska, where she married the unrelated J. O. and had 4 children, 1944.1-1944.4. No information concerning her own or her children's hands has been available. 
194.5 \% L. E. A. (b. Apr. 29, 1866) emigrated to Oregon and married the unrelated driver $\mathrm{E}$. She has 6 children, 1945.1-1945.6 (p. 42). In a letter she states that her own hands are normal, but that one of her sons has shortened index fingers. Her description of his hands is, however, very confused and it is only with great reservation we may assume that she is heterozygous for brachyphalangy while we lack a more exact description and photographs of her hands and those of her son.

194.6 \% V. H. A. (b. May 18, 1868) Christiania, Norway. We have examined this individual and found that her hands are normal. She married the normal L. and has a son. We have not examined his hands, but his relatives state that they are normal, which was to be expected.

194.7 \& S. A., Christiania, Norway. Photographs of her hands are given in fig. 21 and fig. 22 . The III and IV fingers on one hand were injured by an accident. Also in this case the hands when seen from the dorsal surface would easily be regarded as normal. As seen from the volar surface, however, the second phalanges of the indices are markedly shortened, judging from the distance between the second and third grooves.

The radiographs (fig. 48) prove definitely the brachyphalangous condition, the lengths of II 2 and IV 2 being 18 and $28 \mathrm{~mm}$. respectively on both hands. Like both her older brothers, she has the B-type of brachyphalangy.

She married Aa. and has a daughter, 1947.1 (p. 43).

$194.8 \sigma^{7}$ H. Ø. (b. Feb. 15, 1874), Christiania, Norway. Seen from the dorsal surface the hands of this man look as if they were normal (fig. 23). From the inside, however (fig. 24), the second phalanges of the indices seem to be slightly shortened, because the distance between the second and third grooves, compared with the corresponding distance on the fourth finger, is shorter than is the case in a normal hand.

On the other side, the radiographs (fig. 49) give measures of the phalanges which fall within the limits of variation in normal hands based on the material collected by Pfitzner. The lengths of II 2 and IV 2 are 22 and $27 \mathrm{~mm}$. respectively on both hands. A radiograph from the right foot (fig. 50) shows, however, a marked shortening of the second phalanx of the second toe. This fact taken together with the appearance of the volar surface of the indices and the information the man gives spontaneously that he uses the third finger instead of the second in all sorts of finer work, indicates that he is really brachyphalangous. He states that when he unties a knot he always uses the third finger, as he also does when he picks up a needle from the floor and in doing similar delicate operations with his fingers. We accordingly interpret this case as an instance of the B-type of brachyphalangy, corresponding to that of 1151.2 \% (p. 33). This man is not married and therefore the genetic proof can not be obtained, as it could in the other case just mentioned. 
$194.9 \sigma^{7}$ L. S. A. This man emigrated to the United States and lives in San Francisco. He married a lady from western Norway and has several children. Our efforts to get information concerning this individual and his children have hitherto led to no result.

194.10 o L. S. A. She died at the age of two years and nothing is known concerning her hands.

Summing up, it will be seen that our information concerning the members of this family is incomplete. Out of 10 members, we have been able to examine only 5 ; of these, 4 are brachyphalangous of the B-type and one is normal. In one more case we have obtained direct information which indicates that the individual is brachyphalangous of the B-type. In still another case, where we have obtained direct information, the description of the hands is too imperfect to be of use.

\section{Line 9, V Generation.}

In this record of the $\mathrm{V}$ generation, line 9 , only the families belonging to the descendants of the individuals $194.2 \sigma^{7}, 194.3 \sigma^{7}, 194.5$ o , and 194.7 o will be dealt with. They represent families $6,7,8,11$, and 12 , of the $\mathrm{V}$ generation, line 9 ; and family 1 of the VI generation.

\section{Sixth Family of V Generation.}

The B-type brachyphalangous $194.2 \sigma^{\top} \mathrm{A} . \mathrm{N}$. A. C., by his first marriage with an unrelated wife, has a daughter, 1942.1 \%

1942.1 ㅇ J. G. (b. July 7, 1883), living in Chicago, Illinois. A photograph of her hands is given in fig. 27. Both from the dorsal and from the volar surface a very striking shortening of the indices is clearly seen. The distance between the second and third groove on the inside of the index fingers is very much shorter than is the case in normal hands. The affected fingers are straight.

The radiographs (fig. 51) prove that the brachyphalangy is restricted to the second phalanx of the indices only. The shortened phalanx has two articular surfaces, but the form is markedly changed, the whole bone being thickened and clumsy. The shortening is somewhat asymmetrical, most pronounced on the right hand. The lengths of II 2 and IV 2 are 8 and $25 \mathrm{~mm}$. respectively on the right hand, 11 and $25 \mathrm{~mm}$. on the left hand. The external aspect of the indices, as well as the radiographs, makes it clear that we are dealing with a case of B !-type brachyphalangy, the only certain one within line 9.

This individual, who is heterozygous for the factor for brachyphalangy, married O. P. H. and has had 3 children, 19421.1-19421.3 (p.43).

Seventh Family of V Generation.

194.2 o A. K. A. G., by his second marriage with the unrelated, normal A. E. M., has 4 children, 1942.2-1942.5.

1942.2 \% G. E. G. (b. Jan. 4, 1908). Photographs and radiographs of her hands show that she is normal. The lengths of II 2 and IV 2 are respectively 18 and $22 \mathrm{~mm}$. on the right hand, 17 and $22 \mathrm{~mm}$. on the left hand. 
1942.3 \% A. E. G. (b. Dec. 16, 1910). Photographs and radiographs of her hands prove that she is free from brachyphalangy. The lengths of II 2 and IV 2 are 15 and $19 \mathrm{~mm}$. respectively on both hands.

1942.4 o $^{7}$ E. L. H. G. (b. July 1, 1912). Photographs and radiographs from his hands prove that he is free from brachyphalangy. The lengths of II 2 and IV 2 are 17 and $19 \mathrm{~mm}$. respectively on both hands.

$1942.50^{7}$ A. M. G. (b. Aug. 16, 1914). A photograph and a radiograph of his hands are given in fig. 28 and fig. 52. The radiograph shows that the second phalanges of the indices are markedly shortened, even shorter than the corresponding phalanges of the fifth fingers.

The epiphysial cartilages are present and the external aspect of the hands makes it clear that we are here dealing with the B-type of brachyphalangy. The lengths of II 2 and IV 2 are 8 (?) and $15 \mathrm{~mm}$. on the right hand, 9 and $15 \mathrm{~mm}$. on the left hand. The individual is genetically heterozygous for the factor for brachyphalangy.

Summing up, we have been able to show that the B-type brachyphalangous $194.2 \sigma^{7} \mathrm{~A}$. K. A. G. has one B !-type brachyphalangous child by his first marriage. By his second marriage he has 3 normal children and one child brachyphalangous of the B-type.

\section{Eighth Family of V Generation.}

The B-type brachyphalangous $194.3 \sigma^{\top} \mathrm{E}$. A. L., by his marriage with the normal A. M. S., has 5 children, 1943.1-1943.5.

1943.1 or E. A. L. (b. June 26, 1899). The photographs and radiographs, figs. 29, 30, and 53, are typical for a case of B-type of brachyphalangy. The shortening of the distance between the two distal grooves of the index fingers is very marked and can be noticed both from the dorsal and volar surface of the hand. The lengths of II 2 and IV 2, measured from the radiographs, are 22 and $29 \mathrm{~mm}$. on the right hand, 21 and $29 \mathrm{~mm}$. on the left hand.

In Pfitzner's material only 1 out of 301 normal hands is found which shows the same lengths of II 2 and IV 2 as in the right hand of this individual. This case represents an extreme variation, but it furnishes us with another example analogous to that of 1151.2 o S. R., discussed above.

The brachyphalangous condition of this individual is clearly indicated, however, by the external aspect of the hands; and the relative lengths of II 2 and IV 2 of the left hand fall outside the limits of extreme variation in normal hands.

The individual is genetically heterozygous for the factor for brachyphalangy.

$1943.2 \sigma^{7}$ H. J. L. (b. Aug. 26, 1900). His hands are perfectly normal as shown from photographs and radiographs. Lengths of II 2 and IV 2 are 25 and $30 \mathrm{~mm}$. respectively on the right hand, 25 and $29 \mathrm{~mm}$. on the left hand. 
1943.3 o $^{7}$ H. R. L. (b. Feb. 28, 1902). His hands are normal, as shown by photographs and radiographs. Lengths of II 2 and IV 2 are 24 and $29 \mathrm{~mm}$. respectively on the right hand, 25 and $30 \mathrm{~mm}$. on the left hand.

1943.4 ㅇ E. M. L. (b. Aug. 1, 1903). The photographs (figs. 31, 32) and radiographs (fig. 54) of her hands give us a typical case of the B type of brachyphalangy. The volar surface of the indices shows the characteristic shortening of the distance between the second and third grooves of the indices. The lengths of II 2 and IV 2 , measured from the radiographs, are 21 and $29 \mathrm{~mm}$. on the right hand, 20 and $29 \mathrm{~mm}$. on the left hand. The epiphysial cartilages of the shortened phalanges are present. She was 14 years old when the radiographs were taken. She is heterozygous for the factor for brachyphalangy.

1943.5 \& E. S. L. (b. Dec. 30, 1907) represents, as the photographs (figs. 33, 34) and radiographs (fig. 55) demonstrate, a very characteristic case of the B-type of brachyphalangy. The distance between the second and third grooves of the indices is characteristically shortened. The second phalanx of the index of the left hand is a little irregular in shape. This calls forth a slight bending in the radial direction of the terminal phalanx of this finger. The epiphysial cartilage is present in both the affected phalanges. The individual was 10 years old when the radiographs were taken.

The lengths of II 2 and IV 2 are 13 and $22 \mathrm{~mm}$. respectively on both hands. The individual is genetically heterozygous for the factor for brachyphalangy.

Summing up, we find that the B-type of brachyphalangous 194.3 $\sigma^{7}$ E. A. L. has 2 normal and 3 B-type brachyphalangous children.

\section{Tenth Family of V Generation.}

194.5 ㅇ L. E. A., by her marriage with the normal E., has 6 children, 1945.1-1945.6.

1945.1 \% B. M. E. (b. 1893).

1945.2 or L. H. E. (b. 1895).

1945.3 ㅇ H. E. (b. 1896).

1945.4 \% A. M. E. (b. 1898).

1945.5 or A. M. E. (b. 1899).

1945.6 or H. E. E. (b. 1902).

The information obtained concerning this family is very unsatisfactory. Their mother states in a letter:

"We have one son in our family who has both index fingers shorter than they ought to be. It is the end of the finger, the joint nearest to the nail which is shorter than it ought to be. It looks as if he had no joint there; he can not bend it."

Several attempts to obtain a better description or photographs have failed, and we have therefore refrained from paying any attention to the information in the discussion. The only thing which probably 
may be concluded from these data is that brachyphalangy occurs in the offspring of 194.5 o L. E. A., and that she herself is heterozygous for the factor for the malformation. As to the type of her son's brachyphalangy no conclusions can be drawn.

\section{Twelfth Family of V Generation.}

The B-type brachyphalangous $194.7 \& \mathrm{~S}$. A., by her marriage with the normal Aa, has 1 daughter, 1947.1 $ᄋ$.

1947.1 ㅇ E. Aa. (b. 1908). She is, as the photographs (figs. 35, 36) and radiographs (fig. 56) indicate, brachyphalangous of the B-type. The lengths of II 2 and IV 2 are 15 and $21 \mathrm{~mm}$. respectively on both hands. The epiphysial cartilages of the affected phalanges are present. The individual is heterozygous for the factor for brachyphalangy.

Line 9, VI Generation.

First Familit of VI Generation.

The B-type brachyphalangous 1942.1 \& J. G., by her marriage with the normal, unrelated O.P. H., has had 3 children, 19421.1-19421.3.

$19421.1 \sigma^{7}$ F. L. H. (July 6, 1905-Jan. 29, 1907) and 19421.2 or S. V. H. (Oct. 4, 1906-May 4, 1907). Both died young and according to the statement of their mother they had normal hands.

$19421.3 \sigma^{7}$ R. F. H. (b. June 26, 1911). Radiographs of his hands (fig. 38) prove that he is free from brachyphalangy. Lengths of II 2 and IV 2 are 18 and $21 \mathrm{~mm}$. respectively on the right hand, 18 and 20 $\mathrm{mm}$. on the left hand.

Summing up, it is probable that the three children of the B !-type brachyphalangous $19421.1 \%$ all have been free from brachyphalangy. The possibility that one or both of the two sons who died young may have been brachyphalangous of the B-type can not, however, be excluded.

The supplementary material we have been able to obtain within the "line 9 " of the family comprises radiographs and photographs of 10 brachyphalangous and 6 normal individuals. The interesting point here is that the B-type of the malformation seems to be prevailing within this line, descending from the B !-type brachyphalangous 1.9 $\sigma^{7}$ F. J. Ø. In only one case have we seen the B !-type occur among his descendants; and a limited investigation would easily have led to the conclusion that all the brachyphalangous individuals of this line belonged to the B-type, in striking contrast to what was the case in "line 1." 


\section{HEREDITARY TYPE OF THE CHARACTER STUDIED.}

\section{GENERAL DISCUSSION.}

On the basis of the data given in the family record, it is now possible to state the hereditary type of the malformation with absolute certainty. It is not necessary to emphasize that we are dealing with a clear-cut case of Mendelian heredity (cf. the pedigree). The fundamental Mendelian principle, the principle of segregation, is strikingly demonstrated. The character behaves in every respect as a typical mutant character.

In line 1 we have been able to follow the brachyphalangy for 6 generations through heterozygous individuals, who may have brachyphalangous or normal children. The latter are free from the gene causing brachyphalangy and their descendants will be normalprovided no intermarriage with brachyphalangous individuals takes place. A good illustration of this fact is 11.4 ㅇ L. A. H. H., a daughter of the brachyphalangous $1.1 \circ$ G. H. Ø. Her hands were normal and all the 28 individuals of her descendants in the following three generations are free from brachyphalangy, as was to be expected.

The character is not sex-linked, as may be easily seen from the pedigree.

The fact that the brachyphalangy appears in heterozygous individuals shows that it is a dominant character, and the material we are dealing with furnishes us with interesting facts for a further discussion of this special point.

The individuals showing a dominant character in human material will in the large majority of cases be heterozygous for the factor involved. Intermarriage is in general rare and it is obvious that individuals affected by the same hereditary malformation are even more unlikely to marry each other.

Although the data concerning dominant hereditary malformations in man, therefore, are generally restricted to heterozygous individuals, it is nevertheless usually taken for granted that the dominant character described is the same that would appear in homozygous individuals. Besides this, another statement is very often met with, namely, that the characteristic for a dominant character is the fact that it never skips a generation, in the sense that only individuals that show the character can transmit it to their children. Both these points are open to serious criticism. A reservation is necessary, especially because both matters are of importance from a medical point of view.

It must first be strongly emphasized that a knowledge of the effect of a gene when heterozygous by no means entitles us to conclude that the effect will be the same when it is homozygous. The complete dominance found, for instance, in mice, where a gray individual heterozygous for albino can not be somatically distinguished from homozygous 
gray individuals, represents an extreme condition. Numerous cases, both in animal breeding and in experimental heredity, present a striking difference in the character when the dominant genes are homozygous and when they are heterozygous.

In this connection the following statements might be quoted:

"The failure of many characters to show complete dominance raises doubt as to whether there is such a condition as complete dominance." (Morgan, Sturtevant, Muller, and Bridges, 1915.)

Baur in his book (1914) emphasizes the same point:

"Man hat dieser Dominanzerscheinung, die durchaus keine allgemeine Regel ist, vielfach übertrieben, grosse Bedeutung zugeschrieben und von einer 'Dominanzregel' gesprochen. Das ist ganz verkehrt. Eine irgendwie allgemein gültige Dominanzregel giebt es nicht und sehr haüfig ist eine Dominanz nur scheinbar."

The same opinion is expressed by East (1916):

"But as a matter of fact, absolute dominance is rare. A heterozygous gene very seldom produces an effect identical with that of homozygous genes."

Many examples might be used to illustrate this relation. One of us (Wriedt) studied a case of "short ears" in sheep which behaves as a dominant character (Wriedt, 1914,1916,1919;Ritzman, 1916). Recently we have been able to see the offspring of two short-eared sheep. In some of these the external ears are entirely absent. These are probably the homozygotes.

One of the most striking cases of this kind is found in the mutant character Star in Drosophila melanogaster (s. ampelophila), found by Dr. Bridges. Star has been very much used in the experimental analysis in Dr. Morgan's laboratory in the past few years and an account of the character is now in press. Dr. Bridges has kindly permitted us to refer to the case, which in many respects furnishes us with very interesting parallels to the character we are here dealing with. Star is a dominant eye character. When heterozygous the gene for Star causes a slight irregularity of the ommatidia of the eyes, giving the eye surface a shimmering aspect. This trifling malformation is of no practical importance and does not affect the viability of the individuals at all. When homozygous, however, this gene is lethal. Flies homozygous for Star die without exception.

The mutant character Star, here chosen as an example, is not unique in this respect. In fact, 5 of the known 9 dominant mutants in Drosophila are completely lethal when homozygous, 1 is semilethal, and only 3 are not lethal when homozygous (Muller, 1917). Another wellknown example is the yellow body-color in mice (Cuénot, 1915, 1918; Castle and Little, 1910).

Just as Star in Drosophila, so the brachyphalangy here described is of no practical importance at all in heterozygous individuals. But it 
is well worth noticing that in the single case where the possibility for homozygous individuals was present in our material, a child, 115.2 \& C. F. H., was born who was a cripple "without fingers and toes" and "with her whole osseous system in disorder." As described above (pp. 28-29), this individual was unable to develop and died when one year old. The possibility that we are here dealing with a homozygous individual is pointed out above.

From a medical point of view, this relation is of great importance. The fact that an hereditary malformation in heterozygous individuals is without any practical consequences by no means guarantees that the malformation when the genes are homozygous will be as. slight. In similar cases a physician should warn affected members of such a family against marrying each other, however trifling the malformation may be. This attitude is fully justified by the facts established through the experimental heredity work.

The second point mentioned above - a statement often met with in publications concerning Mendelian heredity in man-is that only individuals who show the dominant character are able to transfer it to their children. Here, too, a certain amount of reservation is necessary, for the statement disregards entirely the fact that a great many Mendelian characters are extremely variable in their somatic appearance. This holds not only for recessive characters, but for dominant characters as well.

In Drosophila, for instance, numerous mutations are found that in some individuals are very striking, but in others of exactly the same genetic constitution are not visible at all. Between the striking appearance of the character and its total failure of somatic manifestation a series of variations are found.

The dominant eye-character Star might here again with profit be used as an illustration. In some individuals this character is very marked in its appearance. The ommatidia are scattered around without any regularity, the form and size of the eye is influenced and the whole aspect is entirely different from that of the eye of the wild fly. In other individuals the alterations caused by the Star gene are so slight that it requires special training to use the character in experimental work, and even a trained observer will meet cases where a genetic test is necessary to decide whether the individual is Star or not. Between these extremes all degrees in the manifestation of the character are found.

The parallelism with the character we are here dealing with in human material is easily seen. Disregarding the question of two types, to be discussed later, the fact is that some of the heterozygous individuals show alterations of a nature so striking they they can not escape even the most superficial observer. This was, for instance, the case in the individuals $11.5 \sigma^{7}, 115.4 \sigma^{7}, 115.8 \sigma^{7}$, and $11512.1 \sigma^{7}$ 
(figs. 4, 7, 11, and 18). The shortening of the affected phalanx is here so pronounced that an external examination might lead to the conclusion that it was entirely absent. On the other side, we have cases where heterozygous individuals show so slight an alteration that the affected individuals themselves do not realize that they are brachyphalangous. This is the case in most of the individuals who show the B-type of brachyphalangy.

The most instructive example here is the individual 1151.2 o S. G. (figs. 13 and 14). Even measurements provided by the radiographs of her hands fall within the limits of extreme variation in a correlation table made up from measurements from normal hands (p. 53). The slight shortening of the distance between the second and third grooves of the indices is as a diagnostic very uncertain, and from the examination of her hands it would be perfectly allowable to conclude that she is somatically normal. That she nevertheless is genetically brachyphalangous is shown by the fact that her son is brachyphalangous of the B !-type.

This controlled case is perhaps the first in human material where an individual heterozygous for a dominant gene is shown to be somatically normal. It is valuable because an exact examination can be carried out through the radiograph, while the test of the genetic constitution at the same time is at hand. The importance of such an analyzed case is obvious from several points of view: In the first place it gives a satisfactory explanation of many contradictions in records concerning heredity in man. The situation often met with in such publications, that characters which in some generations show a clear Mendelian inheritance are recorded as behaving in a way disagreeing with Mendel's laws, is easily explained by the supposition of a similar occurrence. Cases are well known where authors have concluded from such material that the results obtained in experimental heredity work in animals and plants can not be applied to inheritance in man.

A very characteristic example of this type is Rabaud's paper as recently as 1912. In his severe criticism of "Le dogme mendélien" as applied to human heredity he arrives at the following conclusion:

"Un jour viendra peut-être où, grace à lui $[i$. e. , 'le langage physico-chimique'] les phénomènes de la vie, les phénomènes héréditaires en particulier, pouront être soumis au calcul. Ce jour-là, n'en doutons pas, les formules mendélien paraîtront à nos arrière-neveux prodigieusement naĩves."

This criticism is mainly based on an analysis of material collected by Vidal (10), who followed a case of hereditary brachyphalangy through four generations "sans se préoccuper en aucune façon du point de vue mendélien" (Rabaud).

It is true that the pedigree given by Vidal shows exceptions from the Mendelian rule that a dominant character never skips a generation, 
taken in its old uncritical sense. But the author has trusted in secondhand information and also characterized as "not brachyphalangous" several members of the family, in which the character manifests itself under another somatic type, "doigt crochu" (cf. p. 12).

A case so extreme as that of 1151.2 \% S. G., discussed above, might be comparatively rare. But the frequent occurrence of very slight shortening of the affected phalanx in the heterozygous individuals in our material makes it clear how absolutely insufficient and misleading second-hand information is in heredity work in man.

We are here dealing with a malformation, in many individuals better defined, simpler, and therefore more easily controlled than most of the hereditary characters hitherto studied in human material. Here, if anywhere, it might a priori seem probable that inquiries directed to the family members would furnish a trustworthy basis for the study of the heredity of the malformation. Yet such a method of investigation would have led to entirely false results. In fact, almost none of the B-type individuals would have been recorded, though they are as numerous as the B !-type ones. A pedigree of the descendants of $11.5 \sigma^{\top}$ C. A. B. H. as it would have looked if based on the information obtained from family members and examination only of the reported brachyphalangous ones, is given in text-figure 2 as an illustration.

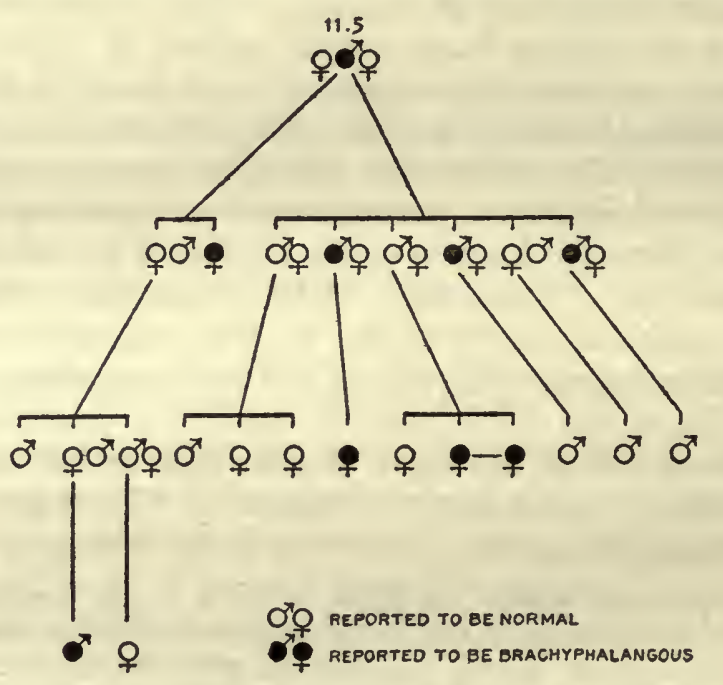

Text-Figure 2.-Pedigree of the descendants of $11.5 \sigma^{\top}$ constructed on basis of information obtained by the members of the family.

The quite unsatisfactory nature of the material upon which Rabaud principally founds his criticism is obvious in the light of such a pedigree.

When a personal examination of all family members has shown the complete inadequacy of the "second-hand" method of collecting data, 
even in the case of a character so easily controlled as the one here described, it is superfluous further to emphasize how much more necessary this method of personal examination of all family members is when far more vague characters are studied. This is especially true when applied to such characters as physical and mental defects where the diagnosis is difficult even for a trained specialist, not to mention cases where imponderabilia (such as mental abilities, etc.) are the object of the research.

The consequence is that in human material, where one observer will not be able to examine more than three, or in especially favorable cases four, generations it is in general much more valuable to carry out an exact examination of as many members as possible of these few generations than to try to follow the character farther backwards. The only source of information is here in most cases the more than questionable memory of individuals now living, and the reliability of the data obtained is inversely proportional to the length of the pedigree studied. The information obtained will be more likely to decrease than to improve the value of the investigation.

It is unnecessary to mention that this reasoning is especially applicable to the study of dominant characters in man. Where recessiveness is involved the situation is of course different. But the working out of the heredity of recessive characters in man will in general be possible only where special sources of information are at hand-for instance, in the case of Lundborg's investigation of the Myoclonus epilepsy (1913).

\section{THE RATIO BETWEEN AFFECTED AND NORMAL INDIVIDUALS.}

As for the numerical ratio between affected and normal individuals in the families here studied, the expectation is that half of the children of the heterozygous individuals should be brachyphalangous, provided no intermarriage of heterozygotes takes place.

In many publications on human material too much attention is paid to the question, whether the actual ratio is in harmony with the Mendelian expectation. It is obvious that it will be a mere chance if distinct "Mendelian ratios" are found in material where the fraternities and the number of examined individuals are so small as is the case in this sort of heredity work. Not the numerical ratios, but "the fundamental principle of segregation, is the essential feature of Mendel's discovery." (Morgan, Sturtevant, Muller, and Bridges, 1915.)

In this publication elaborate information has been given concerning all members of 15 families, born alive, in which one of the parents was heterozygous for brachyphalangy, the other normal. The numerical ratio between affected and normal individuals in the offspring are shown in table 1. 
TABLE 1.-Numerical ratio between affected and normal individuals in the offspring of heterozygous individuals.

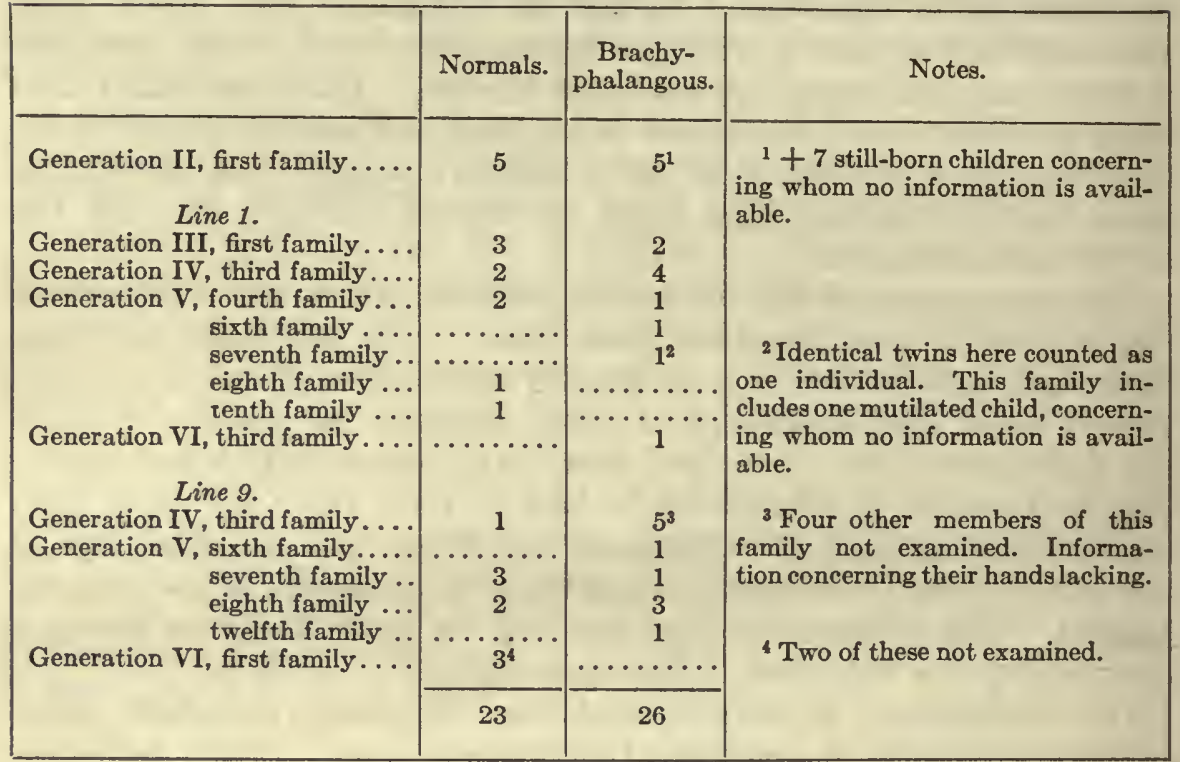

This ratio, 23 normals to 26 brachyphalangous individuals, is strikingly in accord with the expectation 1:1. But it is necessary to keep in mind the source of error introduced by the fact that in generations II and III we have information about only the B !-type individuals. It is impossible to tell if some of the family members here characterized as "normals" in reality were brachyphalangous of the B type.

It is worth mentioning that there is a tradition in the family, as we have heard several times, that every second child of a brachyphalangous family will have the malformation and that the oldest one always is affected. The germ of truth in this tradition is that half of the children are likely to be brachyphalangous, but the slightest attention shows that the family's belief in alternative repetition is not in accord with the facts. ${ }^{1}$

We have in our material one case interpreted as a marriage between two individuals heterozygous for brachyphalangy, namely, the marriage between $11.5 \sigma^{7}$ C. A. B. H. and his cousin 17.1 \& F.G. Ø. (p. 26). The expectation is in such a case that one out of four children should be normal, while two should be heterozygous and one homozygous for brachyphalangy. The family resulting from this marriage, family 3 of the IV generation, comprises 2 individuals; one of those is shown to have been heterozygous for brachyphalangy. The reasons supporting the supposition that the other was homozygous for the factor are discussed above (pp. 44-46).

\footnotetext{
${ }^{1}$ After this chapter had been written we noticed, curiously enough, that Farabee met exactly a similar tradition in the family studied by him: "The family tradition is that every other child born of a short-fingered parent has short fingers" (1905).
} 


\section{THE B-TYPE AND THE B I-TYPE.}

In the general description, as well as in the description of the single cases of brachyphalangy, it has been stated that the anomaly here studied manifests itself in two different somatic types, the B-type (brachyphalangous, shortened) and the B !-type (very brachyphalangous, much shortened). The reasons why this distinction seems indicated may now be discussed.

It has already been pointed out that in the diagnosis of this character the general aspect of the index fingers, and the distance between the two distal grooves especially might be used as valuable and often fully sufficient diagnostic features. But better than this method of diagnosis by mere inspection is the one based on the objective measurements of the phalanges obtained from the radiographs, which are far more trustworthy indices.

The supposition that we here are dealing with two distinct somatic types of brachyphalangy is confirmed by the analysis of these measurements. To be able to estimate from the measure of a certain phalanx whether a shortening is present, it is evidently necessary to have an exact normal standard of comparison. The material here used is obtained from measurements of the hand bones of 301 normal-hand skeletons, given by Pfitzner $(1892,1893)$. It needs no explanation that absolute values are useless for our purpose. The point is not whether the questioned phalanx is shorter than the corresponding phalanx of an average normal hand, but whether it is shortened in comparison with the normal finger bones of the same hand. It has, therefore, been necessary to calculate the correlation coefficients between different finger bones in normal hands.

Based on Pfitzner's material, the correlation coefficients were worked out for the lengths of the first and second phalanx of theindex finger (II 1 and II 2) of the second phalanx of index and middle finger (II 2 and III 2) and of the second phalanx of the index and ring finger (II 2 and IV 2). The values obtained are given in table 2 .

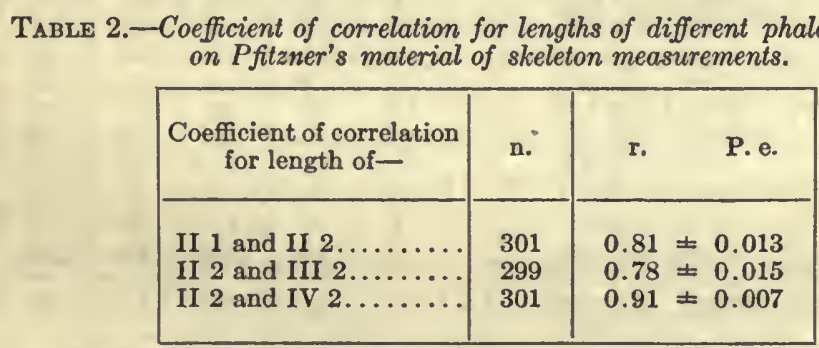

The result shows that there is a very high correlation between the lengths of the second phalanges of the second and ring finger, and the latter measure is therefore used for comparison when estimating whether II 2 is shortened or not. 
Table 3 gives (in millimeters) the lengths of the second phalanges of the index and ring fingers measured from the radiographs representing the hands of family members studied.

TABLE 3.-Length in millimeters of second phalanx of index finger and ring finger of family members studied, measured from the radiographs.

LINE 1.

\begin{tabular}{|c|c|c|c|c|c|c|}
\hline \multirow[t]{2}{*}{ Generation. } & \multirow[t]{2}{*}{ Individual. } & \multirow[t]{2}{*}{ Age. } & \multicolumn{2}{|c|}{$\begin{array}{l}\text { Length of } \\
\text { II } 2 \text { in } \mathrm{mm} .\end{array}$} & \multicolumn{2}{|c|}{$\begin{array}{l}\text { Length of } \\
\text { IV } 2 \text { in } \mathrm{mm}\end{array}$} \\
\hline & & & Right. & Left. & Right. & Left. \\
\hline III & 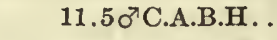 & ca. 80 & 6 & 6 & 27 & 27 \\
\hline IV & 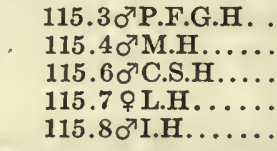 & $\begin{array}{r}42 \\
\text { ca. } 26 \\
\text { ca. } 23 \\
35 \\
33\end{array}$ & $\begin{array}{r}25 \\
5 \\
6 \\
24 \\
6\end{array}$ & $\begin{array}{c}25 \\
5 \\
8 ? \\
24 \\
10\end{array}$ & $\begin{array}{l}29 \\
29 \\
27 \\
29 \\
29\end{array}$ & $\begin{array}{l}29 \\
28 \\
26 \\
29 \\
29\end{array}$ \\
\hline $\mathrm{V}$ & 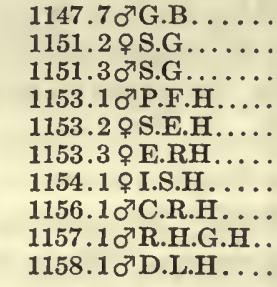 & $\begin{array}{r}24 \\
41 \\
36 \\
12 \\
10 \\
7 \\
12 \\
10 \\
7 \\
4\end{array}$ & $\begin{array}{r}23 \\
21 \\
25 \\
21 \\
18 \\
18 \\
8 \\
17 \\
14 \\
13\end{array}$ & $\begin{array}{l}23 \\
20 \\
25 \\
21 \\
18 \\
18 \\
10 \\
17 \\
14 \\
13\end{array}$ & $\begin{array}{l}27 \\
(1) \\
30 \\
25 \\
20 \\
21 \\
23 \\
21 \\
17 \\
17\end{array}$ & $\begin{array}{l}27 \\
26 \\
29 \\
25 \\
20 \\
21 \\
23 \\
22 \\
17 \\
17\end{array}$ \\
\hline VI & $\begin{array}{l}11474.1 \sigma^{2} \text { K.L.J. . . . } \\
11512.1 \text { o O.R. . . . . } \\
11531.1 \text { \& E.G. . . }\end{array}$ & $\begin{array}{r}7 \\
19 \\
7\end{array}$ & $\begin{array}{r}13 \\
9 \\
16\end{array}$ & $\begin{array}{r}14 \\
8 \\
16\end{array}$ & $\begin{array}{l}16 \\
28 \\
19\end{array}$ & $\begin{array}{l}16 \\
27 \\
18\end{array}$ \\
\hline
\end{tabular}

LINE 9.

\begin{tabular}{|c|c|c|c|c|c|c|}
\hline IV & $\begin{array}{l}\text { 194.2 } \text { o }^{\top} \text { A.K.A.G. } \\
194.3 \sigma^{\top} \text { E.A.L. . . } \\
194.7 \text { o S.A. . . . . } \\
194.8 \sigma^{7} \text { H.Ø. . . . }\end{array}$ & $\begin{array}{r}57 \\
55 \\
\text { ca. } 47 \\
43\end{array}$ & $\begin{array}{l}17 \\
22 \\
18 \\
22\end{array}$ & $\begin{array}{l}17 \\
22 \\
18 \\
22\end{array}$ & $\begin{array}{l}26 \\
30 \\
28 \\
27\end{array}$ & $\begin{array}{l}26 \\
30 \\
28 \\
27\end{array}$ \\
\hline V & 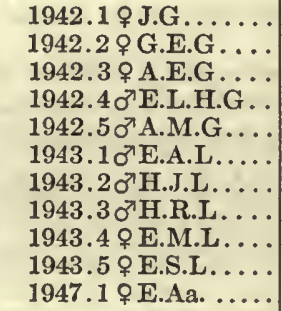 & $\begin{array}{r}35 \\
9 \\
7 \\
5 \\
3 \\
19 \\
18 \\
16 \\
15 \\
11 \\
9\end{array}$ & $\begin{array}{c}8 \\
18 \\
15 \\
17 \\
8 ? \\
22 \\
25 \\
24 \\
21 \\
13 \\
15\end{array}$ & $\begin{array}{r}11 \\
17 \\
15 \\
17 \\
9 \\
21 \\
25 \\
25 \\
20 \\
13 \\
15\end{array}$ & $\begin{array}{l}25 \\
22 \\
19 \\
19 \\
15 \\
29 \\
29 \\
29 \\
29 \\
22 \\
21\end{array}$ & $\begin{array}{l}25 \\
22 \\
19 \\
19 \\
15 \\
29 \\
30 \\
30 \\
29 \\
23 \\
21\end{array}$ \\
\hline VI & 19421. ○’R.J.H . . . & 7 & 18 & 18 & -21 & 20 \\
\hline
\end{tabular}

${ }^{1}$ Right ring finger lost by an accident.

When these values are plotted in the correlation table comprising Pfitzner's material a very illuminating result is obtained. 
TABLE 4.-Corrclation table for 301 normal hands of adult individuals (Pfitzner) and for 70 normal and brachyphalangous hands from individuals of the family here studied. Length of second phalanx of the index, subject. Length of second phalanx of the ring finger, relative. Pfitzner's measures are written in total numbers for each class; measures from normal family members are indicated singly by /; those from individuals described as brachyphalangous by | .

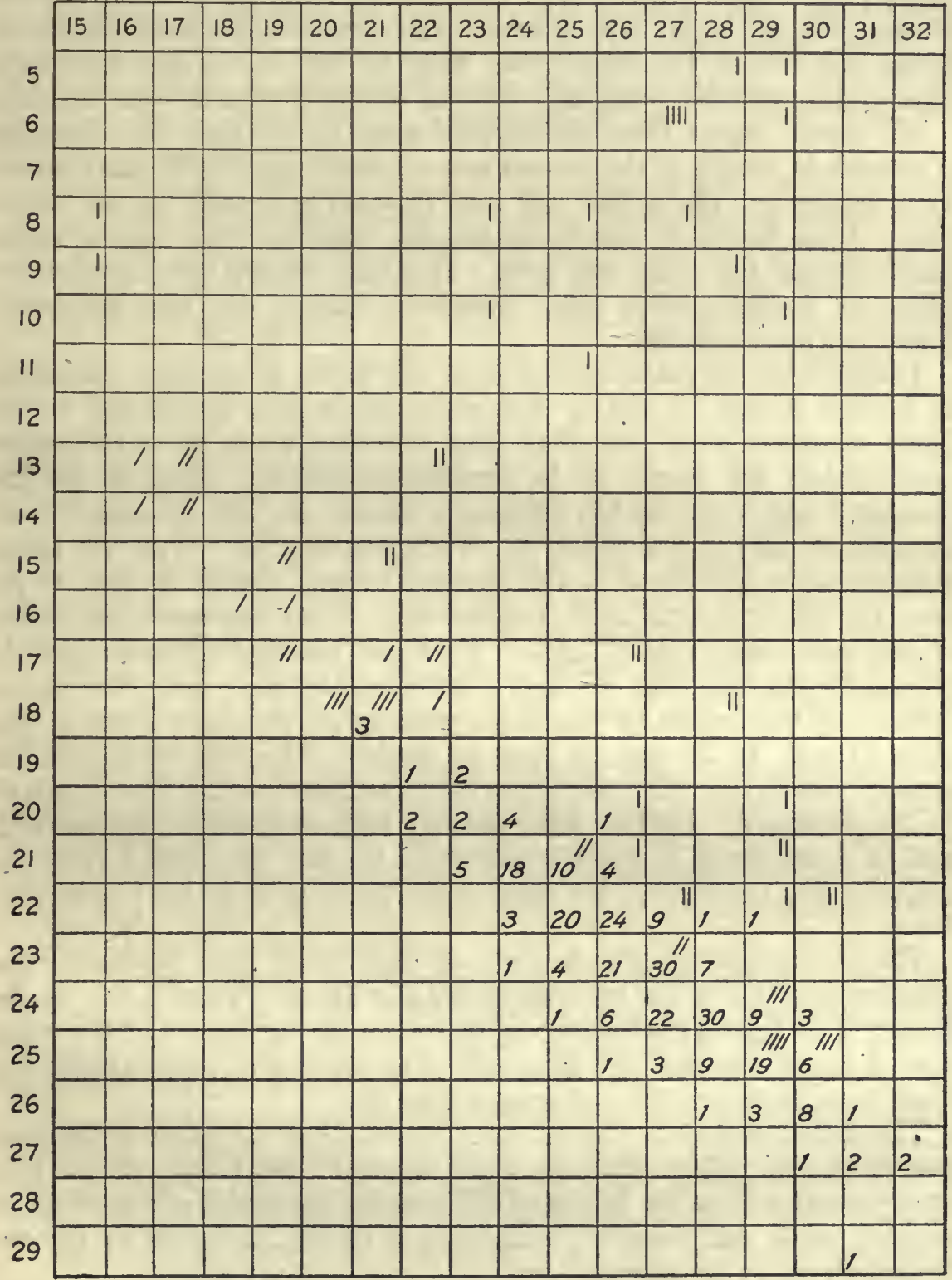

Figures at tops of columns represent the length in millimeters of second phalanx of ring finger. Figures in column at extreme left of the table represent the length in millimeters of second phalanx of index finger. 
It will be seen from table 4 that 22 of the measures obtained from the radiographs fall within the classes which are represented in Pfitzner's material. 21 measures are seen to be grouped in the correlation table close around the line which represents the axis of the "swarm" formed by Pfitzner's numbers. These are all from hands which by our examination are found to be normal. They are obtained from children's hands and this is the reason why they do not fall within Pfitzner's classes, his material consisting only of hands from adult individuals.

We would expect from Holmgren's work (1910) that the checking of growth in length of the second row of phalanges should start somewhat earlier on the radial side and proceed gradually to the ulnar side. Thus hands of brachyphalangous children may appear more nearly normal than they will later. This may disturb the comparative value of measurements from children's hands, but the difference would not be significant.

Twenty-nine measures fall outside the limits of extreme variation in normal hands, as clearly demonstrated in the correlation table. These measures are all obtained from individuals who by our external examination are found to be brachyphalangous. Five of the 22 measures which fall within Pfitzner's classes are also obtained from individuals above described as brachyphalangous. Two of these measurements are found in the extreme normal classes $20 \mathrm{~mm}$. to 26 $\mathrm{mm}$. and $21 \mathrm{~mm}$. to $26 \mathrm{~mm}$., respectively. They represent the hands of the individual 1151.2 o S.G. That she was brachyphalangous is proved by the fact that she had a brachyphalangous son. The introduction of the length of the index phalanx of the right hand in the class $21 \mathrm{~mm}$. to $26 \mathrm{~mm}$. is open to doubt. The individual lost, as already stated, her right ring finger by an accident, so that the length of IV 2 is unknown. Judging from the very high correlation between II 2 and IV 2 less error is probably involved by this proceeding than by omitting the measure of her right index phalanx from the correlation table.

The two measurements in class $22 \mathrm{~mm}$. to $27 \mathrm{~mm}$. represent the phalanx lengths of the individual $194.80^{7} \mathrm{H} . \varnothing$. That he is to be regarded as brachyphalangous is indicated by the aspect of the volar side of his indices and by the marked shortening of phalanx II of his right foot, shown in the radiograph (fig. 50).

The measurement in the extreme normal class $22 \mathrm{~mm}$. to $29 \mathrm{~mm}$. represent the values from the right hand of $1943.1 \mathrm{o}^{7} \mathrm{E}$. A. L. The measurements from his left hand fall outside the limits of variation in normal hands and his brachyphalangy is clearly indicated by the external aspect of his hands.

When these five measurements are added to the 29 which fall outside the limits of variation in the normal hands we have in all 34 phalanx measurements representing brachyphalangous individuals, indicated in the table by vertical marks. 
When the distribution of these measurements is studied in the correlation table it will be seen that they fall into two different groups. One of these forms a group near and parallel to the "swarm" of normal measures and even overlapping it to some degree, as just mentioned. The individuals whose phalanx measurements belong to this group are all described as brachyphalangous of the B-type. The other group of values forms a "swarm" of its own in the upper right corner of the correlation table, removed from the other two swarms. The individuals from whom these phalanx measurements are obtained show the B !-type of brachyphalangy.

It will be seen that two values in the classes $8 \mathrm{~mm}$. to $23 \mathrm{~mm}$. and $10 \mathrm{~mm}$. to $23 \mathrm{~mm}$. seem to form a connective link between the two groups. But this is merely apparently so. In fact these two measurements are obtained from the individual 1154.1 ㅇ I. S. H. who was 12 years old when the radiographs were taken. The radiographs demonstrate that the epiphysial cartilages of her second index phalanges were already entirely ossified, while those of the second ring finger phalanges are quite normal. This means that the growth in length of the shortened index phalanges has stopped, while that of the second ring-finger phalanges will keep on for several years. The final result will be that the values, temporarily found in the classes mentioned, when the individual is adult will be found within the "swarm" in the upper right corner. It has been shown that a similar bony condition of the epiphysial cartilages is not found in the radiographs from hands of B-type brachyphalangous children. When this fact is taken into account the two separate groups stand clearly out without any connecting intermediate link.

The value found in the $11 \mathrm{~mm}$. to $25 \mathrm{~mm}$. class is obtained from the individual $1942.1 \%$. The value representing the measurements from her other hand is found in the $8 \mathrm{~mm}$. to $25 \mathrm{~mm}$. class. The latter value as well as the whole aspect of her indices makes it clear that she belongs to the type whose measurements are grouped in the upper right corner of the correlation table.

It may be objected to this distinction between the two types that the material is too small. The difference might be due merely to an extreme case of somatic variation of the inherited character and the apparent occurrence of two types might be explained by the fact that we have not happened to meet the individuals showing an intermediate condition. Our material, however, is larger than the radiographs alone indicate. If we take the photographs and the cases where we have reliable information of B !-type brachyphalangy into account"index fingers with only one joint"-we get 16 brachyphalangous individuals of the B-type, 11 of the B !-type. It seems highly improbable that within this number of individuals representing 14 different families we should not have met a single intermediate case, if we are here dealing with an ordinary somatic fluctuation. If this were the case 
we should expect the majority of cases to be of an intermediate type between the extreme ones examined.

A possible suggestion that the different occupations of the individuals might be of importance for the development of one or the other type is clearly disproven by the facts. In the family record the occupation of the brachyphalangous individuals is given, and it will be seen there that both types occur within the most different occupations. There is no support for the belief that hard physical work or lack of physical work might favor the development of one type or the other.

The question arises, accordingly, whether or not this occurrence of two types can be explained on a genetic basis. To be able to give an answer we will have to study the distribution of the two types within the part of the family where our information is extensive enough with regard to this special point. This is the case within line 1 for the four generations including $11.5 \sigma^{7}$ C.A. B. H. and his descendants, and within line 9 for most families descending from 19.4 \& L. E. Ø.

In text-figures 3 and 4 the pedigree is given for these parts of the family. A glance at these pedigrees reveals the following points:

The difference in types bears no relation to sex; neither of the types is sex-linked.

A B !-type brachyphalangous individual may have B-type brachyphalangous offspring and vice versa. A good illustration of this fact is found in line 1, where $11.5 \mathrm{o}^{7}$ is brachyphalangous of the B !-type, his daughter 115.1 of the B-type, her daughter 1151.2 of the B-type, and her son $11512.10^{7}$ of the B !-type.

Striking, also, is the fact that the B !-type prevails in line 1 , while the B-type prevails in line 9 . In line 1 only 2 individuals belong to the B-type as against 9 of the $\mathrm{B}$ !-type. In the part of line 9 here studied we know, on the contrary, $10 \mathrm{~B}$-type brachyphalangous individuals and only 1 of the B !-type.

It is clear from these pedigrees that we are not dealing with two independent genes, one causing the B-type and the other the B !-type. The question, then, is whether the presence of a specific modifying gene may account for the appearance of the two different types.

One of the most remarkable features in modern genetic work is the steadily increasing amount of information concerning the very frequent occurrence of specific modifiers which influence the somatic appearance of other Mendelian characters. As Morgan puts it (1918):

"Most interesting of all the mutations that are now engaging the attention of students of mutation are those in which genetic factors or genes occur, or appear, whose most obvious action is to enhance or diminish some other, more conspicuous character. These genes may be called specific modifiers. They do not differ from ordinary genetic factors in any essential respect, but since their presence can not be detected except when other factors are themselves producing some particular effect on the individual, it is convenient to give them a special designation." 
Our knowledge of modifying genes in a more general sense of the word may be said to date back to Cuénot's investigation of the intensifying and diluting genes influencing the effect of other color factors in mice (1907). The perception of their widespread occurrence and of

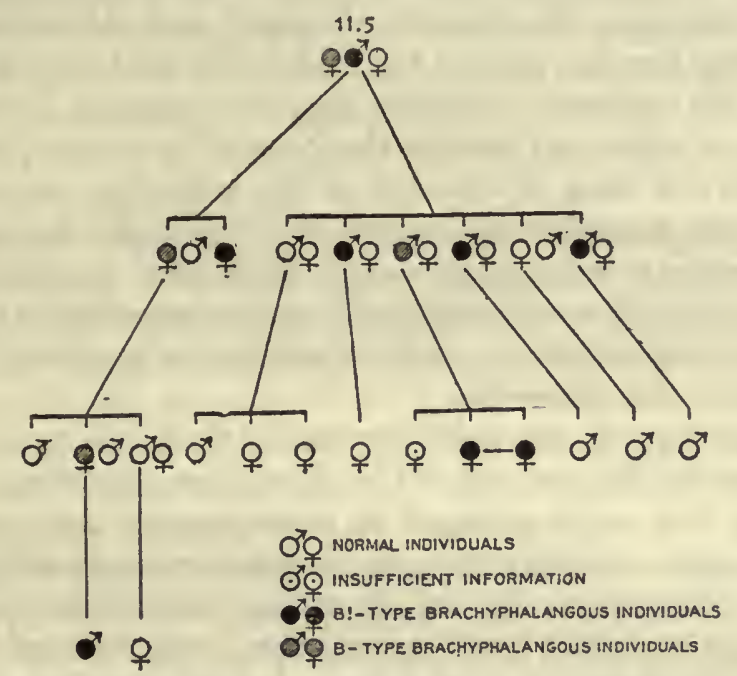

Text-Figure 3.-Pedigree demonstrating the distribution of B-type and B !-type brachyphalangy among the descendants of $11.5 \sigma^{7}$ C.A.B.H., line 1.

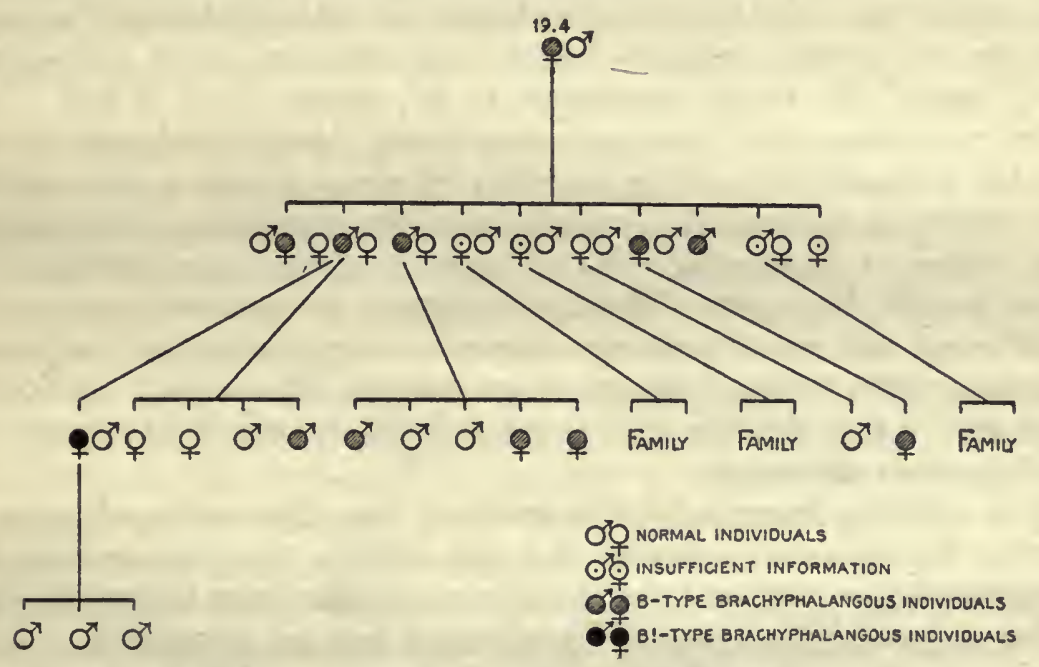

TEXT-FIGURE 4.--Pedigree demonstrating the distribution of B-type and B l-type brachyphalangy among the descendants of 19.4 \% L.E.O., line 9.

their importance grew gradually out of the discussion on the multiplefactor view, inaugurated by the investigations of Nilson-Ehle (1909) and East $(1910,1911)$. East gives (1912) a very clear discussion of the "modifying factors," and in recent years they play the foremost part in all publications dealing with the question of the effect of selection. 
The clear definition of the "specific modifiers" as given above-the term was first used by Bridges (1916) - was, however, first given after they had been found in Drosophila, where their conclusive demonstration is possible through linkage tests.

In Drosophila these genes have been studied by Morgan, Dexter, Bridges, Sturtevant, MacDowell, Muller, and Altenburg, and the work along this line has proved beyond doubt that they are extremely common in this material. Bridges has, for instance, isolated not less than 9 of them, which all modify the "eosin" eye color, while they do not affect the red color of the eye of the wild fly. At present more than 25 specific modifiers are known in Drosophila - according to Dr. Bridges's personal information-and whenever a character shows marked variability it seems practically only a question of time before it will be possible to isolate, through inbreeding, a modifier, or modifiers which influence the character.

In a general way, it can safely be stated that this material is not at all exceptional in this respect. The discussion regarding the effect of selection and the large amount of experimental data underlying it furnish conclusive evidence for the very common occurrence of genes of this kind throughout the whole animal and plant kingdom. ${ }^{1}$ All individuals are probably heterozygous for a multitude of them, and it is a priori unthinkable that man here should represent an exception. Evidence in support of the hypothesis that skin color in man depends on multiple genes of this type is already found in Davenport's investigations on crosses between races with different color (Davenport, G. C. and C. B., 1910; Davenport, C. B., 1913).

In reviewing the literature concerning brachyphalangy in man (p. 13) we noticed that the majority of cases showed a very striking variability in the somatic appearance of the character. Not only was the degree of shortening very different in different members of the same family, but quite different phalanges or metacarpi showed the shortening and some members showed a combination of the brachyphalangy with hyperphalangy or anchylosis, others not. In fact the case we are here dealing with is exceptional in respect to regularity of the inherited character.

The striking irregularities in most of the other reported cases can hardly be explained without the assumption that the normal individuals who married into the families must have been heterozygous for different modifying genes. This would not be surprising. When, for instance, we remember that within comparatively few years more than 50 Mendelian genes have arisen which influence the eye color in Drosophila, more than 40 affecting the shape or length of the wings, it seems very likely that a high number of genes must be involved in the formation and development of any other organ, such as a normal

\footnotetext{
1 As to this we may refer to the discussions by East (1912), MacDowell $(1914,1915,1916)$, Morgan (1918), Sturtevant (1918), and Bridges (1916.).
} 
human hand. When we further take into account the extreme variability in human hands, not only in general, but also within a strain where a characteristic familiar type is inherited for generations, it seems justifiable to suggest that the different individuals also carry numerous modifying genes which may influence the appearance of other characters-for instance, the malformation we are here dealing with.

Let us see if the occurrence of two types in our case may be explained on the hypothesis that some of the normal individuals who married into the family have been heterozygous for a specific modifier, enhancing the effect of the principal gene.

Suppose this modifying gene is dominant: The principal gene "B" causes a shortening of the second phalanges of the indices (B-type brachyphalangy). The specific modifier " $\mathrm{M}_{\mathrm{B}}$ " enhances the effect of $\mathrm{B}$, altering the character into the very short type (B !-type), which is thus a double dominant form.

Applied to line 1 (text-figure 2) the B !-type brachyphalangous $11.5 \mathrm{o}^{7}$ must have been of the constitution $\mathrm{B} \mathbf{M}_{\mathrm{B}}$. Some of his children by his second marriage with a normal wife will receive both $B$ and $M_{B}$ and be of the B !-type (115.4 $\left.\sigma^{x}, 115.6 \sigma^{7}, 115.8 \sigma^{7}\right)$; some will receive only B and be B-type brachyphalangous (115.5 $\left.\sigma^{7}\right)$; and some will receive only $M_{B}$ or neither $B$ nor $M_{B}$ and in both cases be normal $\left(115.3 \sigma^{7}\right.$ and $\left.115.7 \%\right)$. The children of the first marriage of $11.5 \sigma^{7}$ with his cousin 17.1 , who for reasons given above is supposed to have been heterozygous for the principal gene B, may get this gene from one or the other parent and be B-type brachyphalangous (115.1 \%) or from both (115.2 \& ; cf. pp. 28-29). They, too, may or may not get the modifier from their father, involving the eventualities just mentioned. ${ }^{1}$

In two cases within this line (115.5 $\sigma^{7}$ and 1151.2 \&) B-type brachyphalangous individuals have a $\mathrm{B}$ !-type brachyphalangous child. Here the other, the normal parent, must have been heterozygous for the modifier $\mathrm{M}_{\mathrm{B}}$ in order to establish the $\mathrm{BM}_{\mathrm{B}}$ combination causing the B !-type brachyphalangy.

The two genes $B$ and $M_{B}$ can not be supposed to be linked. Not only is the chromosome number in man so high that such a linkage is a priori extremely improbable according to chance, but the striking contrast in the distribution of the two types within the two lines here recorded is decidedly against a linkage hypothesis.

With regard to line 9 , where we have only one certain case of B !-type brachyphalangy against 10 cases of the B-type, we must assume that the individual 19.4 o has received only the principal gene B and not the modifier $\mathrm{M}_{\mathrm{B}}$ from her father. The only known case of $\mathrm{B}$ !-type brachyphalangy within this line (1942.1 o) results from the first marriage of the B-type individual $194.2 \sigma^{\top}$. It is interesting to notice

1 The semi-lethal effect in one of these children (115.2 \%), interpreted as due to a homozygous condition of the principal gene for brachyphalangy, might also be attributable to a homozygous condition of the modifying factor combined with the heterozygous condition of the main gene. 
that he had no $\mathrm{B}$ !-type children by his second marriage. This is well in accord with our hypothesis: $194.20^{7}$ himself being B-type brachyphalangous is heterozygous for B. His first wife was heterozygous for the modifier $M_{B}$, his second was not.

As to the expected numerical ratio between B-type (B) and B !-type $\left(\mathrm{BM}_{\mathrm{B}}\right)$ individuals, the numbers are evidently far too small to be of significance. The expectation would be that a B !-type individual in marriage with individuals who do not carry the modifier should have $\mathrm{B}$ !-type $\left(\mathrm{BM}_{\mathrm{B}}\right)$, B-type (B), and normal children in the ratio $1: 1: 2$, half of the latter carrying the modifier $M_{B}$ in heterozygous condition.

But as the hypothesis demands that this modifier must be quite common, that is, numerous normal people must be heterozygous for $M_{B}$, we have always the possibility of this gene being introduced by both parents. This will change the expected ratio to $3 \mathrm{BM}_{\mathrm{B}}: 1 \mathrm{~B}: 4$ normals, 3 of which carry the modifier in homozygous or heterozygous condition.

On the assumption that we are dealing with a dominant modifier we have seen that two normal individuals married into line 1 and one married into line 9 must have been heterozygous for this gene. We have no evidence of any relationship of these individuals to each other or to the members of the family. An alternative hypothesis assuming the presence of a recessive instead of a dominant specific modifier would demand a much more general occurrence of the modifying gene among normal individuals, since the family has not remained in one locality but has crossed with many other stocks.

As an analogous example of specific modifiers in mammals we might mention the inheritance of the mutant character rough coat in guinea pigs. Rough is dominant over smooth in a typical way, but in crossing smooth individuals from certain (mostly wild) stocks to rough, Castle (1905), Detlefsen (1914), and Wright (1916) obtained so-called "partial-rough" individuals among the offspring. Wright (1916) showed that the "partial-roughs" differ from ordinary full roughs by possessing an independently inherited gene (or genes) introduced by the smooth individuals from the special stocks. In this case the specific modifier is incompletely dominant.

In finishing the discussion of the two types it many be mentioned that the investigation of line 9 alone might easily have led to the entirely false conclusion that the character showed a "weakening" through the later generations - a statement often met with, especially in earlier publications concerning heredity in man. A limited examination might indeed have given a conception of a very marked "weakening" of brachyphalangy when the data collected from now living members of this line were compared with the description of the character found in the family book and with the photograph from generation II (fig. 3). The introduction of modifying factors in later generations (e. g., as that found in this case) would give exactly this impression. 
It is hardly necessary to emphasize further the hypothetical character of the interpretation here given. In human material where experiments are excluded the only way is to test whether the carefully collected data are in accordance with the principles sufficiently well established through experimental genetic work. This is what has been done here and the result is positive.

\section{SUMMARY.}

The investigation deals with a symmetrical shortening of the second phalanx of the second fingers and toes inherited within a Norwegian family, some members of which emigrated to North America.

The malformation is always restricted to this phalanx only, a relation which makes the character especially favorable for genetic investigation, since an exact numerical expression for the character studied can be obtained by direct measurements from the radiographs.

The hands and feet are in every other respect perfectly normal. The affected individuals show no shortness of stature.

The anomaly manifests itself under two distinctly different somatic types, one "slightly" shortened, so-called B-type, which is generally overlooked by the affected individuals, and one very "much" shortened, - so-called B !-type, which is very striking in its somatic appearance. No case of an intermediate condition has been observed.

In the affected phalanges of the B-type there is no premature ossifying of the epiphysial cartilages. Radiographs from hands of children having the B !-type brachyphalangy demonstrate at the age of 12 years a total ossification of the epiphysial cartilage of the affected phalanx.

The inheritance of the malformation is followed without any break through 6 generations, including and descending from an individual born in 1764. The lines descending from one affected daughter and one affected son of this individual form the main subject for the present investigation. Within these lines every individual is recorded. In addition, several families belonging to the IV, V, and VI generation, descending from another affected son, are discussed.

A detailed family record is presented with exact information also concerning the earlier generations. This was possible, because the family owns an old "Family book" with elaborate information concerning each individual belonging to the earlier generations.

The photographs of brachyphalangy cover 5 generations, the radiographs cover 4 .

The brachyphalangy is inherited as a dominant, not a sex-linked character. The numerical ratio between the affected and unaffected individuals in the offspring of brachyphalangous members of the family is in accordance with the theoretical expectation. 
All the brachyphalangous individuals are heterozygous for the gene in question, with one possible exception. This individual resulted from an intermarriage within affected lines, and therefore may have been homozygous for the factor for brachyphalangy. She was a cripple without fingers and toes and was unable to develop. She died at the age of one year.

Analogous cases from experimental genetic work, demonstrating a distinct difference in the appearance of the somatic character when the genes are homozygous from that of the heterozygous condition, and the lethal effect of many dominant genes when homozygous are discussed in this connection. Emphasis is laid on the importance of this experience from a medical point of view.

The material includes one case of identical twins, both brachyphalangous of an identical type.

Based on the numerous measurements from the radiographs, an analysis of the two types of the malformation was possible. Much attention has been paid to this special point. It was found that the B-type of brachyphalangy may overlap the limit of extreme variation in normal hands-i.e., some individuals heterozygous for the gene for brachyphalangy (which generally causes a very characteristic alteration of the hand) may be somatically normal. The conclusive demonstration of this fact was obtained in one case where the radiographs gave normal measures while the genetic test, which was at the same time at hand, proved the individual to be heterozygous for the gene for brachyphalangy.

A genetic explanation of the occurrence of the B-type and B!-type is suggested. Based on analogies from experimental genetic work, the two types are explained through the presence in some of the normal individuals, married into the family, of a dominant specific modifying gene which enhances the effect of the principal gene for brachyphalangy and changes the B-type into a B !-type.

Indications in favor of this view are presented from the earlier literature concerning hereditary brachyphalangy in man which deals with types of brachyphalangy different from the one here studied. The review of this literature includes both "pre-Mendelian" and "post-Mendelian" publications demonstrating inheritance of these malformations in accord with Mendel's laws. 


\section{LIST OF LITERATURE.}

BADR, E. 1914. Einführung in die experimentelle Vererbungslehre. 2 Aufl., Berlin, 1914; pp. 1-401.

Bridges, C. B. 1916. Non-disjunction as a proof of the chromosome theory of heredity. Genetics, vol. 1, pp. 1-52, 107-163.

CAstle, W. E. 1905. Characters in guinea-pigs and rabbits. Carnegie Inst. Wash. Pub. No. 23, pp. 1-78.

and C. C. Litrue. 1910. On a modified Mendelian ratio among yellow mice. Science, n. s., vol. xxxIr, pp. 868-870.

- and S. WRIGHT. 1916. Studies of inheritance in guinea-pigs and rats. Carnegie Inst. Wash. Pub. No. 241, pp. 1-196.

ClARKe, D. S. 1915. Congenital hereditary absence of some of the digital phalanges. Brit. Med. Jour., vol. In for 1915, p. 255.

CragG, E., and H. Drinkwater. 1916. Hereditary absence of phalanges through five generations. Jour. of Gen., vol. 6, pp. 81-89.

Colson, - 1882. Microdactylie. Ann. de la Soc. de Med. de Gand., p. 202. Ref. by Leboucq, 1896.

CutNot, L. 1905. Les races pures et leurs combinaisons chez les souris (4me note). Arch. de Zool. exp. et gên., 4e sér., t. IIr, notes et revue, pp. exxiii-cxxxii.

1907. L'hérédité de la pigmentation chez les souris (5me note), Arch. de Zool. exp. et gén., 4e sér., t. vi, notes et revue, pp. i-xiii.

1908. Sur quelques anomalies apparentes des proportions mendéliennes, (6e note). Arch. de Zool. exp. et gén., 4 sér., t. Ix, notes et revue, pp. vii-xv.

Davenport, G. C., and C. B. Davenport. 1910. Heredity of skin pigment in man. Amer. Nat., vol. xurv, pp. 641-728.

Davenport, C. B. 1913. Heredity of skin color in negro-white crosses. Carnegie Inst. Wash. Pub. No. 188, pp. 1-106.

Detlefsen, J. A. 1914. Genetic studies on a cavy species cross. Carnegie Inst. Wash. Pub. No. 205, pp. 1-134.

Drinkwater, H. 1908. An account of a brachydactylous family. Proc. Roy. Soc. of Edinburgh, vol. xxviII, part 1, pp. 35-57.

1912-1913. Account of a family showing minor-brachydactyly. Jour. of Gen., vol. II, pp. 21-40.

1913-1914. Minor-brachydactyly No. 2. Jour. of Gen., vol. III, pp. 217-220.

- 1914-1915. A second brachydactylous family. Jour. of Gen., vol. rv, pp. 223-340.

EAST, E. M. 1910. A Mendelian interpretation of variation that is apparently continuous. Amer. Nat., vol. Xurv, pp. 173-181.

- 1911. The genotype hypothesis and hybridization. Amer. Nat., vol. xLv, pp. 160-174.

- 1912. The Mendelian notation as a description of physiological facts. Amer. Nat., vol. XLVI, pp. 633-655.

Farabee, W. C. 1905. Inheritance of digital malformations in man. Papers of the Peabody Mus. Harvard Univ., vol. III, pp. 65-78.

Fontana and VACCHELli. 1902. Ưber vier Fälle von angeborener Deformität der Hand. Archivio di Orthopedia, 1902, p. 119. Ref. in Arch. f. Orthop. 1903. Bd. 1.

FÜrST, C. M. 1900. Ein Fall von verkürzten und zweigliedrigen Fingern. Zeitschr. f. Morph. u. Anthrop. Bd. 2, pp. 56-76.

Goldmann, E. E. 1891. Beitrag zưr Lehre von den Missbildungen der Extremitāten. Beitr. z. klin. Chir. Bd. 7, pp. 209-256.

Gubler, M. 1850. Vice de conformation des mains. Gaz. med. de Paris, t. 5, pp. $648-649$.

Grober, W. 1865. Beobachtung des Defectes der Mittelphalangen an allen Fingern und Zehen am Lebenden beobachtet. Oester. Zeitschr. f. prakt. Heilk. XI, Jahrg., pp. 981-985.

Носннгім, K. 1903-1904. Ein Fall von Brachydaktylie an allen Extremitäten. Fortschr. a. d. Geb. d. Röntgenstr., Bd. 7, pp. 273-276.

Holsagren, T. 1910. Uber den Einfluss der Basedow'schen Krankheit und verwandter Zustände auf das Längenwachstum nebst einigen Gesetzen der Ossification. Kap. viII, Über die Ossification der Hand und die frühzeitigere Verknöcherung der grosswüchsigen Individuen. Nord. med. Arch. Afd. II, Bd. 43, pp. 119-185. 
Joachimsteal, G. 1900. Die angeborenen Verbildungen der oberen Extremitäten. Fortschr. a. d. Geb. d. Röntgenstr., Ergänzheft. 2, pp. 1-40.

Kenyeres, B. 1905-1906. Angeborene Missbildungen und erworbene Deformitäten in Röntgenbildern. Fortschr. a. d. Geb. d. Röntgenstr., Bd. 9, pp. 351-355.

KüMmer, W. 1895. Die Missbildungen der Extremitäten durch Defect, Verwachsung und Uberzahl. Bibliotheca Medica, Abt. E, Heft 3, pp. 1-84.

LesoucQ, M. 1896. De la brachydactylie et de l'hyperphalangie chez l'homme. Bull. Acad. Roy. de Med. de Belgique, IVe serie, t. X, pp. 544-561.

LUNDBorg, H. 1913. Medizinisch biologische Familienforschungen innerhalb eines 2232köpfigen Bauerngeschlechtes in Schweden. Jena 1913. Pp. 1-740.

MacDoweld, E. C. 1914. Size inheritance in rabbits. Carnegie Inst. Wash. Pub. No. 196, pp. 1-55.

- 1915. Bristle inheritance in Drosophila, I: Extra bristles. Jour. Exp. Zool., vol. 19 , pp. $61-98$.

- 1916. Piebald rats and multiple factors. Amer. Nat., vol. L, pp. 719-742.

Machor, A. 1907. Beiträge zur Kenntniss der Brachydactylie. Mitteil. a. d. Grenzgeb. d. Med. u. Chir. Gedenkband f. J. v. Mikulicz., pp. 712-766.

MacKinder, D. 1857. Deficiency of fingers transmitted through six generations. Brit. Med. Jour. (Oct. - $\longrightarrow$ ), pp. 845-846.

MaLl, F. P. 1906. Ossification centers in human embryos less than one hundred days old. Amer. Jour. Anat., vol. v, pp. 433-458.

Morgan, T. H., A. H. Sturtevant, H. J. Muller, and C. B. Bringes. 1915. The mechanism of Mendelian heredity. New York and London, pp. 1-262.

Morgan, T. H. 1916. A critique of the theory of evolution. Princeton Univ. Press, pp. 1-197.

- 1917. The theory of the gene. Amer. Nat., vol. LI, pp. 513-544.

Muller, H. J. 1917. An Oenothera-like case in Drosophila. Proc. Nat. Acad. Sci., vol. 3, pp. 619-626.

Nilsson-Ehle, H. 1909. Kreuzungsuntersuchungen an Hafer und Weizen. Lunds Univ. Aarsskrift, Afd. 2, Bd. 5, pp. 1-122.

Pfitzner, W. 1892 and 1893 . Beiträge zur Kenntniss des menschlichen Extremitätenskelets. Schwalbe's Morph. Arb. Bd. I, pp. 1-120; Bd. II, pp. 93-205.

1900. Beiträge zur Kenntniss des menschlichen Extremitätenskelets vIII. Zeitschr. f. Morph. u. Anthrop. Bd. 2, pp. 77-157 and pp. 365-678.

RABAUD, E. 1912. Le mendélisme chez l'homme. L'Anthrop., t. 23, pp. 169-196.

Riebl, H. 1907-1908. Zur Kasuistik der Brachydaktylie. Fortschr. a. d. Geb. d. Röntgenstr., Bd. 11, pp. 447-449.

Ritzman, E. G. 1916. Mendelism of short ears in sheep. Jour. Agric. Res., vol. vi, 2 pp., 797-798.

Rovghton, E. W. 1897. A case of congenital shortness of metacarpal and metatarsal bones. The Lancet, vol. II, p. 19.

Sмrtr, H. M. 1904. Congenital digital malformation in negroes. Amer. Anthropologist, vol. 6.

Sternberg, J. 1902. Zur Kenntniss der Brachydaktylie. Wien. klin. Wochenschr., Bd. 15, pp. 1060-1065.

Sturtevant, A. H. 1918. An analysis of the effects of selection. Carnegie Inst. Wash. Pub. No. 264, pp. 1-67.

VIDAL, E. 1910. Brachydactylie symmétrique, et autres anomalies osseuses, héréditaires depuis plusieurs générations. Bull. Acad. de Méd., Ref. by Rabaud (112).

W AGNER, H. 1903-1904. Ein Beitrag zur Kenntniss der Brachydactylie. Fortschr. a. d. Geb. d. Röntgenstr., Bd. 7, pp. 94-98.

WALKER, G. 1901. Remarkable cases of hereditary anchyloses or absence of various phalangeal joints with defect of the little and ring finger. Johns Hopkins Hosp Bull., 12, pp. 129-133.

Wriedt, Chr. 1914. Die kurzohrige Schafrasse Norwegens. Jahrb. f. wissenschaft. $u$. prakt. Tierzucht., 9 Jahrg.

1916. De kortörete sauer og deres forhold til Mendels spaltningslov. Tidsskr. f. d. Norske Landbr., 23 AArg., p. 622.

1919. Utber die Vererbung von Ohrenlänge beim Schafe. Zeitschr. f. ind. Abst. u. Vererb. lehre. Bd. xx, pp. 262-263. 
PLATE 1

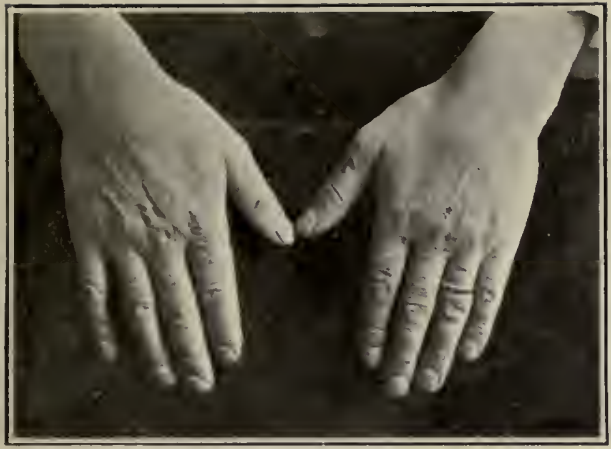

FIG. 1.-115.3 ơ P. F. G. H.

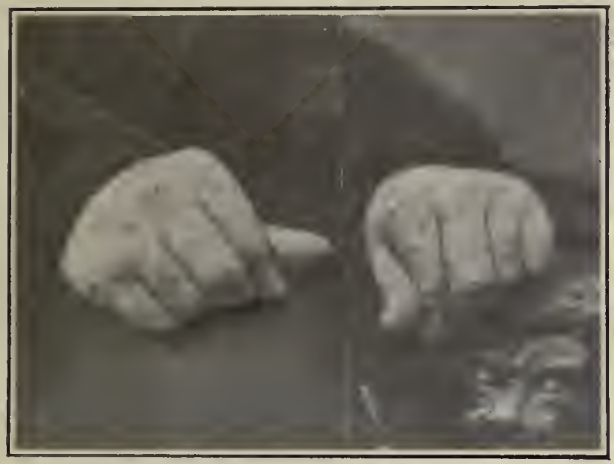

FIG. 3.- $\sigma^{7} \emptyset$. II Generation.

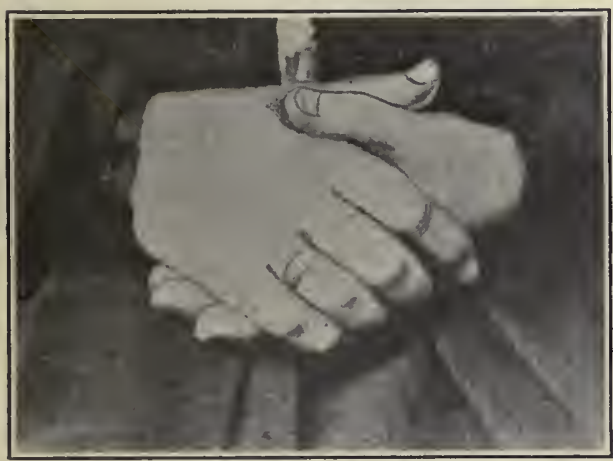

FIG. 5.-17.1 우 F. G. Ø.

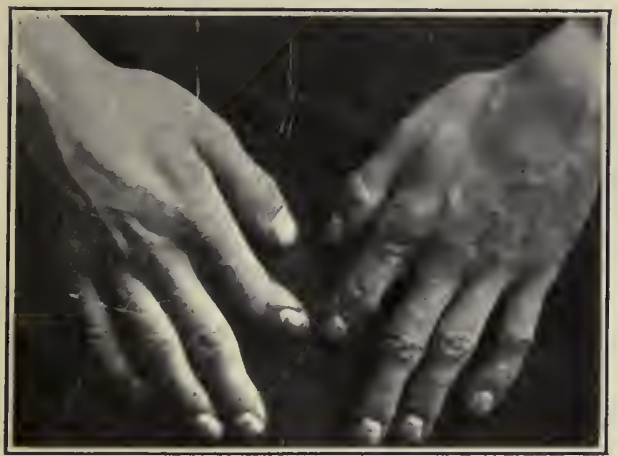

FIG. 7. -115.4 o $^{7}$ M. H.

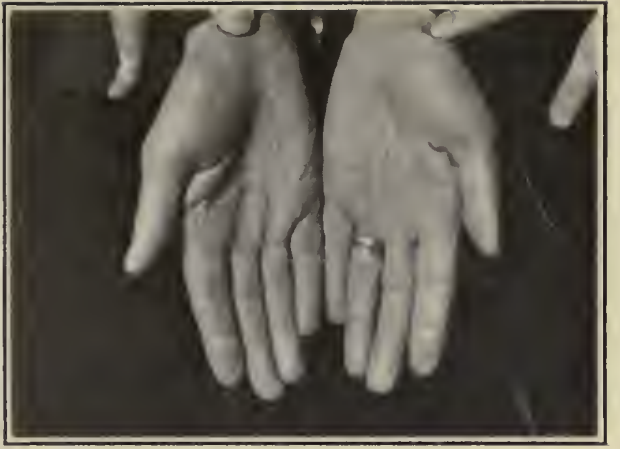

FIG. 2.-115.7 ᄋ L. H.

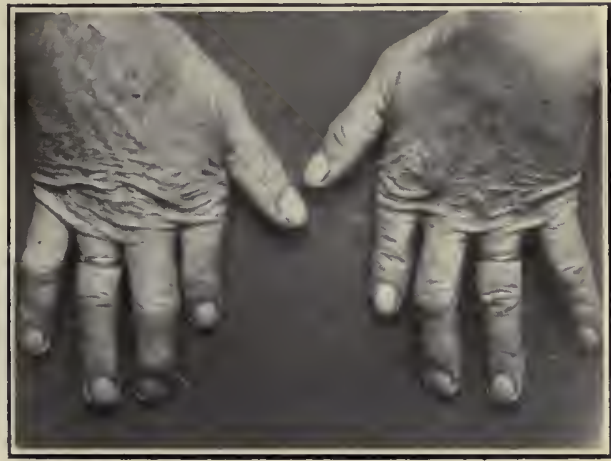

Fig. 4.-11.5 o C. A. B. H.

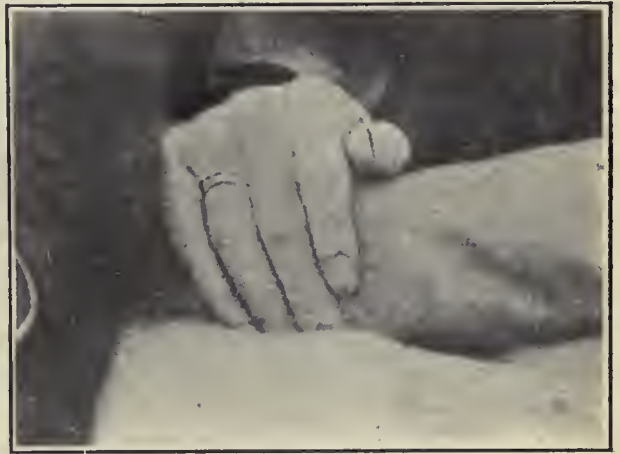

FIG. 6. - 115.1 ㅇ E. A. H.

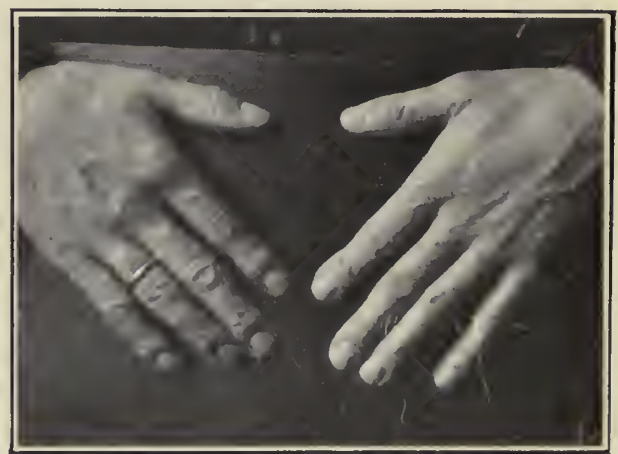

Fig. S. -115.5 o $^{7}$ H. M. H. 


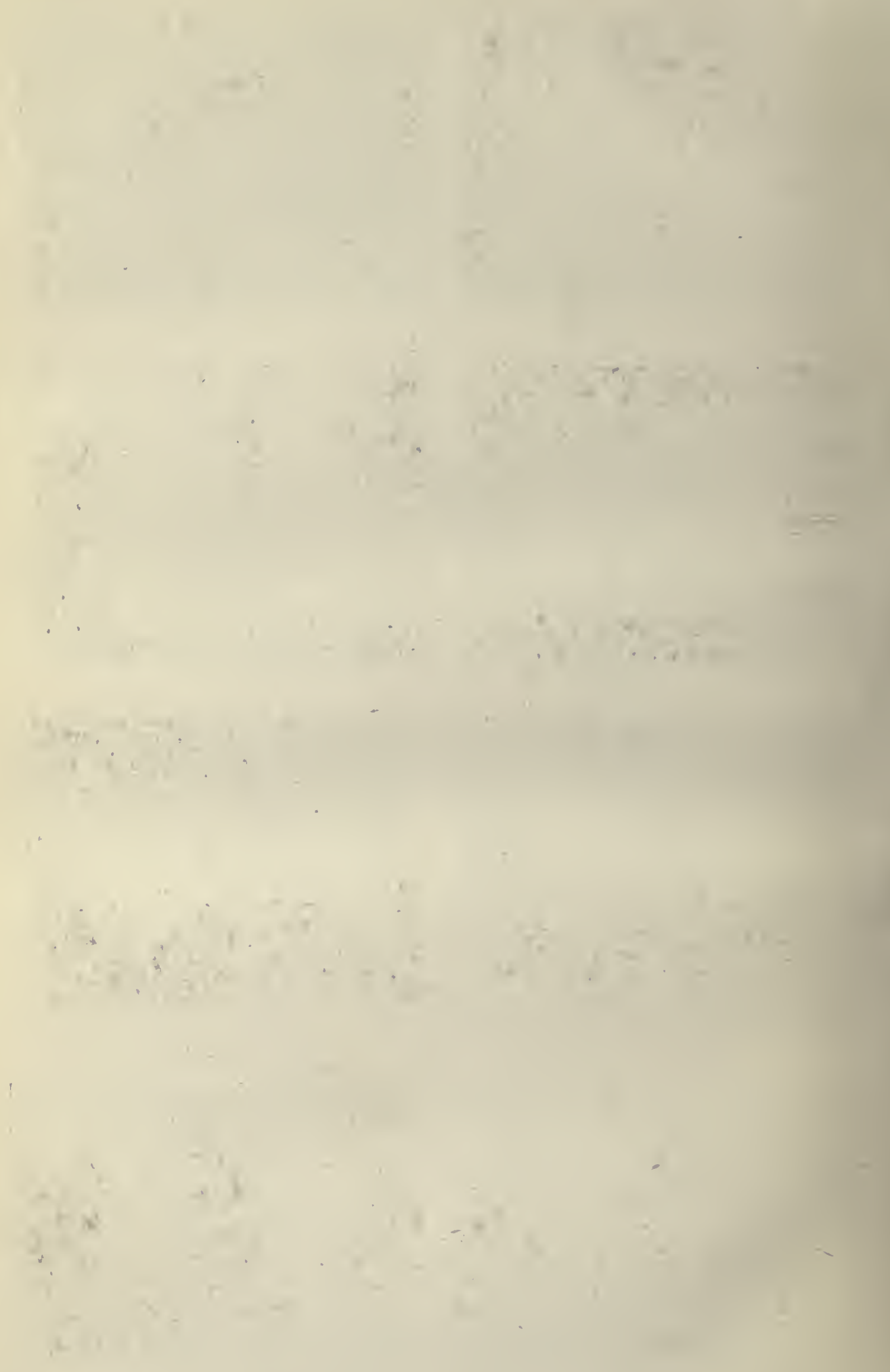


PLATE 2

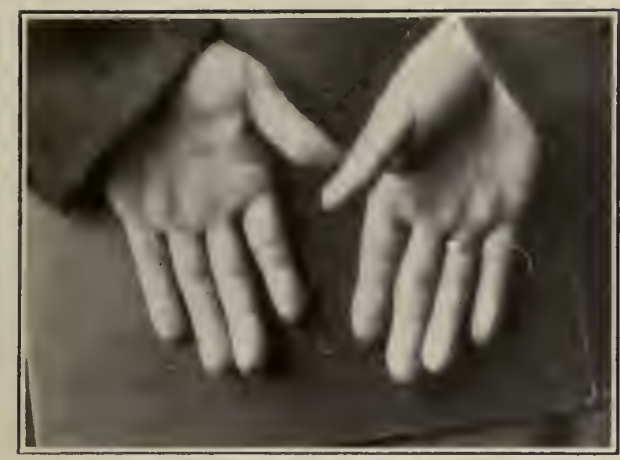

FIf. 9.-115.5 के H. M. H.

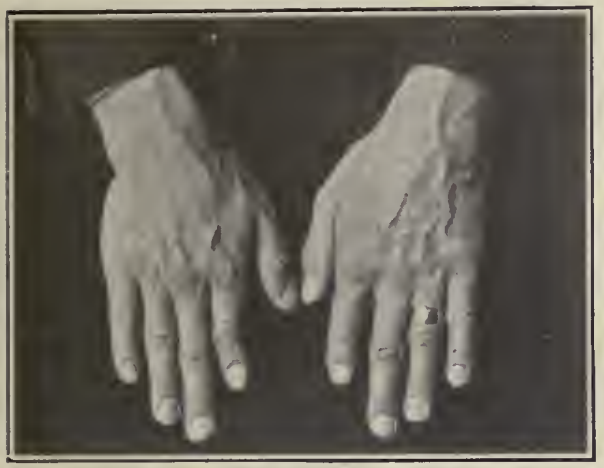

FIG. 11.-115.8 o I. H.

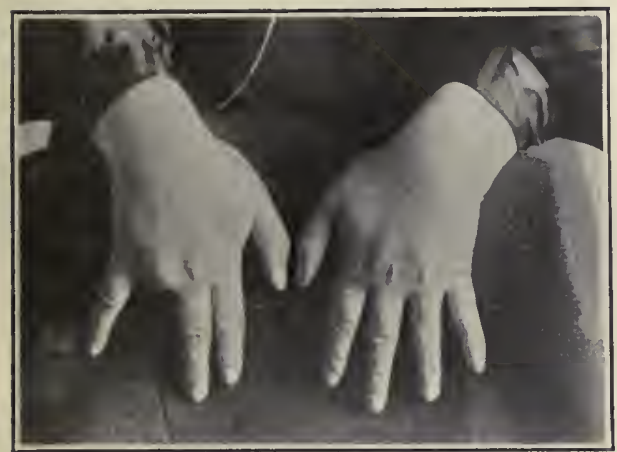

FIf. 13.-1151.2 ᄋ S. G.

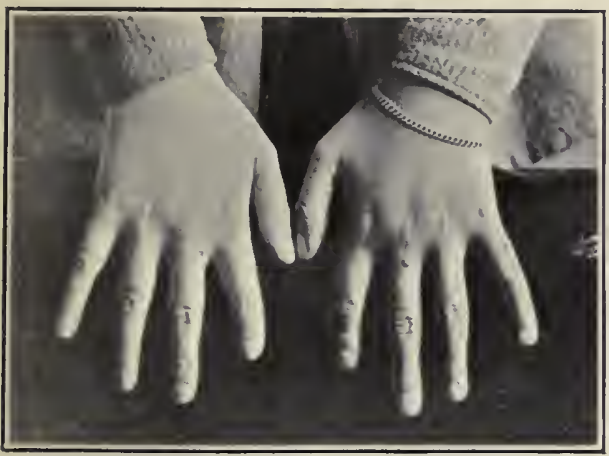

FIG. $15 .-1154.1$ ᄋ I. S. H.

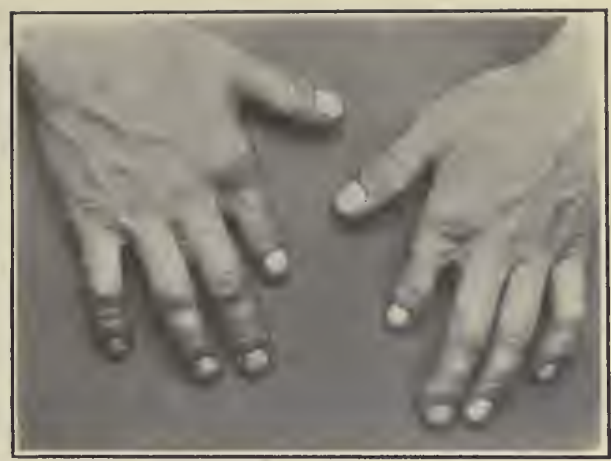

FIG. $10 .-115.6$ ช C. S. H.

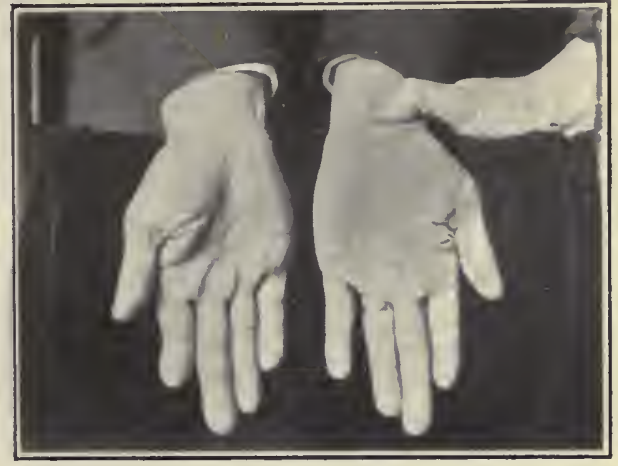

FIG. 12.-115.8 o I. H.

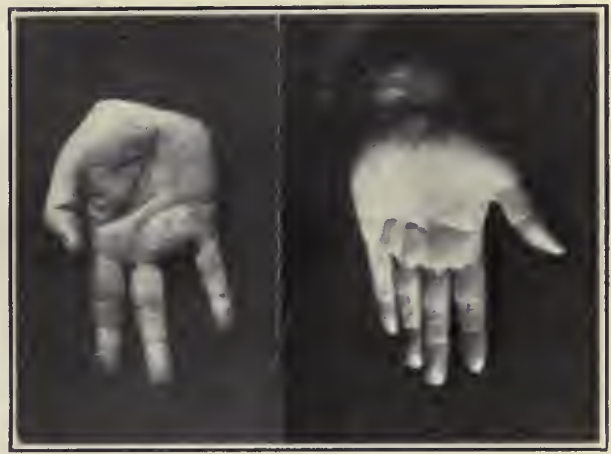

FIg. 14.-1151.2 오 S. G.

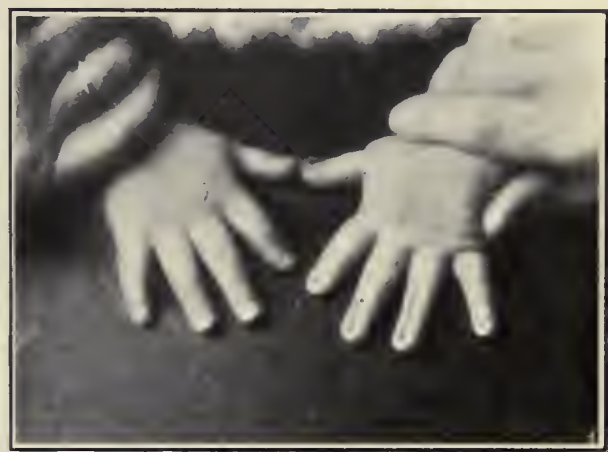

FIG. 16. - $1155.2 a$ ㅇ R. S. H. 

PLATE 3

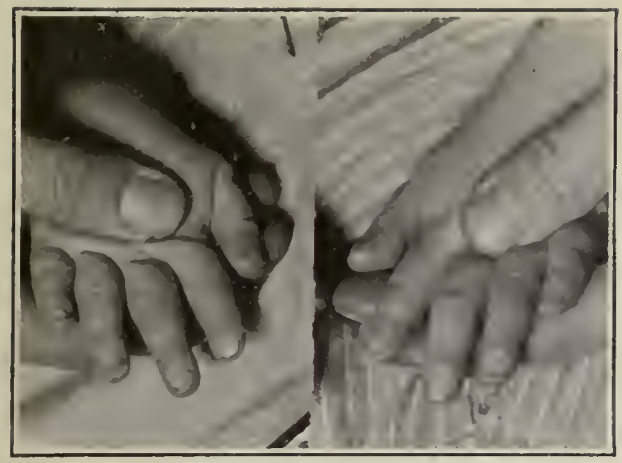

Fig. 17.-1155.2b ㅇ I. J. H., right hand; $1155.2 a$ 우 R. S. H., left hand.

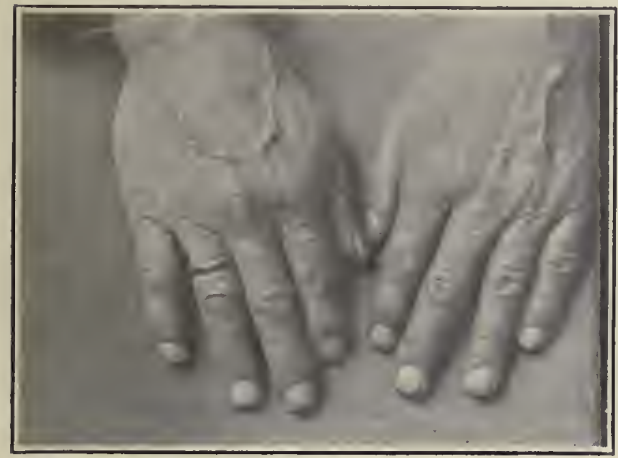

FIG. 19.-194.2 o A. K. A. G.

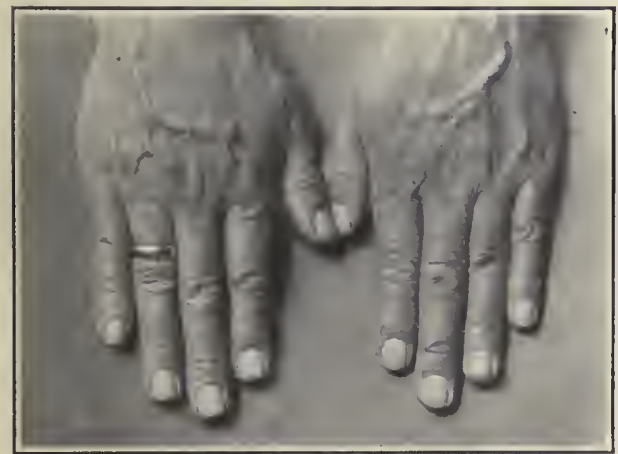

FIG. $21 .-194.3$ ठ E. A. L.

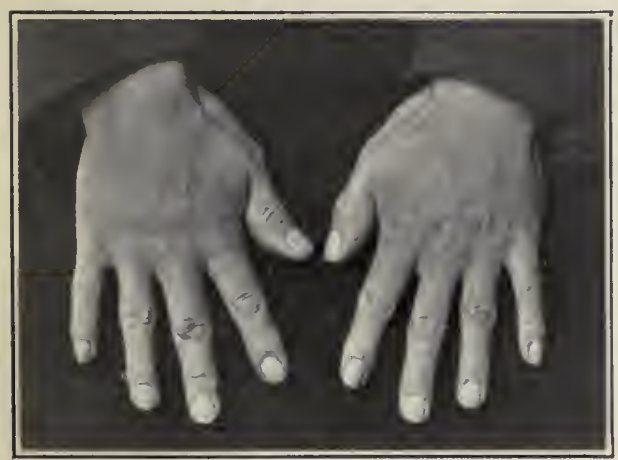

FIG. 23.—194.S ठ H. Ø.

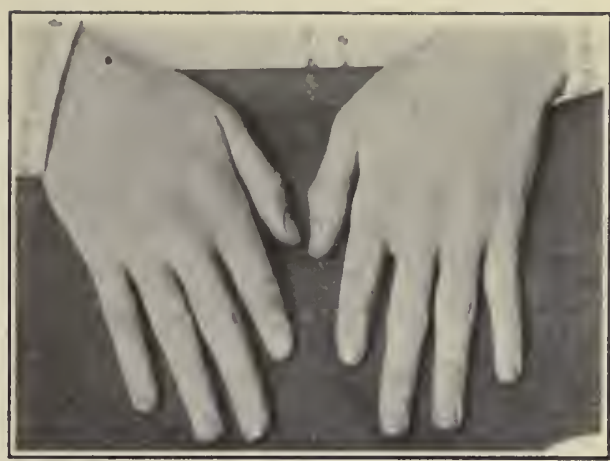

FIG. 18. - 11512.1 ơ O. R.

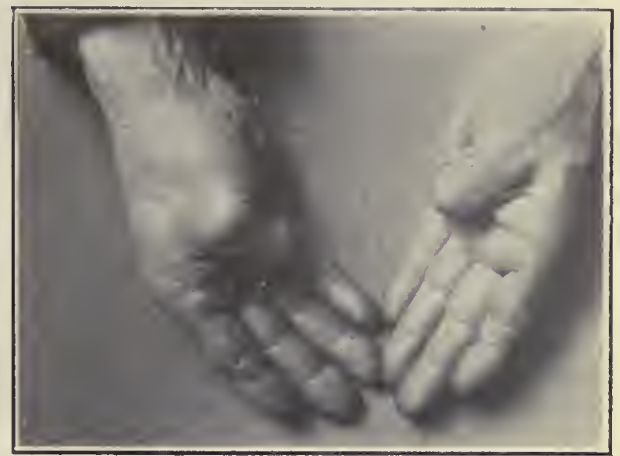

Fig. 20.-194.2 ठ A. K. A. G.

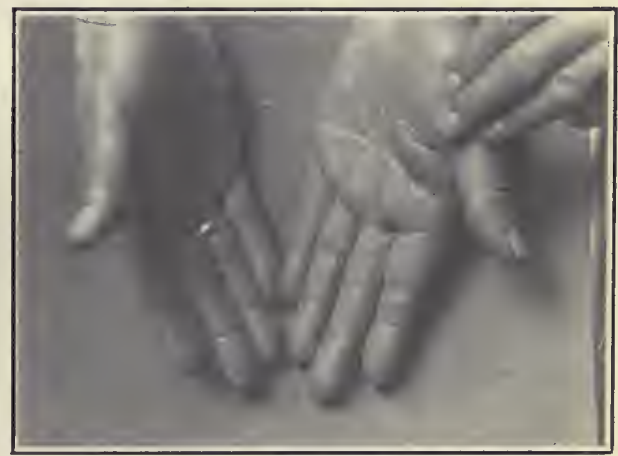

FIG. 22.-194.3 or E. A. L.

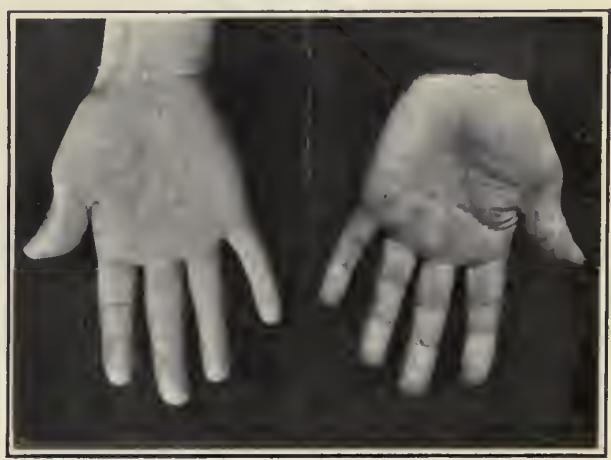

FIG. 24.-194.S ठํ H. Ø. 

PLATE 4

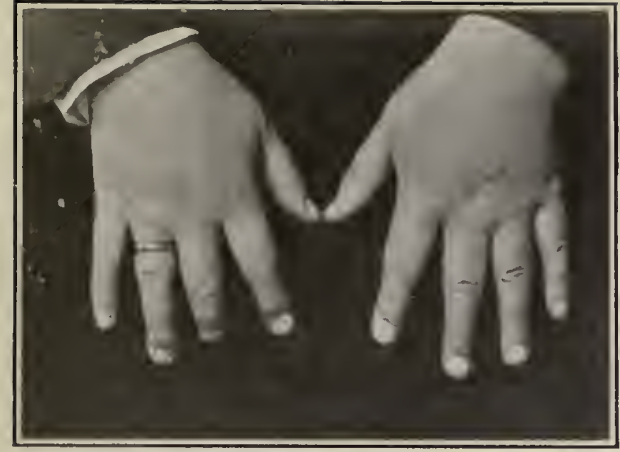

FIG. $25 .-194.7$ ᄋ S. Ail.

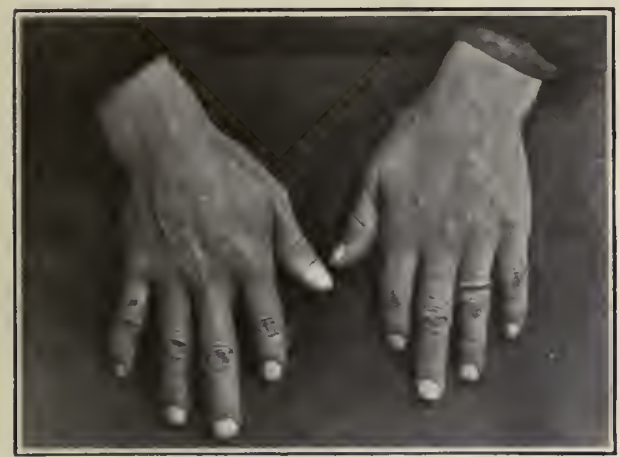

FIF. 27.-1942.1 ९ J. G.

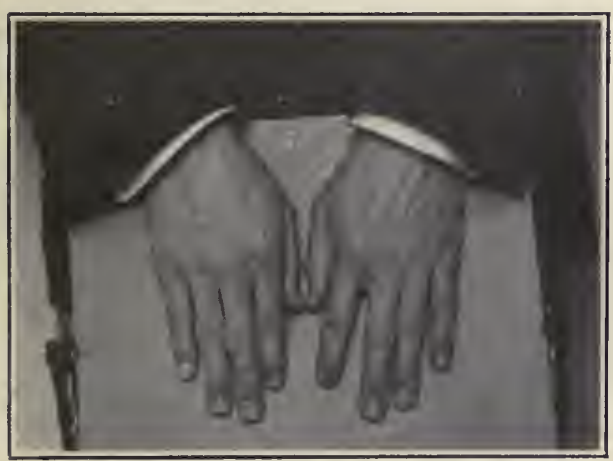

FIG. 28.-1943.1 o E. A. I.

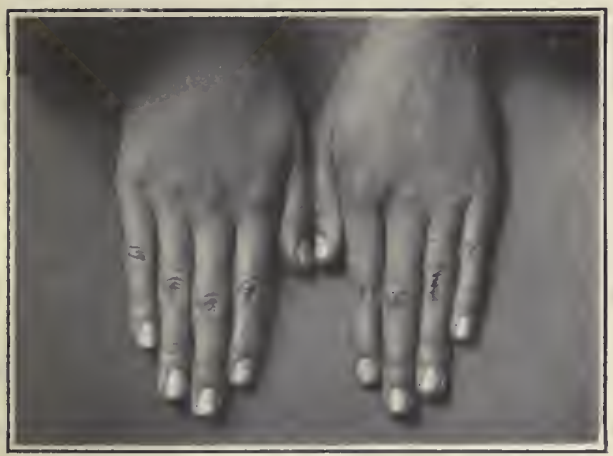

FIG. 31.-1943.4 우 E. M. I.

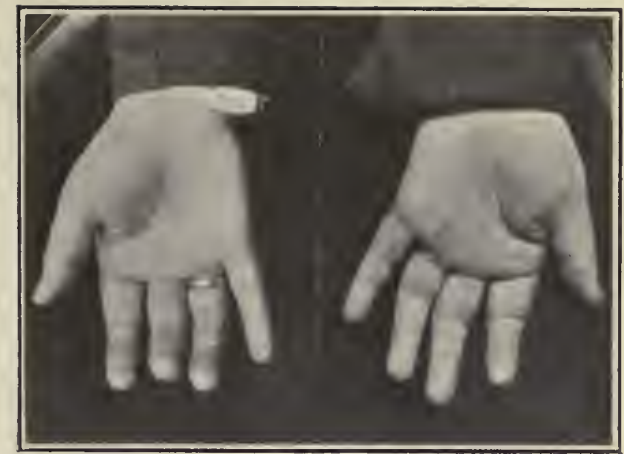

Fig. 26.-194.7 ㅇ S. Aa.

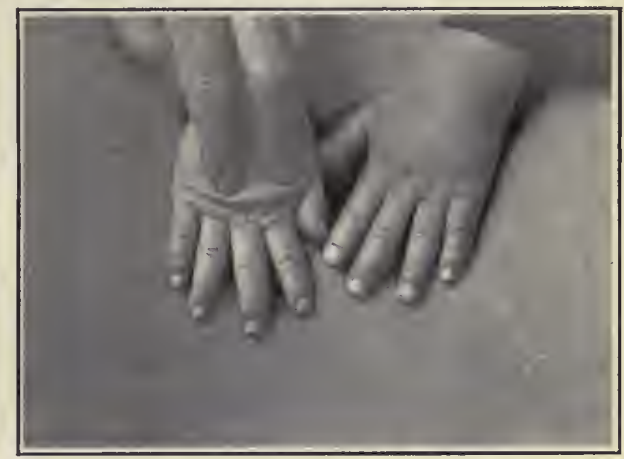

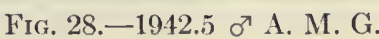

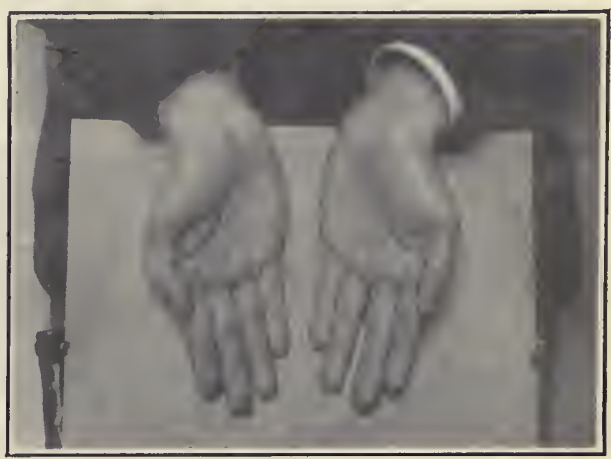

Fig. 30.-1943.1 o E. A. L.

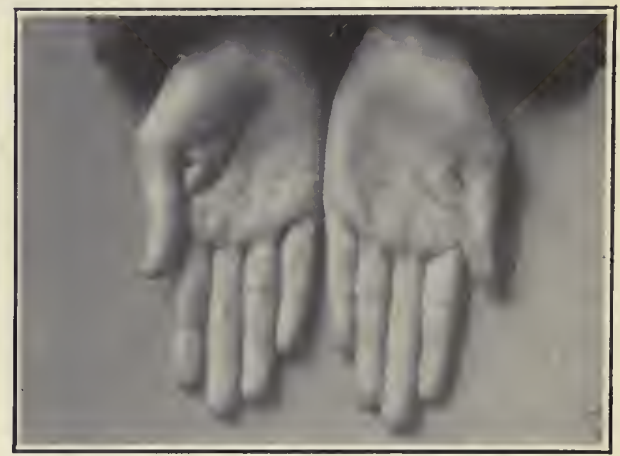

FIG. 32.-1943.4 우 E. MI. I, 

PLATE 6

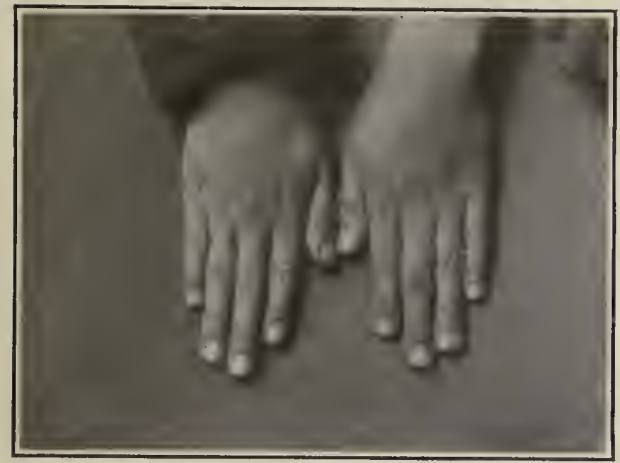

Frg. 33.-1943.5 ㅇ E. S. L.

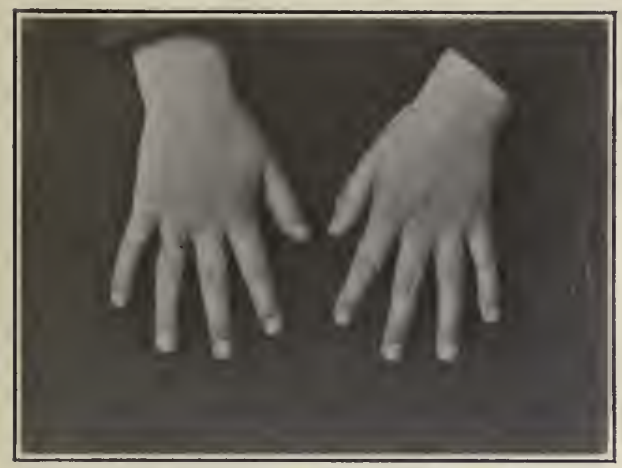

FIG. 35.-1947.1 ㅇ E. Aa.

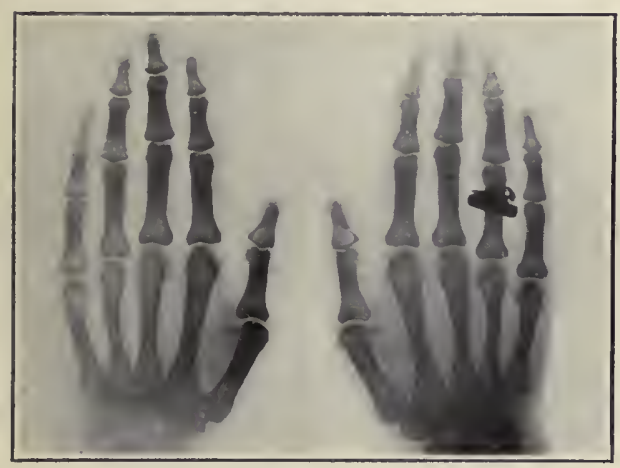

FIG. 37.-115.7 우 L. H.

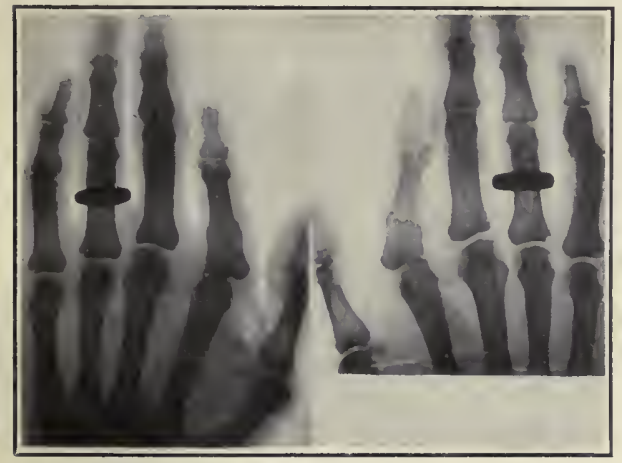

Fig. 39.-11.5 ơ C. A. B. H.

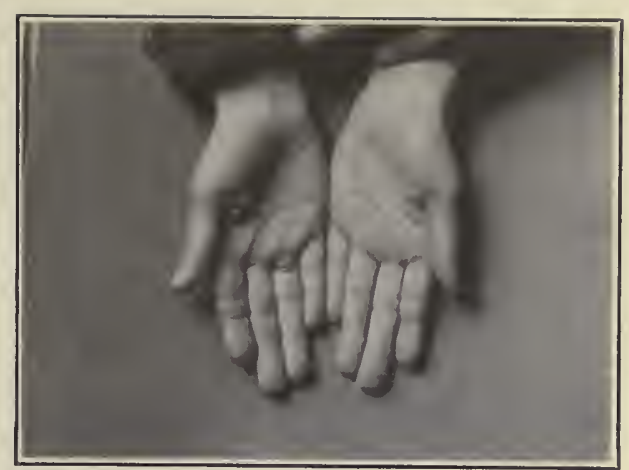

FIG. $34,-1943.5$ o F. S. J.

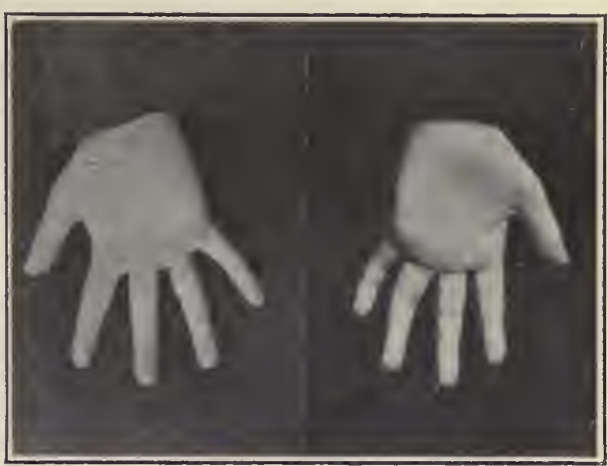

FIG. $36 .-1947.1$ 우 E, Aa.

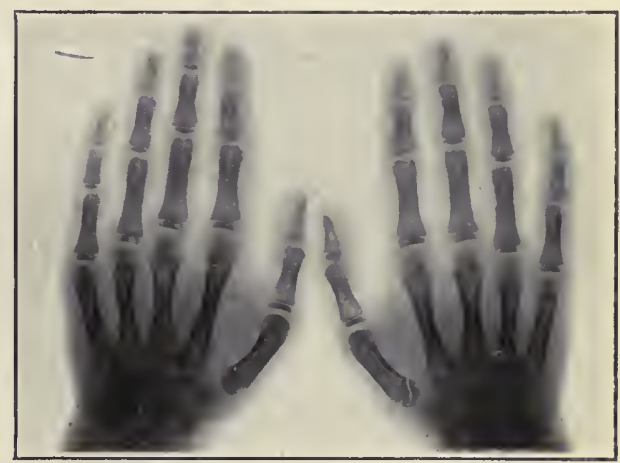

Fig. 38.-19421.3 ơ R. F. H.

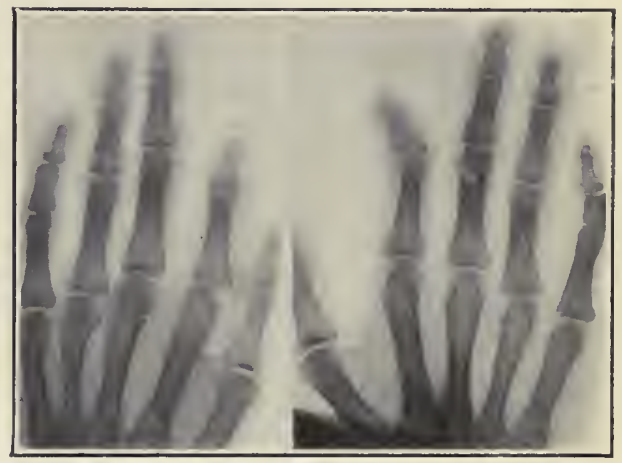

FIG. 40.-115.4 के M. H. 

PLATE 6

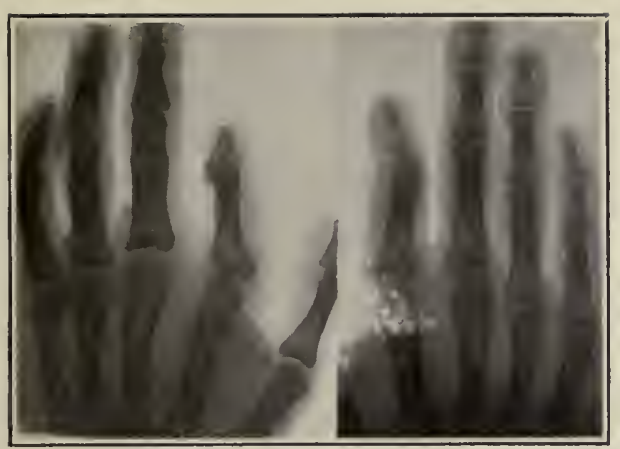

FIg. 41.-115.6 O $^{7}$ C. S. H.

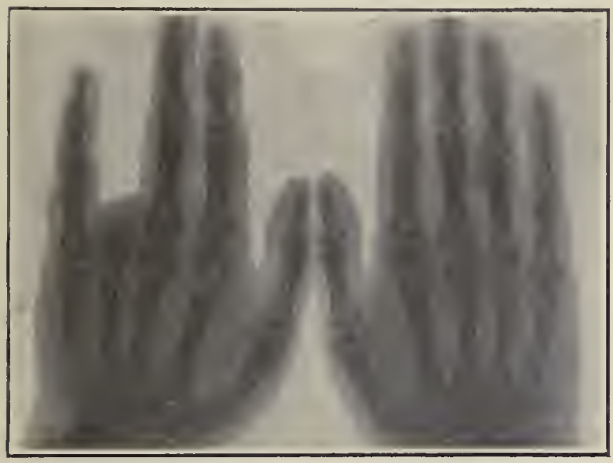

Fig. 43.-1151.2 \& S. G.

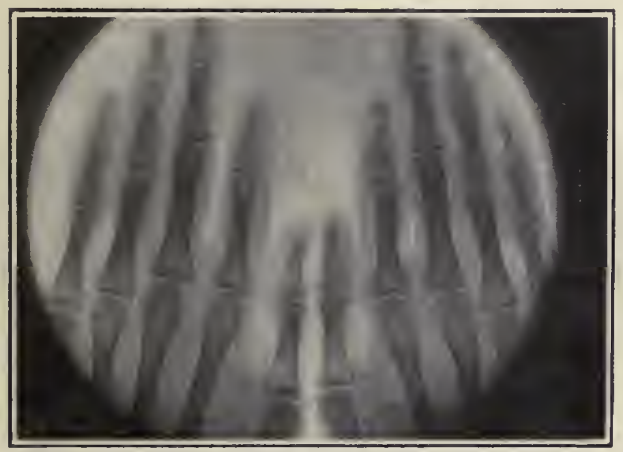

FIG. 45.-11512.1 o O. R.

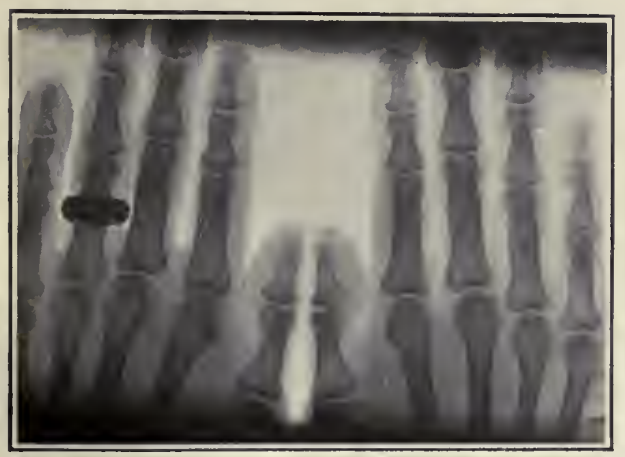

FIG, 47.-194.3 ơ E. A. L.

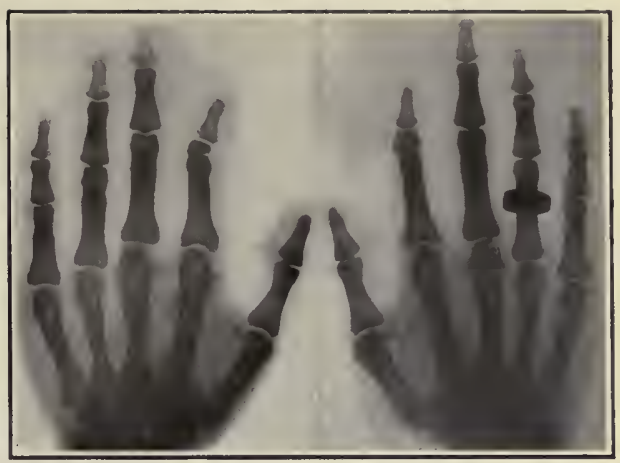

FIG. $42 .-115.8$ ơ T. H.

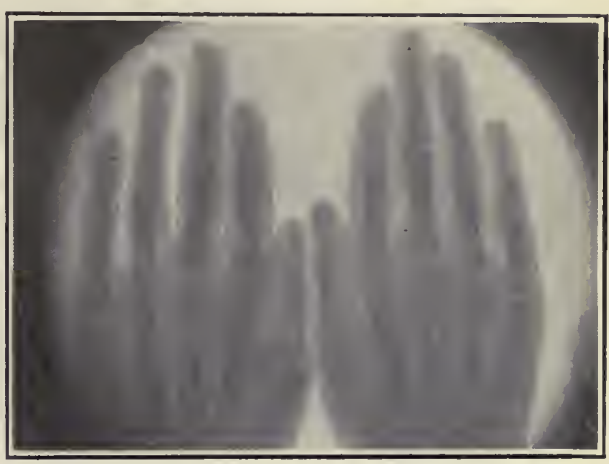

FIG. $44 .-1154.1$ ㅇ I. S. H.

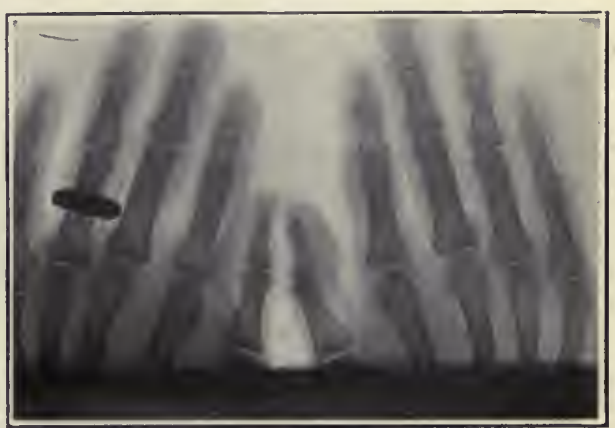

FIG. 46.-194.2 ơ A. K. A. G.

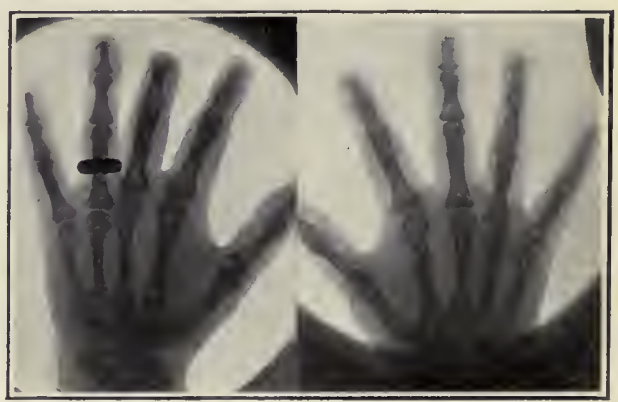

FIG. 48. -194.7 \% S. A. 

F'LATE ,

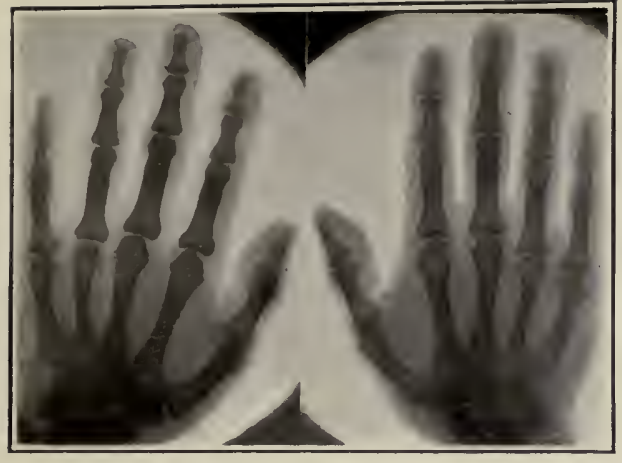

FIG. 49.-194.8 के H. Ø.

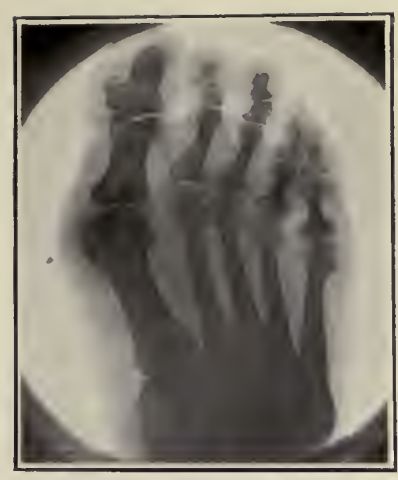

FIG. 50.-194.8 ơ H. $\emptyset$.

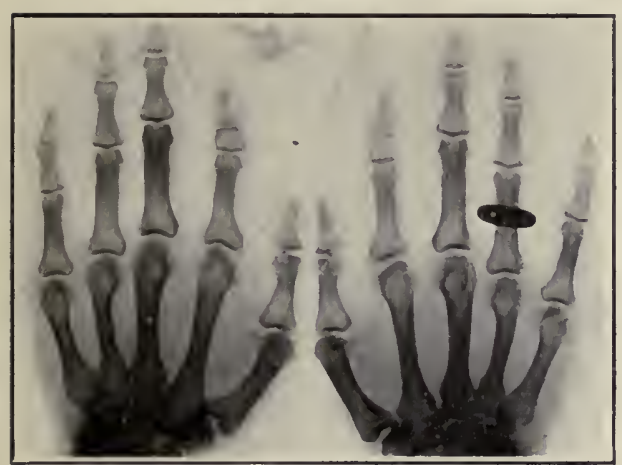

FIG. 51.— 1942.1 J. G.

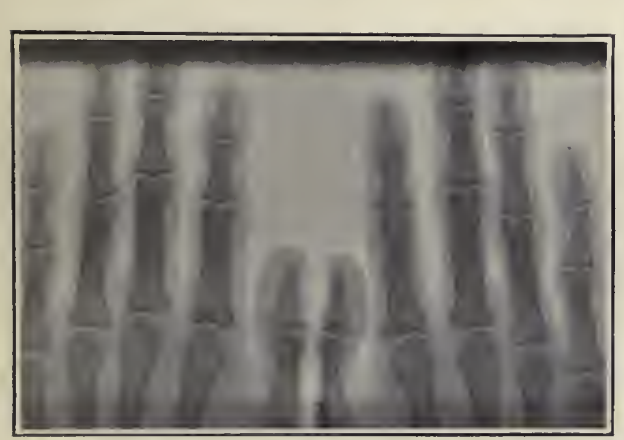

FIG. ถ้ 3. -1913.1 ơ E. A. L.

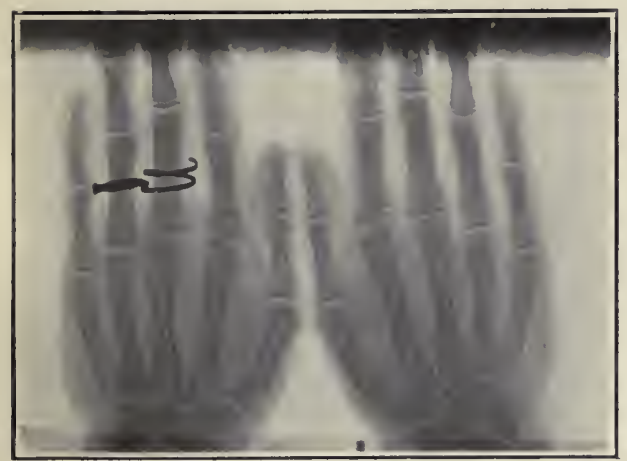

Fig. 55.-1943.5 ㅇ E. S. L.

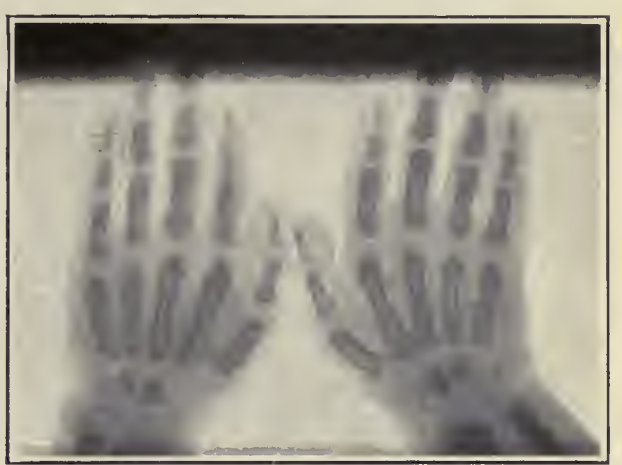

FIG. 52,-1942.5 ơ A. M. G.

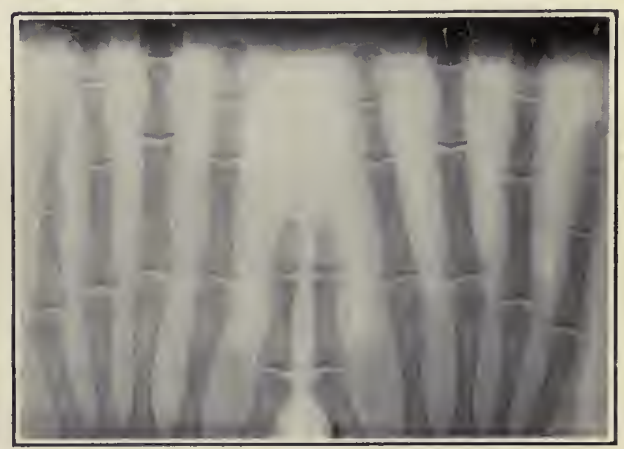

FIG. 54.-1943.4 \& E. M. L.

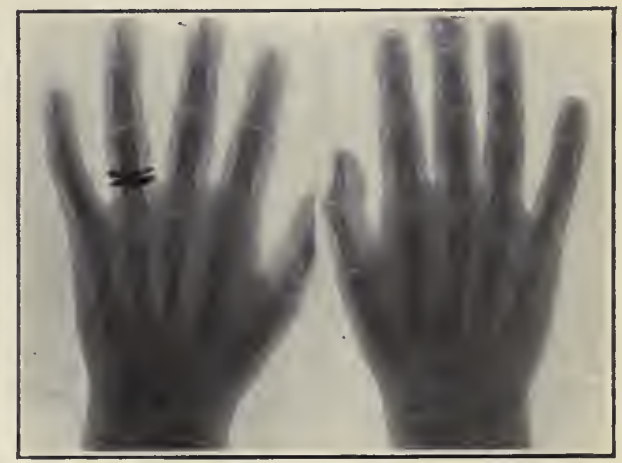

FIG. 56.-1947.1 우 E. Aa. 




- 


\section{THE UNIVERSITY LIBRARY \\ UNIVERSITY OF CALIFORNIA, SANTA CRUZ \\ SCIENCE LIBRARY}

This book is due on the last DATE stamped below.

To renew by phone, call 459-2050.

Books not returned or renewed within 14 days after due date are subject to billing.

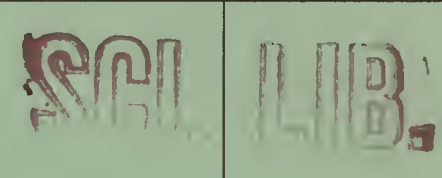




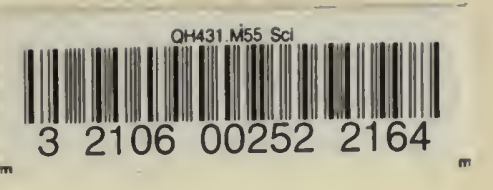


